\title{
A DSGE MODEL WITH PARTIAL EUROIZATION: THE CASE OF THE MACEDONIAN ECONOMY ${ }^{1}$
}

\author{
Mihai Copaciu \\ National Bank of Romania \\ mihai.copaciu@bnro.ro \\ Joana Madjoska \\ National Bank of the Republic of North Macedonia \\ joana.madjoska@gmail.com \\ Mite Miteski ${ }^{2}$ \\ National Bank of the Republic of North Macedonia \\ miteskim@nbrm.mk
}

\begin{abstract}
This paper describes the theoretical structure and estimation results for a DSGE model for the Macedonian economy. Having as benchmark the model of Copaciu et al. (2015), modified to allow for a fixed exchange rate, we are able to match relatively well the volatility observed in the data. Given the monetary policy regime in place, the debt deflation channel is more important relative to the financial accelerator one when compared to the flexible exchange rate case. The lack of balance sheet effects results in no significant differences in terms of net worth evolution across the two types of entrepreneurs when impulse response functions are evaluated. However, the shocks related to the financial sector appear to be especially important for investment, for the domestic interest rate and interest rate spreads, illustrating the relevance of including financial frictions in the model. With the exchange rate not acting as a shock absorber, the external shocks are more relevant for the CPI inflation and the domestic interest rate. The drop in GDP associated with the pandemic mainly reflects the negative innovations to the consumption preference shock and to the permanent technology shock.
\end{abstract}

Keywords: DSGE model, financial frictions, partial euroization, small open economy, Bayesian estimation

\section{JEL classification: E0, E3, FO, F4, GO, G1}

\footnotetext{
${ }^{1}$ This document has been produced with the financial assistance of the European Union. The contents of this document are the sole responsibility of the authors and can under no circumstances be regarded as reflecting the position of the European Union. The views expressed in this paper are those of the authors and do not necessarily reflect the views of the National Bank of Romania or of the National Bank of the Republic of North Macedonia. This model was developed within the IPA Twinning Project: "Strengthening the institutional capacity of the National Bank of the Republic of North Macedonia in the process of its accession to the ESCB".

2 Corresponding author.
}

License: Authors of papers retain copyright and release the work under a Creative Commons Attribution-NonCommercial-ShareAlike 4.0 International License (CC BY-NC-SA 4.0). 


\section{Introduction}

One of the main insights resulting from the financial crisis of 2008 is that explicit modeling of the financial sector is crucial for understanding the business cycle properly. The state of the financial system draws boundaries for the dynamics of economic activity, enabling it to act as a propeller or an impediment to economic growth. In times of heightened economic uncertainty, such as the recent global pandemic, the interaction between business and financial cycles comes to the fore and a better understanding of their interdependence is ever more relevant.

Moreover, many small open economies face a high degree of dollarization3, that allows for a partial use of another, foreign currency in the economy alongside the domestic currency that is recognized as the main legal tender, see Castillo et al. (2006). In fact, financial dollarization is present in many small open economies, such as the Macedonian economy, that is characterized with a relatively high share of foreign-currency denominated deposits and loans (predominantly in euro) in the banking system. Figure 1 displays the share of foreign currency loans in total loans provided to the private sector in the Macedonian economy. The average share of foreign currency loans in total loans over the period shown on the graph is $48.8 \%$, thereby highlighting the need to account for foreign currency denominated financial contracts in the economy. Thus, the high dollarization (euroization) rate is a characteristic of the domestic economy that should be recognized and addressed within the model structure. Backing the euroization, there is also a positive differential between the domestic currency lending rate and the foreign currency lending rate in the economy, which has certain implications for the financial frictions block of the model, as it will be elaborated in the following sections of the paper. All this highlights the relevance of properly modeling the specifics of the Macedonian financial sector and its role in the evolution of the real economy.

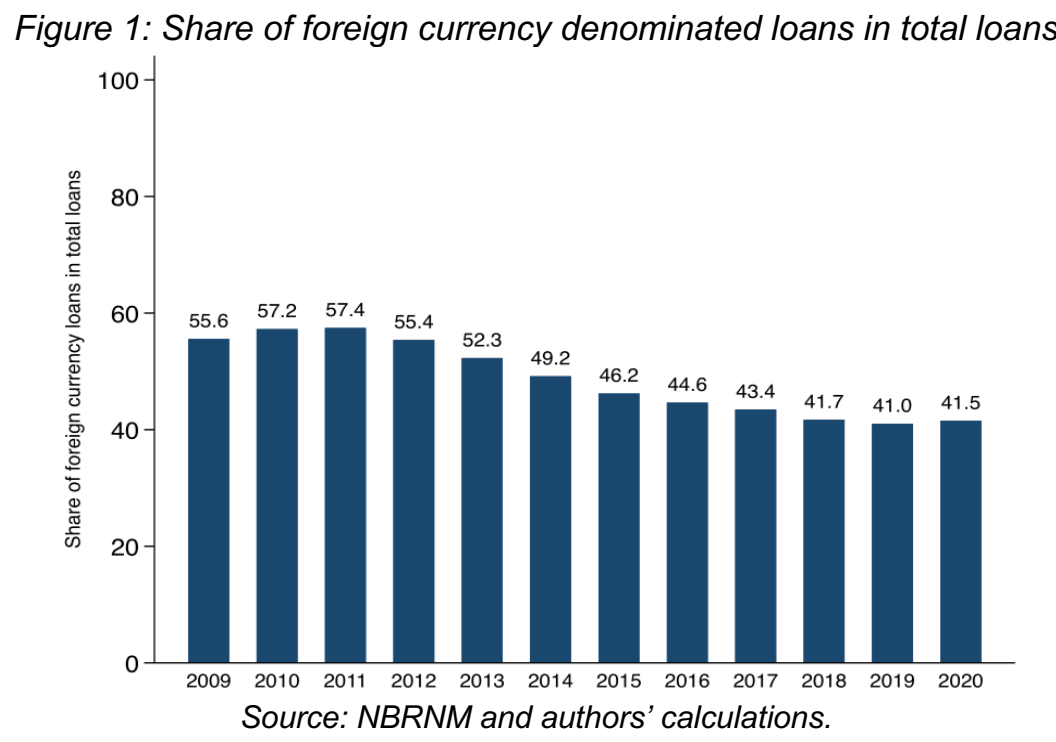

The main goal of this paper is to adapt the standard New Keynesian small open economy model with financial frictions in the spirit of Bernanke et al. (1999) to the specifics of the Macedonian economy. For that purpose, a simplified version of the model presented in Copaciu et al. (2015), which accounts for partial credit euroization, is used and modified to accommodate for the fixed exchange rate regime in place.

The Model presented in this paper is a small, open economy New Keynesian Model, based on the National Accounts System, that includes the standard features developed and used in the literature, such as price rigidities, monopolistic competition, consumption habits, investment adjustment costs, etc.. These features are standard in such models and, as mentioned above, their inclusion and the

\footnotetext{
3 In most of the cases we will use the generic term of dollarization as it is extensively used in the literature, although for the Macedonian economy and other CEE and SEE economies the foreign currency denomination for part of the credits and/or deposits is euro and euroization will be used when necessary.
} 
estimated parameters, have the role to generate model dynamics similar with the one encountered in the data (e.g. match the trade openness). Thus, given a model structure, through parameter estimation and calibration given the data sample available, the model can generate business cycle fluctuations and data moments close to the ones registered in the analyzed economy (i.e. the Macedonian one in this case). For example, our model can through a proper calibration of certain parameters account for country specific degrees of loan euroization or for the monetary regime in place (i.e. inflation targeting for the Romanian economy versus fixed exchange rate regime for the Macedonian economy). As for the latter, it has important implications for the dynamics of the economy, in particular regarding its impact on domestic economic variables, as further elaborated later in the paper when the results are presented.

As compared with the semi-structural models (i.e. so called gap-models) used for policy analysis and forecasting by some central banks (in fact, the National Bank currently uses such model, MAKPAM), the DSGE models have certain advantages coming from their strong microeconomic foundations, making them immune to the "Lucas critique" and suitable for identifying sources of business cycle fluctuations, answering questions about structural changes, forecasting and predicting the effect of policy changes, and performing counterfactual experiments. DSGE models are at the moment also being extensively used for conveying complex research, relevant for policy makers, in particular for central banks. However, most central banks strive not only to adhere to one type of model for their decision-making, but also to apply complementary modeling frameworks, to augment, compare and contrast effects of policy changes with the use of different model assumptions.

The model is estimated using Bayesian techniques over the 2006Q2 to 2020Q2 period, a sample that includes the impact on the economy from both the global financial crisis and from the beginning of the global Covid-19 pandemic. The estimation of the model also calls upon the endogenous prior procedure as in Christiano et al. (2011) in order to better match the relatively high variability in the data. Additionally, throughout the process of calibration and estimation of the model, we also used as references a set of unobserved variables that come out from the main quarterly projection model used by the National Bank to produce the macroeconomic forecasts.

The main contributions of this paper are threefold. First, the paper presents the structure and the results for the first estimated DSGE model for the Macedonian economy, thereby filling an important gap in the area of macroeconomic modeling done in the country. It provides important insights for policy makers and is an important reference for further research and analysis of the impact of macrofinancial developments on the economy. Second, the paper further augments the modeling toolkit of the NBRNM by providing an additional macroeconomic model that can be used for more advanced policy analysis and forecasting exercises and can serve as the basis for further extensions. Unlike the existing macroeconomic models used at the National Bank, the DSGE Model is based on microeconomic foundations, in which the relations between banks, firms, households, the central bank and the government are granularly modeled. Third, the paper is policy-relevant and adds to the empirical literature by enhancing the understanding of the complex interactions between business and financial cycles, thereby laying the foundations for potentially evaluating conceptual aspects of macroprudential policy making.

In terms of parameter estimates, the degree of price stickiness is lower than the empirical values obtained for advanced economies in the literature, but in line with parameter estimates for developing economies. Wage stickiness is lower than price stickiness, with the overall wage and price setting being characterized by a significant partial backward indexation component. Consumption patterns of households are altered by a significant degree of habit persistence, the sensitivity of their labor supply to real wages is similar with the estimates obtained in the micro studies and the investment adjustment costs are small. As for the estimated parameters related to the financial sector, even though the model-implied spreads for foreign and domestic currency are lower than their data counterparts, the estimated monitoring costs parameters are able to generate the same trend observed in the data where the domestic currency spreads are higher than the foreign currency spreads.

As for the impulse response functions, given the monetary policy regime in place, the debt deflation channel is more important relative to the financial accelerator one when compared to the flexible exchange rate case. Furthermore, as the cost of funds for both types of entrepreneurs are similar and 
co-move given the lack of balance sheet effects, there are, in general, no significant differences in terms of net worth evolution across the two types of entrepreneurs. This is the case for example when a shock is applied to the exogenous component of the risk premium, while in an alternative monetary policy regime (e.g. inflation targeting), given the balance sheet effects resulting from implied nominal depreciation of the currency, the effect on the entrepreneurs borrowing in foreign currency will be larger. The evolution of the net foreign assets position, with impact on the risk premium and consequently on the domestic interest rate, reflects both valuation effects and the evolution of the (nominal) net exports in response to different shocks.

By looking at the volatility observed in the data and from the model, it can be seen that the model performs relatively well in terms of its fit, given the constraints imposed by the number of observed variables, length of the sample and the MAKPAM counterparts serving as an exogenous reference. Moreover, the performance is significantly better relative to that resulting from estimating the model without using the endogenous priors' procedure.

The variance decomposition shows that most of the variation in the observed series on GDP and its components is explained by supply shocks, with the exception of consumption where demand shocks account for more than three quarters of its' variation. Regarding labor market variables, technology shocks are very important drivers of the variation in wages and hours worked. When it comes to prices, markup shocks and foreign shocks seem to account for most of the fluctuations in CPI inflation, the latter being expected given the fixed exchange rate regime. As for the domestic interest rate, the sovereign risk premium has a relevant role, accounting for around a quarter of its variation while foreign shocks explain close to half of its variability. The shocks related to the financial sector appear to be especially important for investment, for the domestic interest rate and interest rate spreads, illustrating the relevance of including financial frictions in the model.

Last but not least, the historical shock decomposition reveals that structural shocks on the demand side (consumption preference shocks, foreign demand shocks and financial shocks) are the key driving forces for the dynamics of the output gap over the sample. The dive of the output gap in negative territory once the pandemic hit is mostly explained by the negative contribution of the consumption preference and external demand shocks, while the risk and external interest rate shocks attenuated the fall. As for the aggregate output growth, a combination of supply and demand shocks explains its growth over the sample. The drop in GDP associated with the pandemic reflects the negative innovations to the consumption preference shock, the permanent technology shock and to a lesser extent for the marginal efficiency of investment and the markup for the imports used in the production of exports shocks. As it is expected for a country with a fixed exchange rate regime, foreign shocks along with domestic supply shocks determine the movement of CPI inflation throughout the entire sample, with the former being the key driver of the observed price slowdown at the onset of the global pandemic. Financial sector related shocks appear to be relevant for investment, the net foreign asset position of the country, domestic interest rate, as well as for the interest rate spreads, together with the foreign related ones, given the monetary policy regime in place.

There are several policy implications that come out of this paper. First, given the relevance of openness degree of the Macedonian economy, as evidentiated by the relatively high role of import and export shocks on macroeconomic variables (such as GDP), efforts should be made to stimulate and improve the exports potential of domestic companies that can further strengthen the current account position of the country. Second, given the high dollarization (euroization) rate in the domestic economy, measures aimed at discouraging it, alongside denarization efforts, should intensify to enhance the resilience of the domestic economy to different shocks, especially foreign originating ones. Differentiated minimum reserve requirements based on the currency denomination of the loans can also be maintained, while taking into account the potential increase of costs on consumers' side. Last but not least, keeping an eye on bankruptcy rates, along with early warning signals, especially during the global pandemic, can enable a more smooth conduct of prudent macro financial policy making for the domestic economy in the future.

The paper is organized as follows. Section 2 provides a brief overview of the related literature, while Section 3 describes the model and its theoretical structure. Section 4 contains a description of the 
data and measurement equations, while the estimation of the model and the corresponding results are presented in section 5 . Section 6 concludes.

\section{Literature review}

Prior to the global financial crisis, most of the research in the macroeconomic literature was centered around frictions on the demand side of financial markets. More specifically, the departure from the Modigliani and Miller "irrelevance propositions" from the 1960s stemmed from the constrained access to credit markets imposed on firms and/or households in the economy. One of the early approaches, the financial accelerator mechanism (introduced in a New-Keynesian DSGE model by Bernanke et al. (1999)) (hereafter, BGG), involves an informational asymmetry between borrowers and lenders which augments the interest rate with a risk premium. In this setup, households provide their savings to a financial intermediary that lends funds to heterogeneous firms that are not independent of external finance. The link between the net worth of firms (defined as the firms' assets less outstanding obligations) that is procyclical and the external finance premium (defined as the difference between the cost of external funds and the opportunity cost of internal funds) that is countercyclical amplifies and further propagates shocks to the economy. An alternative approach to limit the amount of credit available to borrowers is to impose a collateral constraint, as in Kiyotaki and Moore (1997). In this framework, firms' assets are used both for the production of goods and as a collateral for loans so that the shock transmission and propagation mechanism arises from the interaction of asset prices and credit limits.

The seminal papers by Bernanke et al. (1999) and Kiyotaki and Moore (1997) have motivated a plethora of extensions in the literature. Christensen and Dib (2008) embed additional features in the financial accelerator mechanism such as debt contracts with a predetermined nominal interest rate and a modified Taylor- rule. Their setup also allows for another propagation channel, known as the debt- deflation route. lacoviello (2005) builds upon the BGG framework by incorporating a collateral constraint for firms (and a subset of households) that is linked to the value of their real estate (as in Kiyotaki and Moore, 1997) and by specifying debt contracts in nominal terms. This allows the financial accelerator mechanism to depend on the source of the shocks hitting the economy - in the case of a negative demand shock, the subsequent decrease in consumer and asset prices diminishes the borrowing capacity of lenders, thereby further amplifying the initial effect on the economy; whereas in the case of a negative supply shock, the following increase in consumer prices lowers the borrowers' obligations, thereby dampening the initial effect on the economy.

Another stream of research aimed to study frictions on the supply side of credit, mostly by modeling the behavior of banks. Goodfriend and McCallum (2007) enrich the financial accelerator mechanism by adding a banking sector within an otherwise standard DSGE model. In their work, banks are treated as separate, perfectly competitive agents that produce loans with collateral and labor as inputs and obtain deposits from households in order to facilitate transactions in the economy (cash-in advance assumption). This setup allows for an additional, off-setting effect of loose monetary policy in terms of the external finance premium - by stimulating employment and output, the external finance premium is reduced, for a given demand of deposits (financial accelerator) or raised (banking attenuator) due to an increase in demand for deposits, for a given supply of collateral in the economy. On the other hand, Curdia and Woodford (2009) use the assumption of heterogeneous agents in their model such that agents (households and/or firms) that borrow or save can differ at each point in time and their modeling of the banking sector does not rely on the cash-in advance assumption that is related to bank deposits.

Finally, other subsets of the literature combine financial frictions on both the demand and the supply side of credit (lacoviello, 2015), analyze imperfectly competitive banks (Gerali and Signoretti, 2010; Andres and Arce, 2012), put capital regulation in the spotlight (Nikolov et al., 2017) or study unconventional monetary policy interventions (Gertler and Karadi, 2009; Gertler and Kiyotaki, 2010).

Our study is also related to the literature on partial dollarization in terms of financial contracts. An important part of this literature focuses on the amplified effect that currency depreciations have on output via their impact on access to credit markets for borrowing agents in the economy (Krugman, 
1999; Aghion et al., 2000; Aghion and Banerjee, 2001; Schneider and Tornell, 2004; Berganza et al., 2004; Christiano et al., 2004). Based on some form of the financial accelerator mechanism, these models aim to explain financial disruptions and their role in economic fluctuations as the result of an interaction between the banking system, capital flows/exchange rates and corporate balance sheets. Additionally, Cespedes and Velasco (2004) and Gertler and Natalucci (2007) compare the impact of the financial accelerator with foreign-indexed debt and fixed versus flexible exchange rates and find that the resulting drop in output (following a country risk premium shock) is much smaller under a flexible exchange rate regime. Using a two-country DSGE model with financial frictions a la Bernanke et al. (1999), Faia (2010) also finds support for the stabilization properties of a flexible exchange rate regime in the presence of external shocks that are not symmetric and correlated4. On the other hand, in their welfare-based comparison of fixed and flexible exchange rate regimes, Elekdag and Tchakarov (2004) show that there is a threshold value of debt-to-GDP at which a peg starts to dominate a floating exchange rate when a financial accelerator is present. Finally, Kolasa and Lombardo (2011) discuss the change in optimal monetary policy when financial frictions interact with other frictions such as debt denominated in foreign currency as well as non-tradeable goods within the confines of a two country DSGE model.

To date, only a few papers have applied some of the above-mentioned approaches to model the economies from the region of Central and South Eastern Europe (CESEE). Urosevic and Grga (2014) and Djukic and VIcek (2017) develop and evaluate numerically/calibrate DSGE models with financial euroization for the Serbian economy by incorporating commercial banks, differing mainly by their treatment of the central bank which in the former is modeled as a partial liquidity provider, while in the latter it includes an inflation-targeting framework. In contrast, Copaciu et al. (2015) develops and estimates a DSGE model for the Romanian economy with both labor market frictions and financial frictions - the latter being modeled with partial credit euroization of entrepreneurs within the financial accelerator mechanism as in Bernanke et al. (1999).

Furthermore, the presence of euroization for the Macedonian economy as part of the broader CESEE region has also been in the focus of a few empirical papers. Thus, several studies have used the OeNB Survey to investigate the impact of declining interest rate differentials between the domestic and foreign currency on euroization (Scheiber et al., 2018), to study the impact of financial literacy for the choice of credit currency (Beckmann and Stix, 2015) or to analyze the drivers of deposit euroization (Brown and Stix, 2015), for the overall CESEE region. Using alternative data sources but with (part of) the same countries on the radar, Luca and Petrova (2008) put an accent on the determinants of credit euroization, Brown and De Haas (2012) disentangle the relationship between bank ownership, bank funding and foreign currency lending and Basso et al. (2007) discuss the joint impact of openness, access to foreign funds, margins and macroeconomic conditions. The latter is also in the focus of Jovanovski (2015) where it is shown that prices, exchange rates and trade openness are important determinants of euroization in the CESEE region. Thus, these studies highlight the importance of interest rate differentials, macroeconomic conditions, presence and funding patterns of foreign banks as well as the (potential) hedging of exchange rate risks for the level of euroization in the region. For a detailed survey on the empirical literature concerned with credit/deposit euroization, please see Haiss and Rainer (2012). Finally, regarding the case of the Macedonian economy, by estimating separate supply functions for loans in domestic and in foreign currency, Bogoev (2016) focuses on the determinants of bank loans according to their currency denomination. $\mathrm{He}$ finds that the supply of foreign currency denominated loans responds only to changes in the foreign interest rate, thereby further constraining the effectiveness of the domestic monetary policy, through the bank lending channel, both on the short and on the long term.

\section{Model description}

\section{Overview of the model}

\footnotetext{
${ }^{4}$ The currency denomination of debt does not have an impact on the author's results.
} 
The New-Keynesian DSGE model for a small open economy used in this paper is a simplified version of the model presented in Copaciu et al. (2015), further modified and adapted to a fixed exchange rate regime. It incorporates partial credit euroization within an otherwise standard DSGE model with financial frictions in the spirit of Bernanke et al. (1999) where some entrepreneurs in the economy are allowed to access loans in either domestic or foreign currency.

A graphical overview of the theoretical structure of the model is presented in Figure 2. The economy is populated by firms, households, banks, entrepreneurs, fiscal and monetary authorities and an external sector.

The price formation mechanism for the intermediate goods, imported goods and export goods producers give rise to New-Keynesian Phillips curves. Thus, for each mentioned sector, there are firms operating in monopolistic competition environment, thus having some pricing power. The presence of nominal price rigidities á la Calvo implies that only part of the firms can re-optimize their price at a given time period by maximizing the expected present value of their discounted profits. The rest of the firms partially index their price to a combination of previous period prices and the inflation target (partial backward indexation). The imperfectly substitutable goods supplied by these firms are aggregated in a homogenous good by representative firms that operate in an environment of perfect competition with the goods further supplied according to their demand.

Thus, the domestic intermediate goods producers provide the value added (VA) in the economy using capital services and labor which is monopolistically supplied to intermediate goods retailers that aggregate what they receive into a homogeneous good. In the production of heterogeneous domestic intermediate goods, the output is affected by permanent and temporary productivity shocks and the price is affected by markup shocks. Next, producers of imported goods buy a homogeneous good from foreign markets and differentiate it into imports for consumption goods, imports for investment goods and imports for export goods before they supply them to import retailers. Imports and domestic intermediate goods are then combined by final goods retailers to make consumption, investment, government and export goods. Both import and export prices are subject to markup shocks and are set following the local currency pricing approach. The main idea behind this approach is that prices are set in the currency of the country where the goods are being consumed to account for the incomplete exchange rate pass-through to prices on the short run.

Capital retailers combine investment goods and the previous stock of undepreciated capital to produce new installed capital that is supplied to entrepreneurs. Note that the transformation of investment to capital is accompanied by investment adjustment costs and is affected by marginal efficiency of investment shocks. The entrepreneurs use the purchased capital to rent capital services to domestic intermediate goods producers. There are two types of entrepreneurs in the economy: i) entrepreneurs that borrow in foreign currency and ii) entrepreneurs that borrow in domestic currency (no transition is possible among these categories). Each entrepreneur has a different net worth that is combined with a bank loan in order to purchase capital. Entrepreneurs are exposed to net worth and idiosyncratic productivity shocks that allow for bankruptcy and exit from the economy. Due to the presence of asymmetric information and costly state verification between banks and entrepreneurs, the model gives rise to financial frictions. Moreover, as lending occurs both in domestic and in foreign currency, the model also allows for balance sheet effects.

Banks operate in perfect competition and act as financial intermediaries between households and entrepreneurs. They obtain domestic deposits from domestic households and foreign deposits from both domestic and foreign households, for which a non-state contingent nominal interest rate is paid, thus debt-deflation effects arise. There are two types of banks in the model: i) banks that work with domestic currency and ii) banks that work with foreign currency. The amount of loans that banks extend to entrepreneurs is proportional to their net worth and is equal to the amount of deposits that they receive.

Households monopolistically supply labor to domestic intermediate producers and use their budget to buy consumption goods from retailers and to save (in domestic or in foreign currency). Apart from their labor market income and the interest rate earned on deposits, their budget additionally includes profits (as households own the firms in the economy) and lump sum transfers (from entrepreneurs and the 
government). In maximizing their utility, households face internal habit in consumption and are exposed to consumption preference and labor disutility shocks.

The role of the fiscal authority is neutral. It collects taxes, provides lump sum transfers and demands government consumption goods, running a balanced budget. A similar role is imposed for the monetary authority, as the central bank of the country pursues a fixed exchange rate regime, the model being adapted to reflect this fact.

Finally, the foreign sector is modeled as a simple 3 equations semi-structural New-Keynesian Model, consisting of an IS Curve, a Philips Curve and a Taylor Rule.

Figure 2: Theoretical structure (diagram)

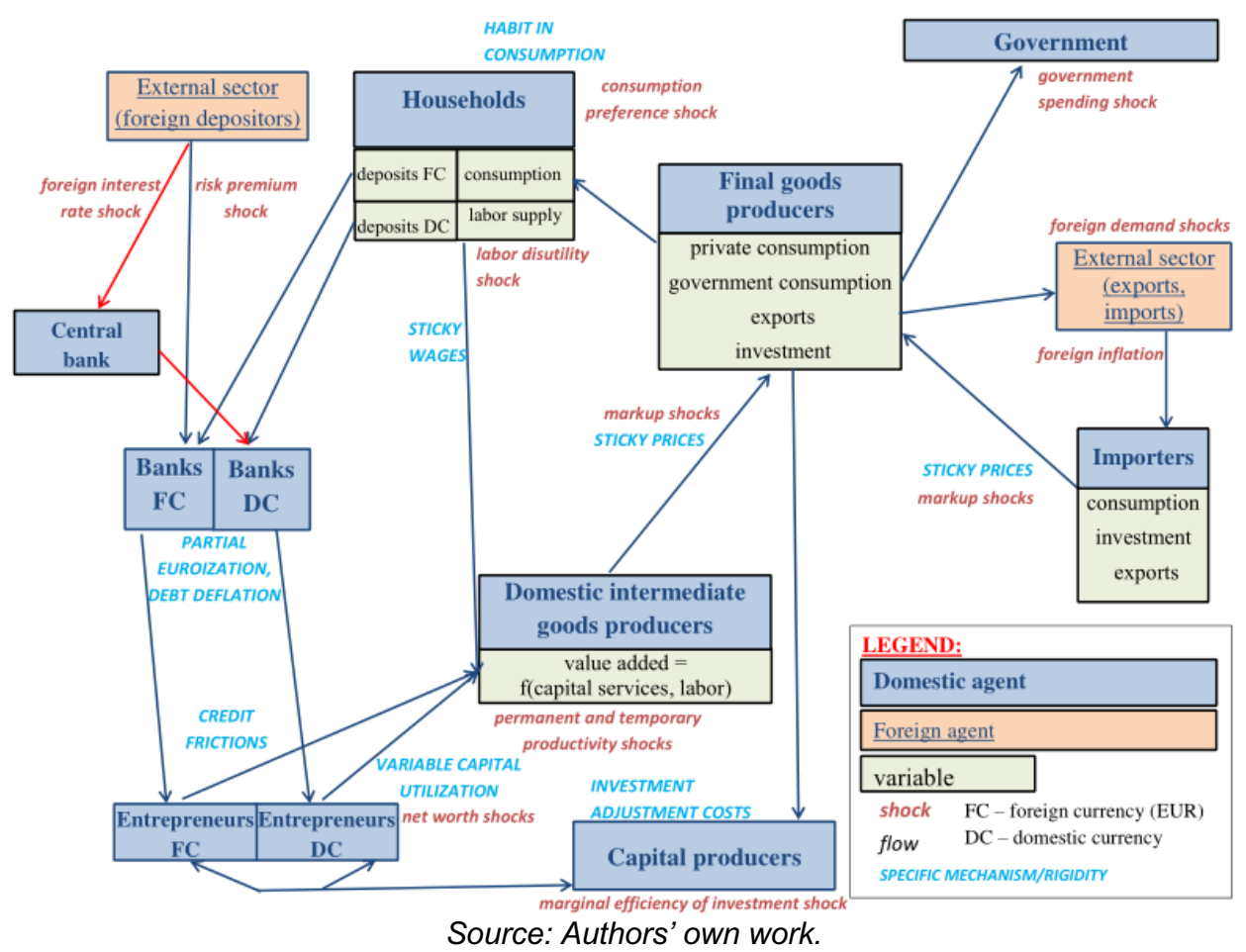

\section{Theoretical structure}

The exposition on the theoretical structure of the model follows closely Copaciu et al. (2015).

\section{Domestic intermediate goods}

A continuum of domestic intermediate goods producers, indexed by i $E[0,1]$, operate in monopolistic competition and use capital and labor using the following technology:

$$
Y_{i, t}=\epsilon_{t}\left(K_{i, t}\right)^{\alpha}\left(z_{t} H_{i, t}\right)^{1-\alpha}-z_{t} \phi
$$

with

$$
K_{i, t}=\left[\left(\omega_{k}\right)^{1 / \eta_{k}}\left(K_{i, t}^{D C}\right)^{\frac{\eta_{k}-1}{\eta_{k}}}+\left(1-\omega_{k}\right)^{1 / \eta_{k}}\left(K_{i, t}^{F C}\right)^{\frac{\eta_{k}-1}{\eta_{k}}}\right]^{\frac{\eta_{k}}{\eta_{k-1}}}
$$

where: 
- $\alpha \in(0,1)$ is the share of aggregate capital services in the total value added (VA) in the economy;

- $Y_{i, t}$ is the output of heterogeneous domestic intermediate goods by each firm $i$ at time $t$;

- $\quad H_{i, t}$ are labor services obtained from households by each firm $i$ at time $t$;

- $K_{i, t}$ are aggregate capital services rented from entrepreneurs by each firm $i$ at time $t$;

- $K_{i, t}^{D C}, K_{i, t}^{F C}$ are capital services rented from entrepreneurs borrowing in domestic or foreign currency, with $\omega_{k},\left(1-\omega_{k}\right) \in(0,1)$ being the mass of entrepreneurs borrowing in domestic or foreign currency, respectively;

- $\quad \eta_{k}$ is the elasticity of substitution between capital services ${ }^{5}$;

- $\epsilon_{t}$ is a stationary technology shock;

- $z_{t}$ is a unit root technology shock;

- $\phi$ is a fixed cost that grows with the aggregate technology rate and allows for zero profits in the steady state.

Each intermediate goods producer i acts competitively on the factor markets and solves the cost minimization problem given below:

$$
\min _{K_{i, t}^{D C}, K_{i, t}^{F C}, H_{i, t}}=W_{t} H_{i, t}+\left(r_{t}^{k, D C} P_{i, t}\right) K_{i, t}^{D C}+\left(r_{t}^{k, F C} P_{i, t}\right) K_{i, t}^{F C}
$$

subject to (3.2.1) and (3.2.2), where:

- $W_{t} H_{i, t}$ are the labor costs of firm $i$ at time $t$;

- $R_{t}^{k, j} K_{i, t}^{j}$ are rented capital services costs of firm $i$ at time $t$, with $r_{t}^{k, j}$ being the real rental rate at time $t$ (gross nominal rental rate scaled by $P_{i, t}$ ), with $j \in\{D C, F C\}$;

The optimization problem results in the following F.O.Cs for the choice variables $H_{i, t}, K_{i, t}^{D C}$ and $K_{i, t}^{F C}$ :

$$
\begin{gathered}
W_{t}=(1-\alpha) m c_{t} P_{i, t} z_{t} \epsilon_{t}\left(\frac{K_{i, t}}{z_{t} H_{i, t}}\right)^{\alpha} \\
r_{t}^{k, D C}=\alpha m c_{t} \epsilon_{t}\left(\frac{K_{i, t}}{z_{t} H_{i, t}}\right)^{\alpha-1}\left(\frac{\omega_{k} K_{i, t}}{K_{i, t}^{D C}}\right)^{\frac{1}{\eta_{k}}} \\
r_{t}^{k, F C}=\alpha m c_{t} \epsilon_{t}\left(\frac{K_{i, t}}{z_{t} H_{i, t}}\right)^{\alpha-1}\left(\frac{\left(1-\omega_{k}\right) K_{i, t}}{K_{i, t}^{F C}}\right)^{\frac{1}{\eta_{k}}}
\end{gathered}
$$

along with the production function (3.2.1), associated with the F.O.C with respect to the Lagrange multiplier.

In the F.O.Cs, $m c_{t}$ is the real marginal cost (with $m c_{t} P_{i, t}$ being the nominal marginal cost and also the Lagrange multiplier). By rearranging the first order conditions of the minimization problem, one can obtain an expression for $m c_{t}$ :

$$
m c_{t}=\tau_{t}^{d}\left(\frac{W_{t}}{(1-\alpha) P_{i, t} z_{t}}\right)^{1-\alpha}\left(\frac{\left[\omega_{k}\left(r_{t}^{k, D C}\right)^{1-\eta_{k}}+\left(1-\omega_{k}\right)\left(r_{t}^{k, F C}\right)^{1-\eta_{k}}\right]^{\frac{1}{1-\eta_{k}}}}{\alpha}\right)^{\alpha} \frac{1}{\epsilon_{t}}
$$

where $\tau_{t}^{d}$ is a tax-like shock (a markup shock in the linearized model) that is not present in the production function.

\footnotetext{
${ }^{5}$ Because all entrepreneurs in the economy are identical $K_{i, t}^{D C}=\omega_{k} K_{i, t}^{D C \text { entrep. }}$ and $K_{i, t}^{F C}=\left(1-\omega_{k}\right) K_{i, t}^{F C, e n t r e p .}$
} 
Price setting for the monopolistically competitive producer is modeled à la Calvo. There is a probability $\xi_{d}$ that the producers will not be able to reoptimize and therefore they follow a (partial) backward indexation rule:

$$
P_{i, t} \equiv\left(\pi_{t-1}\right)^{\kappa_{d}}\left(\bar{\pi}^{c}\right)^{1-\kappa_{d}} P_{i, t-1}
$$

where $\kappa_{d}$ measures the degree of indexation to previous period prices $\left(\pi_{t-1}\right)$ and $\left(\bar{\pi}^{c}\right)$ is the inflation target.

However, with probability $1-\xi_{d}$, producers can set their price to maximize the present discounted future stream of profits:

$$
E_{t} \sum_{j=o}^{\infty} \beta^{j} v_{t+j}\left[P_{i, t+j} Y_{i, t+j}-m c_{t+j} P_{t+j} Y_{i, t+j}\right]
$$

subject to the demand for any domestic intermediate good $i$ from the aggregating domestic intermediate goods retailers given by (3.2.14), where $v_{t+j}$ is the Lagrange multiplier from the households' optimization problem (as households own the firms in the economy).

Using the aggregate price index of the economy (where the optimal reset price $\tilde{P}_{t}$ and the indexed price $P_{t}$ are weighted according to the probability to optimize/index, respectively $)^{6}$ :

$$
P_{t}=\left[\int_{0}^{1} P_{i, t}^{\frac{1}{1-\lambda_{d}}} d i\right]^{\left(1-\lambda_{d}\right)}=\left[\xi_{d} \widetilde{P}_{t}^{\frac{1}{1-\lambda_{d}}}+\left(1-\xi_{d}\right)\left(\pi_{t-1}^{\kappa_{d}} \bar{\pi}_{c}^{1-\kappa_{d}} P_{t-1}\right)^{\frac{1}{1-\lambda_{d}}}\right]^{\left(1-\lambda_{d}\right)}
$$

and the optimal solution to the profit maximization problem from (3.2.9), the Philips curve (in a loglinearized form) can be derived as:

$$
\hat{\pi}_{t}=\frac{\beta}{1+\kappa_{d} \beta} E_{t} \hat{\pi}_{t+1}+\frac{\kappa_{d}}{1+\kappa_{d} \beta} \hat{\pi}_{t-1}+\frac{1}{1+\kappa_{d} \beta} \frac{\left(1-\beta \xi_{d}\right)\left(1-\xi_{d}\right)}{\xi_{d}} \widehat{m c}_{t}
$$

The domestic intermediate goods retailer operates in perfectly competitive environment, taking prices of inputs and output as given, and aggregates heterogeneous domestic intermediate goods into a homogeneous domestic intermediate good using the following technology:

$$
Y_{t}=\left[\int_{0}^{1} Y_{i, t}^{\frac{1}{\lambda_{d}}} d i\right]^{\lambda_{d}}
$$

where $\lambda_{d}$ is the markup in the domestic intermediate goods market and $Y_{t}$ is the value added (VA) in the economy.

Domestic intermediate goods retailers solve the following profit maximization problem:

$$
\max _{\mathrm{i}, \mathrm{t}} \Pi_{t}^{Y}=P_{t} Y_{t}-\int_{0}^{1} P_{i, t} Y_{i, t} d i
$$

The solution of the optimization problem results in the following F.O.C that determines the demand for any domestic intermediate good $i$ :

$$
Y_{i, t}=\left(\frac{P_{t}}{P_{i, t}}\right)^{\frac{\lambda_{d}}{\lambda_{d}-1}} Y_{t}
$$

\footnotetext{
${ }^{6}$ All firms arrive to the same solution after solving the optimization problem.
} 
Under the zero-profits assumption, the maximization problem of the domestic intermediate goods retailer can be rearranged to obtain the aggregate price index, $P_{t}$ :

$$
P_{t}=\left[\int_{0}^{1} P_{i, t}^{\frac{1}{1-\lambda_{d}}} d i\right]^{\left(1-\lambda_{d}\right)}
$$

\section{Imports}

As in the case of domestic intermediate goods, the importing sector consists of producers and retailers. Import producers buy a homogeneous good from foreign markets and differentiate it into imports for consumption goods, $C_{i, t}^{m}$, imports for investment goods, $I_{i, t}^{m}$, and imports for export goods, $X_{i, t}^{m}$. They monopolistically supply the differentiated imports to perfectly competitive import retailers. In this section, the generic notation $\Theta$ is used where $\Theta \in\{C, I, X\}$.

Local currency pricing à la Calvo is assumed for monopolistically competitive $\Theta_{i, t}^{m}$. At each point in time, producers that are unable to reoptimize their price, index it to a combination of previous period prices and the inflation target as shown below:

$$
P_{i, t}^{m, \Theta}=\left(\pi_{t-1}^{m, \Theta}\right)^{\kappa_{m, \Theta}}\left(\bar{\pi}^{c}\right)^{1-\kappa_{m, \Theta}} P_{i, t-1}^{m, \Theta}
$$

where $\kappa_{m, \Theta}$ is the degree of indexation to previous period prices $\left(\pi_{t-1}^{m, \Theta}\right)$ and $\left(\bar{\pi}^{c}\right)$ is the inflation target.

However, with probability $1-\xi_{m, \Theta}$ producers can reoptimize their price in order to maximize the present discounted future stream of profits, such that:

$$
E_{t} \sum_{j=o}^{\infty} \beta^{j} v_{t+j}\left[P_{i, t+j}^{m, \Theta} \Theta_{i, t+j}^{m}-\tau_{t+j}^{m, \Theta} S_{t+j} P_{t+j}^{*} \Theta_{i, t+j}^{m}\right]
$$

subject to the demand given by (3.2.20), where $v_{t+j}$ is the Lagrange multiplier from the households' optimization problem (as households own the firms in the economy).

Again, the solution of the optimization problem combined with the definition of the aggregate import price index, leads to the log-linearized Phillips curve for importers:

$$
\hat{\pi}_{t}^{m, \Theta}=\frac{\beta}{1+\kappa_{m \Theta} \beta} E_{t} \hat{\pi}_{t+1}^{m, \Theta}+\frac{\kappa_{m \Theta}}{1+\kappa_{m \Theta} \beta} \hat{\pi}_{t-1}^{m, \Theta}+\frac{1}{1+\kappa_{m \Theta} \beta} \frac{\left(1-\beta \xi_{m \Theta}\right)\left(1-\xi_{m \Theta}\right)}{\xi_{m \Theta}} \widehat{m c}_{t}^{m, \Theta}
$$

The import retailer uses the technology shown in (3.2.19). The resulting demand curve for any individual imported good $i$ from the profit maximization problem is given by (3.2.20).

$$
\begin{gathered}
\Theta_{t}^{m}=\left[\int_{0}^{1}\left(\Theta_{i, t}^{m}\right)^{\frac{1}{\lambda_{m, \Theta}}} d i\right]^{\lambda_{m, \Theta}} \\
\Theta_{i, t}^{m}=\Theta_{t}^{m}\left(\frac{P_{t}^{m, \Theta}}{P_{i, t}^{m, \Theta}}\right)^{\frac{\lambda_{m, \Theta}}{\lambda_{m, \Theta}-1}}
\end{gathered}
$$

The nominal marginal cost for $\Theta_{i, t}^{m}$ is:

$$
N M C_{t}^{m, \Theta}=\tau_{t}^{m, \Theta} S_{t} P_{t}^{*}
$$


where $\tau_{t}^{m, \Theta}$ is a tax-like shock (markup shock in the linearized model); $S_{t}$ is the nominal exchange rate and $P_{t}^{*}$ is the foreign price level.

The total value of imports $\Theta_{t}$ at the border, the measure we will use when computing GDP, is given by:

$$
S_{t} P_{t}^{*} \Theta_{t}^{m}
$$

\section{Consumption goods}

Consumption goods retailers operate in perfect competition and combine domestic intermediate goods and imported consumption goods using the following technology:

$$
C_{t}=\left\{\left(1-\omega_{c}\right)^{1 / \eta_{c}}\left(C_{t}^{d}\right)^{\frac{\eta_{c}-1}{\eta_{c}}}+\left(\omega_{c}\right)^{1 / \eta_{c}}\left(C_{t}^{m}\right)^{\frac{\eta_{c}-1}{\eta_{c}}}\right\}^{\frac{\eta_{c}}{\eta_{c-1}}}
$$

where $\omega_{c}$ is the share of imported consumption goods $\left(C_{t}^{m}\right)$ and $\eta_{c}$ is the elasticity of substitution between inputs (imports and domestic intermediate goods).

The F.O.Cs with respect to the choice of inputs from the profit maximization problem of the consumption goods retailer result in the following demand functions for domestic intermediate and imported goods:

$$
\begin{gathered}
C_{t}^{d}=\left(1-\omega_{c}\right)\left(\frac{P_{t}^{c}}{P_{t}}\right)^{\eta_{c}} C_{t} \\
C_{t}^{m}=\left(\omega_{c}\right)\left(\frac{P_{t}^{c}}{P_{t}^{m, c}}\right)^{\eta_{c}} C_{t}
\end{gathered}
$$

The price of the consumption good $C_{t}$ is related to the prices of the imported consumption goods and of the domestic intermediate goods with:

$$
P_{t}^{c}=\left\{\left(1-\omega_{c}\right) P_{t}^{1-\eta_{c}}+\left(\omega_{c}\right)\left(P_{t}^{m, c}\right)^{1-\eta_{c}}\right\}^{\frac{1}{1-\eta_{c}}}
$$

and the corresponding inflation rate is defined as: $\pi_{t}^{c}=\frac{P_{t}^{c}}{P_{t-1}^{c}}$.

\section{Exports}

The exports production setup resembles the two-stage production process outlined for imports and domestic intermediate goods. Namely, export producers use imported goods for exports and domestic intermediate goods to produce differentiated export goods that are monopolistically supplied to export retailers. The latter assemble the heterogeneous goods into a homogenous export good, by taking into account the demand for exports from abroad.

The production function of the $t^{\text {th }}$ export producer is given by:

$$
X_{i, t}=\left\{\left(1-\omega_{x}\right)^{1 / \eta_{x}}\left(X_{i, t}^{d}\right)^{\frac{\eta_{x}-1}{\eta_{x}}}+\left(\omega_{x}\right)^{1 / \eta_{x}}\left(X_{i, t}^{m}\right)^{\frac{\eta_{x}-1}{\eta_{x}}}\right\}^{\frac{\eta_{x}}{\eta_{x-1}}}
$$

The cost minimization problem of the $i^{\text {th }}$ export producer, subject to (3.2.27) is:

$$
\underset{\mathrm{X}_{\mathrm{i}, \mathrm{t}}^{\mathrm{d}}, \mathrm{X}_{\mathrm{i}, \mathrm{t}}^{\mathrm{m}}}{\min } \mathrm{P}_{i, t}^{m, x} X_{i, t}^{m}+P_{t} X_{i, t}^{d}
$$


that results in the following F.O.Cs:

$$
\begin{gathered}
X_{i, t}^{d}=\left(1-\omega_{x}\right)\left(\frac{N M C_{t}^{x}}{\tau_{t}^{x} P_{t}}\right)^{\eta_{x}} X_{i, t} \\
X_{i, t}^{m, x}=\left(\omega_{x}\right)\left(\frac{N M C_{t}^{x}}{\tau_{t}^{x} P_{t}^{m, x}}\right)^{\eta_{x}} X_{i, t}
\end{gathered}
$$

with $\tau_{t}^{x}$ as a tax-like shock (markup shock in the linearized model) and $\omega_{x}$ as the share of imported goods used in the production of exports $\left(X_{i, t}\right)$.

$N M C_{t}^{x}$ is the nominal marginal cost in the cost minimization problem, with the real marginal cost being defined as $m c_{t}^{x}=\frac{N M C_{t}^{x}}{S_{t} P_{t}^{x}}$ :

$$
m c_{t}^{x}=\frac{\tau_{t}^{x}}{S_{t} P_{t}^{x}}\left\{\left(1-\omega_{x}\right) P_{t}^{1-\eta_{x}}+\left(\omega_{x}\right)\left(P_{t}^{m, x}\right)^{1-\eta_{x}}\right\}^{\frac{1}{1-\eta_{x}}}
$$

Local currency price setting is modeled à la Calvo. With probability $\xi_{x}$ export producers cannot reoptimize and use the following indexation rule:

$$
P_{i, t}^{x} \equiv\left(\pi_{t-1}^{x}\right)^{\kappa_{x}}\left(\pi^{x}\right)^{1-\kappa_{x}} P_{i, t-1}^{x}
$$

where $\pi_{t-1}^{x}$ is the domestic inflation rate at $t-1$ and $\pi^{x}$ is the steady state of foreign inflation (for export goods).

With probability $1-\xi_{x}$ export producers reoptimize their price to maximize the present discounted future stream of profits, that is:

$$
E_{t} \sum_{j=o}^{\infty} \beta^{j} v_{t+j}\left[P_{i, t+j}^{x} X_{i, t+j}-m c_{t+j}^{x} P_{t+j}^{x} X_{i, t+j}\right.
$$

subject to the demand given by (3.2.37).

The solution to the maximization problem and the aggregate export price index lead to the following log-linearized Phillips curve for exporters:

$$
\hat{\pi}_{t}^{x}=\frac{\beta}{1+\kappa_{x} \beta} E_{t} \hat{\pi}_{t+1}^{x}+\frac{\kappa_{x}}{1+\kappa_{x} \beta} \hat{\pi}_{t-1}^{x}+\frac{1}{1+\kappa_{x} \beta} \frac{\left(1-\beta \xi_{x}\right)\left(1-\xi_{x}\right)}{\xi_{x}} \widehat{m c}_{t}^{x}
$$

The export retailer operates in perfect competition and uses the following technology:

$$
X_{t}=\left[\int_{0}^{1}\left(X_{i, t}\right)^{\frac{1}{\lambda_{x}}} d i\right]^{\lambda_{x}}
$$

and maximizes profits subject to the demand for export goods from abroad:

$$
X_{t}=\left(\frac{P_{t}^{x}}{P_{t}^{*}}\right)^{-\eta_{f}} Y_{t}^{*}
$$

with $P_{t}^{*}$ as the foreign price index for homogeneous goods; $Y_{t}^{*}$ as the foreign GDP; $P_{t}^{x}$ as the price index (in foreign currency) of exports and $\eta_{f}$ as the elasticity of foreign demand for domestic exports.

Using the profit maximization problem and the zero-profits assumption, the optimal choice of inputs and the aggregate export price can be obtained as: 


$$
\begin{gathered}
X_{i, t}=\left(\frac{P_{i, t}^{x}}{P_{t}^{x}}\right)^{-\frac{\lambda_{x}}{\lambda_{x}-1}} X_{t} \\
P_{t}^{x}=\left[\int_{0}^{1} P_{i, t}^{x, \frac{1}{1-\lambda_{x}}} d i\right]^{\left(1-\lambda_{x}\right)}
\end{gathered}
$$

\section{Investment goods}

Investment goods retailers operate in perfect competition and aggregate total investment from imported investment goods and domestic intermediate goods with the use of the following technology:

$$
\begin{aligned}
& I_{t}+a^{D C}\left(u_{t}^{D C}\right) \omega_{k} \bar{K}_{t}^{D C}+a^{F C}\left(u_{t}^{F C}\right)\left(1-\omega_{k}\right) \bar{K}_{t}^{F C} \\
= & \left\{\left(1-\omega_{i}\right)^{1 / \eta_{i}}\left(I_{t}^{d}\right)^{\frac{\eta_{i}-1}{\eta_{i}}}+\left(\omega_{i}\right)^{1 / \eta_{i}}\left(I_{t}^{m}\right)^{\frac{\eta_{i}-1}{\eta_{i}}}\right\}^{\frac{\eta_{i}}{\eta_{i}-1}}
\end{aligned}
$$

Thus, the demand functions for domestic intermediate goods and imported investment goods are given by:

$$
\begin{gathered}
I_{t}^{d}=\left(1-\omega_{i}\right)\left(\frac{P_{t}^{i}}{P_{t}}\right)^{\eta_{i}}\left[I_{t}+a^{D C}\left(u_{t}^{D C}\right) \omega_{k} \bar{K}_{t}^{D C}+a^{F C}\left(u_{t}^{F C}\right)\left(1-\omega_{k}\right) \bar{K}_{t}^{F C}\right] \\
I_{t}^{m}=\omega_{i}\left(\frac{P_{t}^{i}}{P_{t}^{m, i}}\right)^{\eta_{i}}\left[I_{t}+a^{D C}\left(u_{t}^{D C}\right) \omega_{k} \bar{K}_{t}^{D C}+a^{F C}\left(u_{t}^{F C}\right)\left(1-\omega_{k}\right) \bar{K}_{t}^{F C}\right]
\end{gathered}
$$

with $\omega_{i}$ as the share of imported investment goods in the production of investment and $\eta_{i}$ as the elasticity of substitution between input goods (imported investment goods and domestic intermediate goods).

The investment goods retailers' output $\left(I_{t}+a^{D C}\left(u_{t}^{D C}\right) \omega_{k} \bar{K}_{t}^{D C}+a^{F C}\left(u_{t}^{F C}\right)\left(1-\omega_{k}\right) \bar{K}_{t}^{F C}\right)$ is composed of investment goods made to increase the stock of physical capital $\left(I_{t}\right)$ and investment goods used for physical capital $\left(\bar{K}_{t}^{D C}\right.$ and $\left.\bar{K}_{t}^{F C}\right)$ maintenance.

The capital utilization rate, $u_{t}^{j}$, is defined as $u_{t}^{j}=\frac{K_{t}^{j}}{\bar{K}_{t}^{j}}$ with $a^{j}\left(u_{t}^{j}\right)$ being the corresponding utilization cost function, further elaborated in 3.2.8, with $j \in\{D C, F C\}$.

By replacing the expressions for $I_{t}^{m}$ and $I_{t}^{d}$ from the F.O.Cs in (3.2.39), the price of the investment good can also be obtained:

$$
P_{t}^{i}=\left\{\left(1-\omega_{i}\right) P_{t}^{1-\eta_{i}}+\left(\omega_{i}\right)\left(P_{t}^{m, i}\right)^{1-\eta_{i}}\right\}^{\frac{1}{1-\eta_{i}}}
$$

and the corresponding quarterly inflation rate is defined as: $\pi_{t}^{i}=\frac{P_{t}^{i}}{P_{t-1}^{i}}$.

\section{Capital goods}

Perfectly competitive capital goods retailers combine investment goods and old capital in order to obtain new installed capital, with the use of the following technology: 


$$
x^{\prime}=x+F\left(I_{t}, I_{t-1}, \Upsilon_{t}\right)=x+\Upsilon_{t}\left(1-\tilde{S}\left(\frac{I_{t}}{I_{t-1}}\right)\right) I_{t}
$$

where $\Upsilon_{t}$ is a marginal efficiency of investment (MEI) shock as in Justiniano et al. (2011) and $\tilde{S}$ is an investment costs adjustment function following Christiano et al. (2011).

Each capital goods retailer solves the following maximization problem:

$$
\underset{\mathrm{I}_{\mathrm{t}+\mathrm{n}}, x_{t+n}}{\max } \mathrm{E}_{\mathrm{t}}\left\{\sum_{n=0}^{\infty} \beta^{n} v_{t+n} \Pi_{t+n}^{k}\right\}
$$

with:

$$
\Pi_{t}^{k}=P_{t} P_{k^{\prime}, t}\left[x+\Upsilon_{t}\left(1-\tilde{S}\left(\frac{I_{t}}{I_{t-1}}\right)\right) I_{t}\right]-P_{t} P_{k^{\prime}, t} x-P_{t}^{i} I_{t}
$$

and where $v_{t}$ is the multiplier in the households' budget constraint. By making use of: $x_{t+n}=$ $(1-\delta) \bar{K}_{t+n}$ in the profit maximization problem given above, consistent with profit maximization and market clearing, the following F.O.C is obtained:

$$
\begin{aligned}
& I_{t}: v_{t} P_{t}^{i}-v_{t} P_{t} P_{k^{\prime}, t} \Upsilon_{t}\left[\left(1-\tilde{S}\left(\frac{I_{t}}{I_{t-1}}\right)\right)+\tilde{S}^{\prime}\left(\frac{I_{t}}{I_{t-1}}\right)\left(\frac{I_{t}}{I_{t-1}}\right)\right] \\
& -\beta E_{t} v_{t+1} P_{t+1} P_{k^{\prime}, t+1} \Upsilon_{\mathrm{t}+1} \tilde{S}^{\prime}\left(\frac{I_{t+1}}{I_{t}}\right)\left(\frac{I_{t+1}}{I_{t}}\right)^{2}=0
\end{aligned}
$$

where the aggregate stock of physical capital evolves in the economy following the accumulation equation given below:

$$
\bar{K}_{t+1}=\omega_{k} \bar{K}_{t+1}^{D C}+\left(1-\omega_{k}\right) \bar{K}_{t+1}^{F C}=(1-\delta)\left[\omega_{k} \bar{K}_{t}^{D C}+\left(1-\omega_{k}\right) \bar{K}_{t}^{F C}\right]+\Upsilon_{t}\left(1-\tilde{S}\left(\frac{I_{t}}{I_{t-1}}\right)\right) I_{t}
$$

with $\omega_{k} \bar{K}_{t+1}^{D C}$ as the aggregate physical capital that entrepreneurs borrowing in domestic currency demand and $\left(1-\omega_{k}\right) \bar{K}_{t+1}^{F C}$ as the aggregate physical capital that entrepreneurs borrowing in foreign currency demand.

\section{Households}

Households maximize their lifetime expected utility given by:

$$
E_{t}^{j} \sum_{l=0}^{\infty} \beta^{l}\left\{\zeta_{t+l}^{c} \log \left(C_{j, t+l}-b C_{j, t+l-1}\right)-\zeta_{t+l}^{h} A_{L} \frac{\left(h_{j, t}\right)^{1+\sigma_{L}}}{1+\sigma_{L}}\right\}
$$

where $\zeta_{t}^{c}$ and $\zeta_{t}^{h}$ are consumption preferences and labor disutility shocks, respectively; $b$ is the degree of habit formation and $\sigma_{L}$ is the inverse Frisch elasticity.

For each time period $t$, the budget constraint of the household, expressed in nominal terms (and in domestic currency) is:

$$
\begin{gathered}
P_{t}^{c}\left(1+\tau^{c}\right) C_{j, t}+D_{t+1}^{D C}+S_{t} D_{t+1}^{F C, h h} \\
=T R_{t}+\text { profits }_{t}+R_{t-1}^{d, D C} D_{t}^{D C}+S_{t} R_{t-1}^{d, F C} \text { Prem }_{t-1} D_{t}^{F C, h h}+W_{j, t} h_{j, t} \frac{1-\tau^{y}}{1+\tau^{w}}
\end{gathered}
$$


with $P_{t}^{c}\left(1+\tau^{c}\right) C_{j, t}$ as the amount spent on consumption goods; $\tau^{c}$ as a consumption tax; $D_{t+1}^{D C}$ as period $t$ domestic currency deposits for which a non state contingent interest rate $R_{t}^{d, D C}$ is to be received at $t+1 ; S_{t} D_{t+1}^{F C, h h}$ as period $t$ foreign currency deposits converted into domestic currency for which a non state contingent interest rate $R_{t}^{d, F C}$ Prem $_{t}$ is to be received at time $t+1 ; W_{j, t} h_{j, t} \frac{1-\tau^{y}}{1+\tau^{w}}$ as the net labor market income; $T R_{t}$ as the lump sum transfers from the government and from entrepreneurs and the profits $s_{t}$ received from firms owned by households.

Thus, the F.O.Cs of the optimization problem are:

$$
\begin{gathered}
\frac{\zeta_{t}^{c}}{C_{t}-b C_{t-1}}-\beta E_{t} \frac{b \zeta_{t+1}^{c}}{C_{t+1}-b C_{t}}=v_{t} P_{t}^{C}\left(1+\tau^{c}\right) \\
v_{t}=\beta E_{t} v_{t+1} R_{t}^{d, D C} \\
v_{t} S_{t}=\beta E_{t} v_{t+1} S_{t+1} R_{t}^{d, F C} \text { Prem }_{t}
\end{gathered}
$$

Households supply their labor monopolistically to domestic intermediate goods producers and are subject to Calvo wage setting frictions as in Erceg et al. (2000). Heterogeneous labor services supplied by each household $j$ are combined into homogeneous labor services via labor contractors with the use of the following technology:

$$
H_{t}=\left[\int_{0}^{1} h_{j, t}^{\frac{1}{\lambda_{w}}} d i\right]^{\lambda_{w}}
$$

At time $t$, with probability $1-\xi_{w}$, a household is able to reoptimize its wage and with probability $\xi_{w}$ the household uses the following indexation factor for its wage:

$$
\tilde{\pi}_{t}^{w}=\frac{\left(\pi_{t-1}^{c}\right)^{\kappa_{w}}\left(\bar{\pi}^{c}\right)^{1-\kappa_{w}} \mu^{z}}{\pi_{t}^{w}}
$$

The household that reoptimizes its wage at time $t$ takes into account the present discounted utility of the future stream of wages, subject to the demand for each household's labor services ${ }^{7}$ :

$$
\begin{gathered}
E_{t}^{j} \sum_{l=0}^{\infty} \beta^{l} \xi_{w}^{l}\left\{\ldots-\zeta_{t+l}^{h} A_{L} \frac{\left(h_{j, t}\right)^{1+\sigma_{L}}}{1+\sigma_{L}}+v_{t+l} h_{j, t+l} W_{j, t+l} \frac{1-\tau^{y}}{1+\tau^{w}}\right\} \\
h_{j, t+l}=\left(\frac{\widetilde{W}_{t} \bar{\pi}_{w, t+l} \ldots \bar{\pi}_{w, t+1}}{W_{t+l}}\right)^{\frac{\lambda_{w}}{1-\lambda_{w}}} H_{t+l}
\end{gathered}
$$

The solution to the optimization problem leads to the following expressions for the optimal wage:

$$
\begin{gathered}
\frac{K_{w, t}}{F_{w, t}}=\bar{w}_{t}\left[\frac{1-\xi_{w}\left(\tilde{\pi}_{t}^{w}\right)^{\frac{1}{1-\lambda_{w}}}}{1-\xi_{w}}\right]^{1-\lambda_{w}\left(1+\sigma_{L}\right)} \frac{1}{A_{L}} \\
F_{w, t}=\frac{\psi_{z^{+}, t} H_{t}}{\lambda_{w}} \frac{1-\tau^{y}}{1+\tau^{w}}+\beta \xi_{w} E_{t}\left(\frac{\bar{w}_{t+1}}{\bar{w}_{t}}\right)\left(\tilde{\pi}_{t+1}^{w}\right)^{1+\frac{\lambda_{w}}{1-\lambda_{w}}} F_{w, t+1}
\end{gathered}
$$

\footnotetext{
${ }^{7}$ Only the relevant terms for this optimization problem are shown here.
} 


$$
K_{w, t}=\zeta_{t}^{h} H_{t}^{1+\sigma_{L}}+\beta \xi_{w} E_{t}\left(\tilde{\pi}_{t+1}^{w}\right)^{\frac{\lambda_{w}}{1-\lambda_{w}}\left(1+\sigma_{L}\right)} K_{w, t+1}
$$

Finally, note that the expression for the nominal wage inflation rate is:

$$
\pi_{t}^{w}=\pi_{t} \mu_{t}^{z} \frac{\bar{w}_{t}}{\bar{w}_{t-1}}
$$

\section{Banks and individual entrepreneurs}

There are two types of entrepreneurs in the model depending on whether they borrow in domestic or in foreign currency, indexed by $j \in\{D C, F C\}$. There is a fraction $\omega_{k}$ of entrepreneurs from the total population that borrow in domestic currency. There are many entrepreneurs in the economy and each entrepreneur has a different level of net worth $N_{t+1}^{j}$. In order to purchase new installed capital $\bar{K}_{t+1}^{N^{j}}$ from capital goods retailers, each entrepreneur uses their net worth and a bank loan, $L_{t+1}^{N^{j}}$ with the respective price $P_{t} P_{k^{\prime}, t}$. The loans taken by entrepreneurs are given by:

$$
\begin{gathered}
L_{t+1}^{N^{D C}}=P_{t} P_{k^{\prime}, t} \bar{K}_{t+1}^{N^{D C}}-N_{t+1}^{D C} \\
S_{t} L_{t+1}^{N^{F C}}=P_{t} P_{k^{\prime}, t} \bar{K}_{t+1}^{N^{F C}}-N_{t+1}^{F C}
\end{gathered}
$$

With $L_{t+1}^{N^{D C}}$ as the domestic currency loans; $S_{t} L_{t+1}^{N F C}$ as the foreign currency loans, expressed in domestic currency where $P_{t} P_{k^{\prime}, t}$ is the price per unit of new installed capital at $t+1$, expressed in domestic currency. ${ }^{8}$

Following the purchase of capital, each entrepreneur experiences an idiosyncratic productivity shock, which converts $\bar{K}_{t+1}^{N^{j}}$, into efficiency units $\omega_{t+1}^{j} \bar{K}_{t+1}^{N^{j}}$ where $\omega^{j}$ are idiosyncratic productivity shocks that are log-normally distributed with a unit mean and $\operatorname{var}\left(\log \left(\omega^{j}\right)\right)=\left(\sigma^{j}\right)^{2}$, with $j \in\{D C, F C\}$. The cumulative distribution function of $\sigma^{j}$ is $F\left(\omega^{j} ; \sigma^{j}\right)$.

After the idiosyncratic productivity shock, each entrepreneur sets the utilization rate of capital $u_{t+1}^{j}$ independently of the level of net worth and rents capital services at the nominal rental rate, $P_{t+1} r_{t+1}^{k, j}$ to domestic intermediate goods producers. The use of one unit of capital with $u_{t+1}^{j}$ requires the utilization $a^{j}\left(u_{t+1}^{j}\right)$ of investment goods for capital maintenance. The cost of capital utilization function $a^{j}\left(u^{j}\right)$ is increasing and convex, defined by ${ }^{9}$ :

$$
a^{j}\left(u^{j}\right)=0.5 \sigma_{b, j} \sigma_{a, j}\left(u^{j}\right)^{2}+\sigma_{b, j}\left(1-\sigma_{a, j}\right) u^{j}+\sigma_{b, j}\left(\left(\sigma_{a, j} / 2\right)-1\right)
$$

The remaining part of the capital that is undepreciated $(1-\delta) P_{t+1} P_{k^{\prime}, t+1}$ is sold back to capital goods retailers.

For each unit of capital that is purchased, an entrepreneur that draws the idiosyncratic productivity $\omega^{j}$ obtains an after-tax return of $R_{t+1}^{K, j} \omega^{j}$. The average after-tax return across all of the entrepreneurs in the economy is given by:

$$
R_{t+1}^{K, j}=\frac{\left(P_{t+1} r_{t+1}^{k, j} u_{t+1}^{j}-a^{j}\left(u_{t+1}^{j}\right) P_{t+1}^{i}\right)+(1-\delta) P_{t+1} P_{k^{\prime}, t+1}}{P_{t} P_{k^{\prime}, t}}
$$

\footnotetext{
${ }^{8}$ Note that following Christiano et al. (2011), the assumption that entrepreneurs do not take loans from banks that work with the households that they are part of is used.

${ }^{9} \sigma_{b, j} \sigma_{a, j}$ are parameters and the function has the following properties: $a^{j}(1)=0 ;\left(a^{j}\right)^{\prime}(1)=\sigma_{b, j} ;\left(a^{j}\right)^{\prime \prime}=\sigma_{b, j} \sigma_{a, j}>0 ;$ with $j \in$ $\{D C, F C\}$.
} 
When all of the purchased capital is sold, the entrepreneurs use their resources $\omega_{t+1}^{j} R_{t+1}^{k, j} P_{t} P_{k^{\prime}, t} \bar{K}_{t+1}^{N^{j}}$ to pay back their loans to the banks. Out of all the possible values that $\omega^{j}$ can take, there exists a cutoff value $\bar{\omega}_{t+1}^{j}$ at which the entrepreneur has exactly enough resources to pay back the loan with interest:

$$
\begin{gathered}
\bar{\omega}_{t+1}^{D C} R_{t+1}^{k, D C} P_{t} P_{k^{\prime}, t} \bar{K}_{t+1}^{N^{D C}}=Z_{t+1}^{D C} L_{t+1}^{N^{D C}} \\
\bar{\omega}_{t+1}^{F C} R_{t+1}^{k, F C} P_{t} P_{k^{\prime}, t} \bar{K}_{t+1}^{N^{F C}}=Z_{t+1}^{F C} S_{t+1} L_{t+1}^{N^{F C}}
\end{gathered}
$$

with $Z_{t+1}^{D C}$ and $Z_{t+1}^{F C}$ as the interest rates to loans in domestic and in foreign currency respectively.

Entrepreneurs with $\omega^{j}<\bar{\omega}_{t+1}^{j}$ file for bankruptcy and give all of their remaining resources $\omega_{t+1}^{j} R_{t+1}^{k, j} P_{t} P_{k^{\prime}, t} \bar{K}_{t+1}^{N^{j}}$ (with a value lower than the loan) to the respective bank. The monitoring costs of the bank in this scenario are equal to $\mu_{j} \omega_{t+1}^{j} R_{t+1}^{k, j} P_{t} P_{k^{\prime}, t} \bar{K}_{t+1}^{N^{j}}$.

Banks operate in perfect competition and are risk-free. There is free entry on the bank market which enables ex-ante bank profits to be zero. Along with the assumption of a non-negative cash flow, the zero profit conditions (ZPC) of banks are:

$$
\left[1-F\left(\bar{\omega}_{t+1}^{j} ; \sigma^{j}\right)\right] Z_{t+1}^{j} L_{t+1}^{N^{j}}+\left(1-\mu_{j}\right) \int_{0}^{\bar{\omega}_{t+1}^{j}} \omega^{j} d F\left(\omega^{j} ; \sigma^{j}\right) R_{t+1}^{k, j} P_{t} P_{k^{\prime}, t} \bar{K}_{t+1}^{N^{j}}=\operatorname{Cos}_{t}^{j} L_{t+1}^{N^{j}}
$$

where the left-hand side represents the return of the banks from share $1-F\left(\bar{\omega}_{t+1}^{j} ; \sigma^{j}\right)$ of entrepreneurs that pay back their loans and share $F\left(\bar{\omega}_{t+1}^{j} ; \sigma^{j}\right)$ of entrepreneurs that go bankrupt. The average $\omega^{j}$ value of bankrupt entrepreneurs is $G\left(\bar{\omega}_{t+1}^{j} ; \sigma^{j}\right)=\int_{0}^{\bar{\omega}_{t+1}^{j}} \omega^{j} d F\left(\omega^{j}, \sigma^{j}\right)$.

Banks operate either in foreign or in domestic currency. Domestic currency banks obtain domestic currency deposits from domestic households. Foreign currency banks obtain foreign currency deposits from both domestic and foreign households. Note that in the steady state it is assumed that all foreign currency funds are obtained from abroad and they equal the net foreign liabilities of the economy in the model.

Banks use the deposits to offer FC/DC loans to FC/DC entrepreneurs, respectively, using nominal debt contracts that specify the amount and the interest rate to be paid. The amount of loan that entrepreneurs can get depends on their level of net worth. The interest rate on domestic currency loans is $R_{t}$ and on foreign currency loans is $R_{t}^{*} \operatorname{Prem}_{t} \frac{s_{t+1}}{s_{t}}$, representing for the banks the cost of attracted funds, $\operatorname{Cost}_{t}^{j}$. Note that the interest rate for the loans in both FC and DC does not depend on the net worth of the entrepreneur.

Using the information given above, the ZPC can be written as:

$$
\left[\Gamma\left(\bar{\omega}_{t+1}^{j} ; \sigma^{j}\right)-\mu_{j} G\left(\bar{\omega}_{t+1}^{j} ; \sigma^{j}\right)\right] R_{t+1}^{k, j} P_{t} P_{k^{\prime}, t} \bar{K}_{t+1}^{N^{j}}=\operatorname{Cost}_{t}^{j} L_{t+1}^{N^{j}}
$$

where:

$\Gamma\left(\bar{\omega}_{t+1}^{j} ; \sigma^{j}\right)=\bar{\omega}_{t+1}^{j}\left[1-F\left(\bar{\omega}_{t+1}^{j} ; \sigma^{j}\right)+G\left(\bar{\omega}_{t+1}^{j} ; \sigma^{j}\right)\right]$ is the share of gross return given to the bank.

Furthermore, defining the leverage as:

$$
\varrho_{t}^{j}=\frac{P_{t} P_{k^{\prime}, t} \bar{K}_{t+1}^{N^{j}}}{N_{t+1}^{j}}
$$


The ZPC of the banks can be simplified to:

$$
\left[\Gamma\left(\bar{\omega}_{t+1}^{j} ; \sigma^{j}\right)-\mu_{j} G\left(\bar{\omega}_{t+1}^{j} ; \sigma^{j}\right)\right] \frac{R_{t+1}^{k, j}}{\operatorname{Cos} t_{t}^{j}}=\frac{\varrho_{t}^{j}-1}{\varrho_{t}^{j}}
$$

Finally, the expected utility of the entrepreneur is given by:

$$
E_{t}\left\{\frac{\int_{\bar{\omega}_{t+1}^{j}}^{\infty}\left[R_{t+1}^{k, j} \omega^{j} P_{t} P_{k^{\prime}, t} \bar{K}_{t+1}^{N^{j}}-Z_{t+1}^{j} L_{t+1}^{N^{j}}\right] d F\left(\omega^{j} ; \sigma^{j}\right)}{N_{t+1}^{j} \operatorname{Cos}_{t}^{j}}\right\}=E_{t}\left\{\left[1-\Gamma\left(\bar{\omega}_{t+1}^{j} ; \sigma^{j}\right)\right] \frac{R_{t+1}^{k, j}}{\operatorname{Cost}_{t}^{j}} \varrho_{t}^{j}\right\}
$$

The equilibrium contract between a bank and an entrepreneur is a contract with $\bar{\omega}_{t+1}^{j}$ and $\varrho_{t}^{j}$ chosen such that the utility of the entrepreneur is maximized (relative to $N_{t+1}^{j} \operatorname{Cos} t_{t}^{j}$ ) subject to the ZPC of the bank.

The F.O.Cs of the optimization problem are:

$$
E_{t}\left\{\left[\begin{array}{c}
{\left[1-\Gamma\left(\bar{\omega}_{t+1}^{j} ; \sigma^{j}\right)\right] \frac{R_{t+1}^{k, j}}{\operatorname{Cost} t_{t}^{j}}+\frac{1-F\left(\bar{\omega}_{t+1}^{j} ; \sigma^{j}\right)}{1-F\left(\bar{\omega}_{t+1}^{j} ; \sigma^{j}\right)-\mu_{j} \bar{\omega}_{t+1}^{j} F^{\prime}\left(\bar{\omega}_{t+1}^{j} ; \sigma^{j}\right)}} \\
\left\{\left[\Gamma\left(\bar{\omega}_{t+1}^{j} ; \sigma^{j}\right)-\mu_{j} G\left(\bar{\omega}_{t+1}^{j} ; \sigma^{j}\right)\right] \frac{R_{t+1}^{k, j}}{\operatorname{Cost}_{t}^{j}}-1\right\}
\end{array}\right]\right\}=0
$$

that can be reorganized to obtain:

$$
E_{t}\left\{\frac{1-F\left(\bar{\omega}_{t+1}^{j} ; \sigma^{j}\right)}{1-\Gamma\left(\bar{\omega}_{t+1}^{j} ; \sigma^{j}\right.}-\frac{\frac{R_{t+1}^{k, j}}{\operatorname{Cos} t_{t}^{j}}\left[1-F\left(\bar{\omega}_{t+1}^{j} ; \sigma^{j}\right)-\mu_{j} \bar{\omega}_{t+1}^{j} F^{\prime}\left(\bar{\omega}_{t+1}^{j} ; \sigma^{j}\right)\right]}{1-\frac{R_{t+1}^{k, j}}{\operatorname{Cost}_{t}^{j}}\left[\Gamma\left(\bar{\omega}_{t+1}^{j} ; \sigma^{j}\right)-\mu_{j} G\left(\bar{\omega}_{t+1}^{j} ; \sigma^{j}\right)\right]}\right\}
$$

From the F.O.Cs, $\frac{1-F\left(\bar{\omega}_{t+1}^{j} ; \sigma^{j}\right)}{1-\Gamma\left(\bar{\omega}_{t+1}^{j} ; \sigma^{j}\right.}$ is the expected return elasticity with respect to $\bar{\omega}_{t+1}^{j}$, and $\frac{\frac{R_{t+1}^{k, j}}{\operatorname{Cost}_{t}^{j}}\left[1-F\left(\bar{\omega}_{t+1}^{j} ; \sigma^{j}\right)-\mu_{j} \bar{\omega}_{t+1}^{j} F \prime\left(\bar{\omega}_{t+1}^{j} ; \sigma^{j}\right)\right]}{\left.\left.1-\frac{R_{t+1}^{k, j}}{\operatorname{Cost}_{t}^{j}} \Gamma \Gamma \bar{\omega}_{t+1}^{j} ; \sigma^{j}\right)-\mu_{j} G\left(\bar{\omega}_{t+1}^{j} ; \sigma^{j}\right)\right]}$ is the elasticity of the leverage ratio with respect to $\bar{\omega}_{t+1}^{j}$.

The leverage value can be recovered using the ZPC of the banks when the value of $\bar{\omega}_{t+1}^{j}$ is obtained. Along with the cutoff value, the interest rates associated with loans in DC/FC, respectively are recovered as:

$$
\begin{aligned}
& Z_{t+1}^{D C}=R_{t+1}^{k, D C} \bar{\omega}_{t+1}^{D C} \frac{\varrho_{t}^{D C}}{\varrho_{t}^{D C}-1} \\
& Z_{t+1}^{F C}=\frac{R_{t+1}^{k, F C}}{\frac{S_{t+1}}{S_{t}}} \bar{\omega}_{t+1}^{F C} \frac{\varrho_{t}^{F C}}{\varrho_{t}^{F C}-1}
\end{aligned}
$$

Thus, the interest rate spreads are defined as:

$$
\begin{gathered}
\operatorname{spread}_{t}^{D C}=Z_{t+1}^{D C}-R_{t} \\
\operatorname{spread}_{t}^{F C}=Z_{t+1}^{F C}-R_{t}^{*} \text { Prem }_{t}
\end{gathered}
$$


Net worth aggregates

The net worth of an entrepreneur who in period $t-1$ had net worth $N^{j}$, with $j \in\{D C, F C\}$, after settling the loans with banks in period $t$ is given by:

$$
V_{t}^{N^{j}}=\left[1-\Gamma\left(\bar{\omega}_{t}^{j} ; \sigma^{j}\right)\right] R_{t+1}^{k, j} P_{t} P_{k^{\prime}, t} \bar{K}_{t+1}^{N^{j}}
$$

Each entrepreneur is faced with an identical and independent probability $1-\gamma_{t}^{j}$ of receiving a signal to exit the economy. The net worth of entrepreneurs that survive is $\gamma_{t}^{j} V_{t}^{N^{j}}$, with $\gamma_{t}^{j}$ being interpreted as a shock to net worth.

The law of motion for the average net worth for each type of entrepreneurs, $j$, with $j \in\{D C, F C\}$ is given by ${ }^{10}$ :

$$
\bar{N}_{t+1}^{j}=\gamma_{t}^{j}\left\{\begin{array}{c}
R_{t}^{k, j} P_{t-1} P_{k^{\prime}, t-1} \bar{K}_{t}^{j}-R_{t-1}^{j}\left(P_{t-1} P_{k^{\prime}, t-1} \bar{K}_{t}^{j}-\bar{N}_{t}^{j}\right) \\
-\mu_{j} \int_{0}^{\bar{\omega}_{t}^{j}} \omega^{j} d F\left(\omega^{j} ; \sigma^{j}\right) R_{t}^{k, j} P_{t-1} P_{k^{\prime}, t-1} \bar{K}_{t}^{j}
\end{array}\right\}+W_{t}^{e, j}
$$

Thus, the average net worth for each type of entrepreneurs is represented by the earnings net of interest rate payments on previous period bank loans and monitoring costs, adjusted with the probability of remaining in the economy, $\gamma_{t}^{j}$, plus the transfers received from households, $W_{t}^{e, j}$. The latter are provided to both remaining entrepreneurs and new entrants. This is necessary, given that exit from the economy is exogenous, since both the bankrupt entrepreneurs and the ones entering the economy have zero net worth.

\section{Central bank and government}

The government is modeled with the use of an $A R(1)$ process:

$$
\log \left(g_{t}\right)=\left(1-\rho_{g}\right)(g)+\rho_{g} \log \left(g_{t-1}\right)+\varepsilon_{g, t}
$$

There are three types of taxes in the model - consumption tax $\left(\tau_{c}\right)$, labour tax $\left(\tau_{w}\right)$,) and income tax $\left(\tau_{y}\right)$, ,). The budget of the government is assumed to be balanced and any difference between revenues and expenditures is offset by lump-sum transfers to/from households.

The central bank does not play an active role in the model given the fixed exchange rate regime adopted by the NBRNM since $1995^{11}$. Implicitly, the domestic monetary policy rate is set as being the sum of the foreign relevant interest rate and of the sovereign risk premium, thus not reacting to domestic real sector variables like inflation or output gap.

\section{Foreign sector}

The foreign sector is represented by the following 3 equations, standard New- Keynesian semistructural model:

IS curve:

$$
y_{t}^{*, \text { gap }}=i s_{b l} y_{t-1}^{*, g a p}+\left(1-i s_{b l}\right) E_{t} y_{t+1}^{*, g a p}-i s_{r}\left[\left(R_{t}^{*}-E_{t} \pi_{t+1}^{*}\right)-\left(R^{*}-\pi^{*}\right)\right]+\varepsilon_{y^{*}, t}
$$

Phillips curve:

\footnotetext{
${ }^{10} \mathrm{~A}$ bar over a letter indicates the aggregate average value.

${ }^{11}$ Up to end-2001 with respect to the Deutsche Mark, starting 2002 with respect to the Euro.
} 


$$
\pi_{t}^{*}-\pi^{*}=p c_{b l}\left(\pi_{t-1}^{*}-\pi^{*}\right)+\left(1-p c_{b l}\right)\left(E_{t} \pi_{t+1}^{*}-\pi^{*}\right)-p c_{m c} y_{t}^{*, g a p}+\varepsilon_{\pi^{*}, t}
$$

Taylor rule:

$$
R_{t}^{*}-R^{*}=t r_{b l}\left(R_{t-1}^{*}-R^{*}\right)+\left(1-t r_{b l}\right)\left[t r_{y} y_{t}^{*, g a p}+t r_{\pi}\left(\pi_{t}^{*}-\pi^{*}\right)\right]+\varepsilon_{R^{*}, t}
$$

\subsubsection{Resource constraints, market clearing and equilibrium equations}

The aggregate resource constraint that must hold in a symmetric equilibrium (i.e. without price dispersion in the steady state) is:

$$
\begin{gathered}
Y_{t}-\omega_{k}\left[\mu_{D C} G\left(\bar{\omega}_{t}^{D C} ; \sigma^{D C}\right) R_{t}^{k, D C} P_{t-1} P_{k^{\prime}, t-1} \bar{K}_{t}^{D C}\right] \\
-\left(1-\omega_{k}\right)\left[\mu_{F C} G\left(\bar{\omega}_{t}^{F C} ; \sigma^{F C}\right) R_{t}^{k, F C} P_{t-1} P_{k^{\prime}, t-1} \bar{K}_{t}^{F C}\right] \\
=G_{t}+C_{t}^{d}+I_{t}^{d}+X_{t}^{d}
\end{gathered}
$$

The value of domestically produced goods is $Y_{t}$. As this value also includes the monitoring costs of the banks and the capital utilization costs, it is not equivalent to the series of GDP at market prices published by the State Statistical Office (SSO). In order to obtain a SSO-consistent nominal GDP, the following definition, in terms of market prices, based on the expenditure approach is used:

$$
\begin{aligned}
P_{t}^{G D P} G D P_{t}= & \left(1+\tau^{c}\right) P_{t}^{C} C_{t}+P_{t} G_{t}+P_{t}^{i} I_{t}+S_{t} P_{t}^{X} X_{t} \\
& -\left[S_{t} P_{t}^{*}\left(C_{t}^{m}+I_{t}^{m}+X_{t}^{m}\right)\right]
\end{aligned}
$$

An identical value of the nominal GDP can also be obtained from the model via the income approach with the summation of value added and profits in the economy:

$$
\begin{gathered}
P_{t}^{G D P} G D P_{t}=W_{t} H_{t}+\omega_{k}\left(r_{t}^{D C, k} P_{t}\right) K_{t}^{D C}+\left(1-\omega_{k}\right)\left(r_{t}^{F C, k} P_{t}\right) K_{t}^{F C}+\tau^{c} P_{t}^{c} C_{t} \\
\quad+\text { profits }- \text { monitoring }- \text { maintenance } e_{t} \\
=W_{t} H_{t}+\omega_{k}\left(r_{t}^{D C, k} P_{t}\right) K_{t}^{D C}+\left(1-\omega_{k}\right)\left(r_{t}^{F C, k} P_{t}\right) K_{t}^{F C}+\tau^{c} P_{t}^{c} C_{t} \\
+\left(P_{t} Y_{t}-\frac{m c_{t} P_{t}}{\tau_{t}^{d}}\left(Y_{t}+z_{t} \phi\right)\right)+\left(S_{t} P_{t}^{X}-\frac{N M C_{t}^{x}}{\tau_{t}^{x}}\right) X_{t} \\
+\left(P_{t}^{m, c}-\frac{N M C_{t}^{m, c}}{\tau_{t}^{m, c}}\right) C_{t}^{m}+\left(P_{t}^{m, i}-\frac{N M C_{t}^{m, i}}{\tau_{t}^{m, i}}\right) I_{t}^{m}+\left(P_{t}^{m, x}-\frac{N M C_{t}^{m, x}}{\tau_{t}^{m, x}}\right) X_{t}^{m} \\
-\omega_{k}\left[\mu_{D C} G\left(\bar{\omega}_{t}^{D C} ; \sigma^{D C}\right) R_{t}^{k, D C} P_{t-1} P_{k^{\prime}, t-1} \bar{K}_{t}^{D C}\right] \\
-\left(1-\omega_{k}\right)\left[\mu_{F C} G\left(\bar{\omega}_{t}^{F C} ; \sigma^{F C}\right) R_{t}^{k, F C} P_{t-1} P_{k^{\prime}, t-1} \bar{K}_{t}^{F C}\right] \\
-P_{t}^{i}\left(a^{D C}\left(u_{t}^{D C}\right) \omega_{k} \bar{K}_{t}^{D C}+a^{F C}\left(u_{t}^{F C}\right)\left(1-\omega_{k}\right) \bar{K}_{t}^{F C}\right)
\end{gathered}
$$

As real GDP and the GDP deflator are not defined within the model, an additional equation is needed to pin down the evolution of the GDP deflator. Following Minella et al. (2011) as in Copaciu et al. (2015), the GDP deflator is defined by weighting the components' prices, using constant (i.e. steadystate) nominal weights:

$$
\left.\left(P_{t}^{G D P}\right)^{1-\frac{P G}{P^{G D P} G D P}}=\left(\left(1+\tau^{c}\right) P_{t}^{c}\right)^{\frac{\left(1+\tau^{c}\right) P^{c} C}{P^{G D P} G D P}}\left(P_{t}^{i}\right)^{\frac{P^{I} I}{P^{G D P} G D P}}\left(S_{t} P_{t}^{X}\right)^{\frac{S P^{x} X}{P^{G D P} G D P}}\left(S_{t} P_{t}^{*}\right)^{-\left(\frac{\left(P^{*} S\right)\left(C^{m}+I^{m}+X^{m}\right)}{P^{G D P} G D P}\right.}\right)
$$

The corresponding inflation rate is defined as:

$$
\pi_{t}^{G D P}=\frac{P_{t}^{G D P}}{P_{t-1}^{G D P}}
$$


The share of the trade balance in nominal GDP is obtained by taking the difference between nominal values of exports and imports ${ }^{12}$, expressed in domestic currency, dividing it by nominal GDP:

$$
(N X / G D P)_{t}=\frac{S_{t} P_{t}^{x} X-\left[S_{t} P_{t}^{*}\left(C_{t}^{m}+I_{t}^{m}+X_{t}^{m}\right)\right]}{P_{t}^{G D P} G D P_{t}}
$$

Next, the NFA position as a function of current net exports and previous, risk-adjusted interest rate payments on previous period stock is shown below:

$$
N F A_{t}=N X_{t}+\left[R_{t-1}^{*} \operatorname{Prem}_{t-1} \frac{S_{t}}{S_{t-1}}\right] N F A_{t-1}
$$

where the stock of net foreign assets is defined as:

$$
N F A_{t}=-\left(1-\omega_{k}\right) S_{t} \text { deposits }_{t+1}^{*, F C}
$$

and deposits $t_{t+1}^{*, F C}$ are FC deposits attracted from abroad. In terms of annual GDP, the stock of net foreign assets is defined as:

$$
(N F A / G D P)_{t}=\frac{N F A_{t}}{4 * P_{t}^{G D P} G D P_{t}}
$$

Finally, following Schmitt-Grohe and Uribe (2003) as in Copaciu et al. (2015), closing up the model requires that the risk premium varies negatively with the deviation of the (stationarized) NFA of the economy from their steady state:

$$
\operatorname{Prem}_{t}\left(n f a_{t}, \tilde{\phi}_{t}\right)=\exp \left[-\phi_{n f a}\left(n f a_{t}-n f a\right)+\tilde{\phi}_{t}\right]
$$

with $\operatorname{Prem}_{t}^{\prime}<0, \operatorname{Prem}_{t}(0,0)=1, \phi_{n f a}>0$ and $\tilde{\phi}_{t}$ is an $\mathrm{AR}(1)$ shock to the sovereign risk premium.

\section{Data and measurement equations}

\section{Data}

Data used for estimating the model is at a quarterly frequency with a sample period ranging from 2006Q2 to 2020Q2, as available in September 2020. While this might seem as a short sample, it is a rather common aspect when one analyzes emerging economies. The sample length is chosen to reflect the availability and methodological differences of/for certain data series (such as interest rates on new credit, wages etc.). As for the end of the sample, we choose to include also the immediate impact on the domestic economy of the Covid-19 crisis.

To estimate the model, 18 observable variables are used: GDP components' volumes and deflators, $\mathrm{CPI}$, total hours worked, private sector wages, interest rate, interest rate spreads for new credit in domestic (DC) and foreign (FC) currency, foreign demand, foreign inflation and the foreign interest rate. Whenever necessary, seasonal adjustment is performed using the U.S. Census Bureau's X12 procedure. The series used, the adjustments made in terms of seasonal adjustment and measurement units and the primary data sources are displayed in Table 1.

The primary data sources are the State Statistical Office (SSO), Eurostat and NBRNM. The annualized (log) quarterly inflation rates that account for the change in the prices of investment, import and export goods, as well as the GDP deflator, are obtained from their corresponding data counterparts with the exception of the price of consumption goods for which the CPI inflation series is used. To deal outside the model with an eventual population growth trend, real quantities are first

\footnotetext{
12 The border value of imports is used.
} 
transformed in per capita terms (i.e. divided by the working age population) and then the logged first difference is taken.

The nominal wage of the private sector is not available from the State Statistical Office and therefore it is approximated by using wages weighted by the number of employees in the private sector for each sector of the economy, following the NKD Rev.2 classification, by taking into account the methodological changes in the sample from NKD to NKD Rev.2 in 2011. In addition, a correction for the number of employees in the agricultural sector is made to account for the number of self-employed and unpaid workers. The average number of hours worked is normalized so that the share of hours worked and leisure hours is equal to 1 .

Table 1 Data description

\begin{tabular}{lcc}
\hline \multicolumn{1}{c}{ Series } & Adjustment & Source \\
\hline GDP components & SA, $\Delta$ log & SSO (National accounts) \\
GDP deflators & SA, annualized, $\Delta$ log & SSO (National accounts) \\
Consumer price index (CPI) & SA, annualized, $\Delta$ log & SSO (COICOP) \\
Nominal wage (private sector) & SA, $\Delta$ log & SSO, own calculations \\
Total hours worked & SA, $\Delta$ log & Eurostat, own calculations \\
Relevant policy rate & NSA, annualized, $\%$ & NBRNM \\
New credit spreads (FC, DC) & NSA, $\Delta$ log & NBRNM \\
$1 m$ Euribor & NSA, annualized, $\%$ & Eurostat \\
Foreign effective demand & gap, $\%$ & NBRNM (MAKPAM) \\
Foreign effective inflation & SA, annualized, $\Delta$ log & NBRNM (MAKPAM) \\
\hline
\end{tabular}

\section{Measurement equations}

The observed variables display significant heterogeneity in the mean growth rates, rendering the balanced growth path framework questionable. We partially overcome this issue by demeaning the raw data and imposing the model-related steady state. Moreover, we also allow for white noise measurement errors, given excessive volatility of some series, a high propensity to data revision and possible stochastic singularity problems.

The general formula used to link the observed variables with their data counterparts is:

$$
\text { Demeaned data }- \text { Measurement error }+ \text { Model steady state }=\text { Model variable }
$$

All measurement equations are shown below. The measurement equations for prices are:

$$
\pi_{t}^{i, d a t a}-\varepsilon_{t}^{\pi^{i}, M E}+400 \log \bar{\pi}=400 \log \pi_{t}^{i}
$$

for $i \in\{G D P, C, I, M, X\}$. There is one exception, namely for exported goods the measurement equation is slightly different given the local currency pricing concept used in the model (the export prices in the model are expressed in foreign currency, while the deflator is measured in the data in domestic currency):

$$
\pi_{t}^{X, \text { data }}-\varepsilon_{t}^{\pi^{X}, M E}+400 \log \bar{\pi}=400 \log \pi_{t}^{X}+400 \log s_{t}
$$

The measurement equations for GDP and components are:

$$
\Delta \log i_{t}^{\text {data }}-\varepsilon_{t}^{i, M E}+100 \log \mu_{z}=100\left(\log \mu_{z, t}+\Delta \log i_{t}\right)
$$

for $i \in\{G D P, C, I, M, X\}$. Every endogenous variable (stationarized with $z_{t}$ and log-differenced, as seen on the RHS) is modeled as the corresponding demeaned observed variable net of measurement errors $\left(\Delta \log i_{t}^{\text {data }}-\varepsilon_{t}^{i, M E}\right)$ augmented with the balanced growth path steady state value $\left(100 \log \mu_{z}\right)$.

Measurement equations for labor and financial market variables are given by: 


$$
\begin{gathered}
\Delta \log W_{t}^{\text {data }}-\varepsilon_{t}^{W, M E}=100\left(\log \left(\mu_{z, t} / \mu_{z}\right)+\log \left(\pi_{t} / \bar{\pi}\right)+\Delta \log w_{t}\right) \\
\Delta H_{t}^{\text {data }}-\varepsilon_{t}^{H, M E}=100 \Delta \log H_{t} \\
\Delta H_{t}^{\text {data }}=100 \Delta \log H_{t}+\varepsilon_{t}^{H, M E} \\
\Delta \log \text { Spread }_{t}^{D C, \text { data }}-\varepsilon_{t}^{\text {spread }^{D C}, M E}=100 \Delta \operatorname{logSpread}{ }_{t}^{D C} \\
\Delta \operatorname{logSpread} t_{t}^{F C, \text { data }}-\varepsilon_{t}^{\text {spread }^{F C}, M E}=100 \Delta \operatorname{logSpread}{ }_{t}^{F C}
\end{gathered}
$$

The measurement equation for the main policy rate, with no measurement error allowed for:

$$
R_{t}^{\text {data }}=400\left(R_{t}-R\right)
$$

As a measure of external demand we use a gap measure of the foreign effective demand as used in the MAKPAM model. The measurement equation links it to the model's equivalent:

$$
Y_{t}^{*, \text { data,gap }}-\varepsilon_{t}^{y^{*}, M E}=100\left(y_{t}^{*}-y^{*}\right)
$$

For the demeaned effective foreign inflation rate (as used in the MAKPAM model) and 1M Euribor interest rate we assign the model-implied steady states (which are equal to those of the corresponding domestic variables):

$$
\begin{gathered}
\pi_{t}^{* \text { data }}-\varepsilon_{t}^{\pi^{*}, M E}+400 \log \bar{\pi}=400 \pi_{t}^{*} \\
R_{t}^{*, \text { data }}-\varepsilon_{t}^{R^{*}, M E}=400\left(R_{t}^{*}-R\right)
\end{gathered}
$$

\section{Estimation}

\section{Calibration}

Part of the parameters of the model is calibrated and thus is held fixed throughout the estimation of the model. Moreover, a subset of six parameters is recalibrated throughout estimation to exactly match six observed ratios.

\section{Calibrated parameters}

To begin with, the parameter that determines the steady state growth rate of the aggregate technology $\left(\mu_{z+}\right)$ is set to equal the average growth rate of per capita GDP the real domestic economy for the period 2006Q2-2019Q4 that is around $0.5 \%$ (approx. $2 \%$ in annual terms). The steady state inflation rate is set to match the average growth rate of the CPI COICOP index for the entire sample which is around $2 \%$ in annual terms. The external inflation rate steady state value is set at a similar value, matching also the primary objective of the ECB that aims to keep inflation below, but close to $2 \%$ over the medium term.

Furthermore, following the approach in Christiano et al. (2011) and Copaciu et al. (2015), given the aggregate growth rate of economy and the inflation rate steady state values, the discount factor, $\beta$, is calibrated to 0.999 in order to match the sample average of the nominal interest rate of around $1.1 \%$ per quarter (around $4.4 \%$ in annualized terms).

The parameter $\alpha$ that determines the share of capital services in the production function of the intermediate goods producers is determined using the shares of factor income derived from the National Accounts definition of GDP with data on a yearly frequency. Using data for the period 2005- 
$2017^{13}$, the value for $\alpha$ is determined to be around 0.66. As Copaciu et al. (2015) and Iradian (2007) argues and provides evidence, although the share of capital services might seem relatively high (and the implicit share of labor services, that is $(1-\alpha)$, relatively low), this is a rather common feature for (models for) developing economies where the marginal product of capital is higher. Moreover, the above mentioned value is very close to the 0.6 average value used by Jovanovic and Kabashi (2011) in their study on the output gap for the Macedonian economy. Also, Iradian (2007) investigating an earlier period (i.e. 1996-2006) estimates a share of capital above 0.7 for a group of south eastern European economies (Albanian, Bosnian-Herzegovinian, Bulgarian, Croatian, Macedonian, and Romanian). Last but not least, in the presence of a (relatively high) external finance premium, a comparatively higher value for $a$ is needed to generate at the prior steady state a capital to annual GDP ratio, in nominal terms, close to the empirical counterpart. In our case, this ratio is 1.6, whereas Petkovska (2008), analyzing the 1997-2006 finds values over the 1.35-1.6 range.

To calibrate the share of import content in final goods (consumption, investment, and export), data from input-output tables from the State Statistical Office with an average for 2005, 2010 and 2015 is used, considering both the direct and indirect impact of imports in the production of final demand goods, but excluding the share of imported oil/energy products ${ }^{14}$. Thus, following the approach of Bussiere et al. (2011), the calibrated values for the import shares in the production of final consumption, investment and export goods are: $38.4 \%$ for $\omega_{c}, 56.2 \%$ for $\omega_{i}$ and $50.9 \%$ for $\omega_{x}$. These relatively high shares emphasize once again the relatively high openness degree of the domestic economy.

In terms of the parameters related to taxes in the model, the average tax rate on consumption is obtained as a ratio of VAT and excises to private and government non-wage consumption net of these taxes (16.2\%); the average tax rate on income is set to equal the flat personal income tax (PIT) of $10 \%$ that is set from 2007 on-wards and the average labor tax rate $(26.9 \%)$ is retrieved with a formula $\left(\frac{1-W T}{1-P I T}-1\right)$ that uses the average net wage as a proportion of the average gross wage to obtain the wage tax.

The markups parameters are calibrated to either match the average value obtained by the NBRNM ${ }^{15}$ using two distinct approaches to calculate the economy- wide markup or the standard values used in the literature (see Christiano et al., 2011). Thus, the price markups $\lambda_{j}$ are set to 1.5 for the domestic intermediate and imported goods (i.e. $j \in\{d, m x, m c, m i\}$ ), with the exception of $\lambda_{x}$, the export markup, which is set to 1.05 , in order to avoid the impact of multiple markups and the wage markup, set to 1.6 .

In terms of the financial frictions parameters, as separate data on bankruptcy rates with a currency decomposition of the loans obtained by domestic entrepreneurs / firms is not available, we obtain these rates, $F\left(\bar{\omega}_{D C}\right)$ and $F\left(\bar{\omega}_{F C}\right)$, by matching the prior steady-state means of different spreads of the interest rates on loans in foreign currency and loans in domestic currency observed in the data. The transfers given to entrepreneurs that borrow in foreign currency $\left(w_{e}^{F C}\right)$ and those that borrow in domestic currency $\left(w_{e}^{D C}\right)$ are assumed equal and set to $0.05 \%$ of the nominal gross value added, following Copaciu et al. (2015).

The share of government consumption in GDP in real terms, $\eta_{g, r e a l}$, is set to match the historical share in the data which is around $15.2 \%$. As we chose not to observe government expenditures, the persistence coefficient, $\rho_{g}$, in the $\mathrm{AR}(1)$ equation describing their evolution is set to 0.75 , and the corresponding standard deviation of the shock, $\sigma_{g}$, to 1 . Last but not least, the elasticity of the risk premium with respect to NFA is set to 0.001 , a value similar with those usually assumed in the literature.

The calibrated parameters are shown in table 2 below.

\footnotetext{
${ }^{13}$ The latest final data on GDP calculated by the income approach is 2017.

${ }^{14}$ More precisely, the share of imported Mining and quarrying and Coke and refined petroleum products is excluded.

${ }^{15}$ As detailed in the Quarterly Report for the Macedonian economy: Q2 2020, Box 4.
} 
Table 2 Calibrated parameters

\begin{tabular}{clc}
\hline Parameter & Description & Value \\
\hline$\alpha$ & Share of capital in production & 0.66 \\
$\beta$ & Discount factor & 0.99 \\
$\mu_{z}$ & SS aggregate technology & 1.005 \\
$\bar{\pi}$ & SS domestic inflation & 1.005 \\
$\pi^{*}$ & SS foreign inflation & 1.005 \\
$\omega_{c}$ & Import share in consumption goods & 0.384 \\
$\omega_{i}$ & Import share in investment goods & 0.562 \\
$\omega_{x}$ & Import share in export goods & 0.509 \\
$\tau_{c}$ & Consumption tax rate & 0.162 \\
$\tau_{y}$ & Income tax rate & 0.10 \\
$\tau_{w}$ & Labour tax rate & 0.269 \\
$\eta_{g, r e a l}$ & Share of real government expenditures in GDP & 0.152 \\
$\sigma_{g}$ & St. deviation real gov. expenditures shock & 0.3 \\
$W_{e}^{F C / D C}$ & Transfers to $j \in(D C, F C)$ entrepreneurs & 0.05 \\
$F\left(\bar{\omega}_{D C}\right)$ & SS DC entrepreneurs bankruptcy rate & 0.0113 \\
$F\left(\bar{\omega}_{F C}\right)$ & SS FC entrepreneurs bankruptcy rate & 0.022 \\
$\phi_{n f a}$ & Elasticity of country risk to NFA & 0.001 \\
$\lambda_{d}$ & Domestic intermediate goods markup & 1.5 \\
$\lambda_{m x}$ & Imports for export goods markup & 1.5 \\
$\lambda_{m c}$ & Imports for consumption goods markup & 1.5 \\
$\lambda_{m i}$ & Imports for investment goods markup & 1.5 \\
$\lambda_{x}$ & Export goods markup & 1.05 \\
$\lambda_{w}$ & Wage markup & 1.6 \\
$\rho_{g}$ & Persistence government expenditure & 0.75 \\
$\rho_{\tau_{i}}$ & Persistence mark-up shocks $(x, m c, m i, m x, d)$ & 0
\end{tabular}

Source: Authors' calculations.

\section{Matching of posterior steady state ratios with observed average ratios}

Following the approach outlined in Christiano et al. (2011) and in Copaciu et al. (2015), the average sample values for 6 observed ratios are matched exactly in the process of estimation with an equal number of parameters being recalibrated after each parameter draw. The values for the matched ratios and the posterior values for the corresponding parameters are illustrated in table 3 . Thus:

- the parameter scaling the disutility of labor, $A_{L}$, is used to match the average fraction of time spent working by an individual;

- the depreciation rate of capital, $\delta$, is set to match the average nominal investment to GDP ratio;

- the steady state level of the real effective exchange rate, $\tilde{\varphi}$, set to match the mean nominal exports to GDP ratio;

- the entrepreneurial survival rates, $\gamma^{D C}$, and $\gamma^{F C}$, are set to match the average equity to assets ratios for entrepreneurs ${ }^{16}$;

- the parameter controlling the share of entrepreneurs borrowing in domestic currency, $\omega_{k}$, to match the average ratio of foreign to domestic currency denominated new loans.

Table 3 Matched posterior steady states with observed average ratios

\begin{tabular}{lccc}
\hline \multicolumn{1}{c}{ Observed ratio } & Data mean & Parameter description & Posterior SS \\
\hline Hours worked & 0.228 & Disutility of labour $\left(A_{L}\right)$ & 1366.366 \\
Investment/GDP & 0.226 & Depreciation rate $(\delta)$ & 0.042 \\
Exports/GDP & 0.473 & RER steady state $(\varphi)$ & 0.291 \\
Net worth/capital, FC & 0.5 & Survival rate $\left(\gamma^{F C}\right)$ & 0.935 \\
Net worth/capital, DC & 0.5 & Survival rate $\left(\gamma^{D C}\right)$ & 0.972 \\
FC loans/DC loans & 0.74 & DC entrepreneurs share $(\omega)$ & 0.389 \\
\hline
\end{tabular}

\footnotetext{
${ }^{16}$ The Financial Stability Report available database does not differentiate according to the data type of currency. Thus, similar values are assumed for the equity to assets ratio for both companies with most of the loans in domestic or foreign currency.
} 


\section{Prior distributions}

The priors for the estimated parameters were set following either the general values used in the literature or the previous empirical evidence available for the Macedonian economy. In general, they are pretty tight, reflecting the relatively short period of time our sample covers. Tables 4 and 5 present the prior distributions for both the structural parameters as well as for the structural shocks' autoregressive coefficients and standard deviations.

To start with, the mean prior values for the stickiness parameters (i.e. $\xi$ ), representing the a la Calvo probability to keep the prices fixed, are obtained, using the formula for duration: $\frac{1}{(1-\xi)}$, from the value for duration estimated for the Macedonian economy in the survey presented in Ramadani and Naumovski (2015). Using this approach, the mean and the standard deviation of the prior beta distribution for the stickiness parameters are set to 0.5 (implying an average duration of two quarters) and 0.075 , respectively, with the exception of the wage stickiness (mean of 0.8 - implying a duration of about five quarters and standard deviation of 0.075$)$ and the domestic intermediate goods (0.6 and 0.025) parameters. In terms of the indexation parameters, we assume prices to be homogeneously indexed to a combination between lagged and steady-state inflation rates, while for real wages a partial indexation to the real growth trend is assumed. The prior beta distribution mean for the past inflation indexation coefficients is set to 0.5 , with an associated standard deviation of 0.1 , with the exception of the prior mean and standard deviation for the wage indexation that are set to 0.25 and 0.075 , respectively.

Furthermore, the prior mean for the inverse Frisch elasticity parameter is set to 3 , with a standard deviation of 1 . The resulting prior value for the Frisch labor supply elasticity, centered around 0.33 , is in the range of estimates usually obtained in the micro studies ${ }^{17}$. In terms of the parameter that determines the degree of habit formation, following Christiano et al. (2011), the prior mean and standard deviation are set to 0.65 and 0.15 .

The prior for the investment adjustment costs parameter (i.e. the second derivative of the investment cost adjustment function), following Smets and Wouters (2007) and Copaciu et al. (2015), is centered at 4 , with a 1.5 corresponding standard deviation. For the capital utilization parameters in FC and DC, we use relatively tight priors, with mean values relatively higher than those previously used in the literature. Thus, the parameters are centered at 0.75 , with a standard deviation of 0.025 .

The prior means and standard deviations of the elasticities of substitution are set to 1.5 and 0.075 , with the mean values being extensively used in the literature. The exception is represented by the elasticity of substitution of capital services, rqk, where the prior mean and standard deviation are set to 2.5 and 0.25 respectively.

The monitoring costs for the $\mathrm{DC}$ and $\mathrm{FC}$ entrepreneurs have a prior mean of 0.3 , with standard deviations of 0.05 each, close to the value used in Christiano et al. (2011) (i.e. 0.33) or Copaciu et al. (2015).

Last but not least, the priors for the auto-regressive coefficients (where the case) and the standard deviations of the structural shocks are presented in table 5 . To deal with very volatile data, while the mark-up shocks are specified as white noise, for the remaining shocks we set prior means for the persistence parameters either at relatively low values (i.e. 0.3 for the temporary technology, marginal efficiency of investment, consumption preference and labor disutility shocks) or to relatively high ones (i.e. 0.75 for the risk premium, net worth shocks and 0.85 for the growth rate of the permanent technology shock).

\footnotetext{
${ }^{17}$ Pencavel (1987) surveys estimates for the U.S. ranging between 0 and 0.45 .
} 


\section{Shocks and measurement errors}

We allow for 13 structural shocks in the estimation of the domestic sector core model. Eight of them are modeled as $A R(1)$ processes, while the 5 markup shocks are estimated as white noise:

- Permanent neutral technology $\mu_{z, t}$

- Stationary neutral technology $\epsilon_{t}$

- Marginal efficiency of investment $Y_{t}$

- Consumption preference $\zeta_{t}^{c}$

- Labor disutility $\zeta_{t}^{h}$

- Sovereign risk premium $\tilde{\phi}_{t}$

- DC entrepreneurial net worth $\gamma_{t}^{D C}$

- $\mathrm{FC}$ entrepreneurial net worth $\gamma_{t}^{F C}$
- Markup, domestic intermediate producers $\tau_{t}^{d}$

- Markup, exports $\tau_{t}^{x}$

- Markup, imports for consumption $\tau_{t}^{m c}$

- Markup, imports for investment $\tau_{t}^{m i}$

- Markup, imports for exports $\tau_{t}^{m x}$

In addition, the external sector model accounts for 3 structural shocks, assumed as i.i.d. processes:

- $\quad$ Foreign aggregate demand $\epsilon_{y^{*}, t}$

- Foreign Philips curve inflation $\epsilon_{\pi^{*}, t}$

- $\quad$ Euro area monetary policy $\epsilon_{R^{*}, t}$

It should be noted that some of the potential shocks in the theoretical model are shut down in the model estimation. In this regard, the idiosyncratic entrepreneur risk shocks $\left(\sigma_{t}^{D C}\right.$ and $\left.\sigma_{t}^{F C}\right)$ and the government spending shock $\left(\epsilon_{g, t}\right)$ are excluded from the estimation since we do not observe the corresponding variables in the dataset (net worth of entrepreneurs and government consumption). In line with Copaciu et al. (2015), consumption, labor and income tax rates are assumed to be constant over time and hence the corresponding tax shocks are excluded as well. All shocks are scaled by 10 $\left(\mu_{z, t}, \epsilon_{t}, \zeta_{t}^{c}, \zeta_{t}^{h}, \Upsilon_{t}, \tau_{t}^{d}, \tau_{t}^{x}, \tau_{t}^{m c}, \tau_{t}^{m i}, \tau_{t}^{m x}, \gamma_{t}^{D C}\right.$ and $\left.\gamma_{t}^{F C}\right)$, except for $\tilde{\phi}_{t}$ which is scaled by 100. This is done in order to ensure that the estimated standard deviations are comparable.

Corresponding to each of the 18 observed data series, there is a measurement equation that links the actual data with the endogenous domestic and foreign model variables, as shown in section 4.2. With the exception of the domestic monetary policy interest rate equation, we include white noise measurement errors. This is rather common practice when Bayesian estimation of the DSGE models is performed (see for example Adolfson et al. (2007); Christiano et al. (2011); Copaciu et al. (2015)). Besides this rather common procedure, there are additional arguments for adding measurement errors when estimating the model. The main reason is related to the significant noise in the measurement of macroeconomic series, especially for emerging economies. In the Macedonian economy this is especially the case, for example, with the data for GDP components' volumes and the corresponding prices, which are subject to sizable revisions before the publication of the final data, the latter itself subject to measurement errors. In addition, some of the macroeconomic series also exhibit extremely high volatility, which may not be entirely captured by the structural shocks present in the model. Another reason is of a technical nature and refers to the problem known as 'stochastic singularity' most DSGE models suffer from. Namely, this problem arises when there are more observable time series than theoretical shocks, which is also the case with our model, and adding measurement errors in each of the observation equations helps to overcome this issue and allows the model to have rather well-defined identification results. With regards to the calibration of the prior variance of the measurement errors, we specify it so that it corresponds to $10 \%$ of the sample variance of the observed data series, except for investment (volume and deflator), import deflator and interest rate spreads on new loans in domestic and foreign currency, for which we set the measurement error at $25 \%$ of their variance. In line with the literature, the prior for the standard deviation of the measurement errors follows an inverse gamma distribution with an infinite standard deviation.

\section{Estimation results}

The model is estimated using the endogenous priors modified Bayesian procedure as proposed by Christiano et al. (2011). Thus, besides the usual Bayesian procedure that combines the specified 
priors and the information from the data as summarized by the likelihood function, the standard deviation of the observed data is taken also into account when obtaining the posterior distribution of the estimated structural parameters.

\section{Posterior parameter values}

The posterior mode for the estimated parameters is obtained by using the Monte-Carlo based optimization routine, on the log posterior density. In the next step, the posterior distributions are approximated by running a single Metropolis chain simulation with 1000000 draws, from which we discard half ${ }^{18}$. In what follows, we focus our discussion on the results for the posterior mean, emphasizing from the beginning the relatively high uncertainty around it as measured by the re-ported 10th and 90th percentiles. This reflects the relatively ample parameter space covered by the estimation with a relatively short data sample. The posterior estimates, together with the respective priors for the domestic sector part of the model are provided in tables 4 and 5 . The external sector parameters and the standard deviations of the shocks are available in table 8 from the Appendix A.1.

The estimates of Calvo related parameters reflect, given their posterior mean values and the associated standard deviations, the existence of information in the data. Moreover, they are pretty heterogeneous across sectors, reflecting the heterogeneity in the variability of the associated observed inflation rates. Thus, the highest degree of stickiness is found for prices of domestic goods and prices of imported goods used for consumption, having a posterior mean of the Calvo probability of 0.57 and 0.54 , respectively. This is consistent with the CPI inflation rate having by far the lowest standard deviation among the observed prices, as illustrated in table 6 . The implied average durations for firms operating in these sectors are around 2.3 and 2.2 quarters. These values are in line with the average period of price duration found by Ramadani and Naumovski (2015) from a representative survey on the wage and price setting behavior of Macedonian firms. The remaining Calvo parameters are in the (0.26-0.39) range with the export prices being the most flexible, followed by the imports related ones. The relatively low implied durations for the external sector related parameters reflect the extremely much higher variability in the associated observed deflators. Moreover, the relatively lower stickiness of export prices might be also explained by the fact that a significant portion of Macedonian exporters (over $60 \%$ ) produce intermediate goods, prices of which adjust relatively quickly. In general, these results suggest that Macedonian firms operate in an environment characterized by pretty flexible prices.

When we compare our results with the DSGE related findings for other countries we conclude that prices are more flexible than in developed countries, but they are comparable with some other values reported usually for other emerging countries. For example, de Walque et al. (2017) report values of 0.85 for the euro area and 0.83 for the USA. On the other hand, Copaciu et al. (2015) estimates values of the Calvo parameters between 0.34 and 0.73 for Romania, Elekdag and Alp (2011) report values between 0.3-0.56 for Turkey and Ajevskis and Vitola (2011) report a value of 0.53 for Latvia. Grabek et al. (2011) find slightly higher values for Poland, between 0.53-0.8, as well as Kustrin (2019) for Slovenia, with values ranging between 0.52 and 0.9 .

The posterior mean of the Calvo parameter for domestic wages is significantly lower than the ones for domestic prices and imported consumption prices, implying that wages are re-optimized on average around 1.4 quarters. The posterior value departs significantly from the equivalent 5 quarters prior value that is borrowed from the microeconomic evidence for the Macedonian economy as in Ramadani and Naumovski (2015). Yet, evidence that wages are more flexible than consumer prices is provided also by Jakab and Vilagi (2008) for Hungary. The Calvo parameter is also lower than the reported one of 0.57 for Slovenia in Kustrin (2019) and of about 0.7 for Czech Republic in Hlousek (2016) and for Hungary in Jakab and Vilagi (2008).

Turning to the parameters related to the degree of indexation of prices to lagged inflation, we find that data is rather uninformative, given that almost all estimated parameters are close to the mean value of 0.5 assumed in their prior distribution. These values are broadly similar to the values reported for Romania by Copaciu et al. (2015) and for Slovenia by Kustrin (2019). Compared to price indexation,

\footnotetext{
18 The estimations are carried out in Matlab R2014 with Dynare version 4.4.3.
} 
we find wage indexation to be lower (i.e. 0.2), although this posterior estimate is also very close to its prior value, that is 0.25 . The latter result confirms the survey based evidence regarding the practice of Macedonian firms for adjusting wages to inflation at a low level as provided by Ramadani and Naumovski (2015). The parameter is similar to the estimate made by Jakab and Vilagi (2008) for Hungary (0.17-0.19) and the one of de Walque et al. (2017) for the euro area (0.24), but lower than the ones estimated for: Romania (0.41) by Copaciu et al. (2015), Slovenia (0.6) by Kustrin (2019) or Slovakia (0.69) as reported in Papai (2017). The estimates of most of the elasticities of substitution are also close to their prior values, implying that data is not very informative about the posterior values of these parameters.

The estimated parameter for the (internal) consumption habit persistence parameter, $b$, has a posterior mean value of 0.68 , close to the prior one and reflecting the relatively low volatility of private consumption among GDP components. The value is relatively similar with the ones estimated by Jakab and Vilagi (2008) for Hungary (0.65), Papai (2017) for Slovakia (0.73) and Argov et al. (2012) for Israel (0.71). On the other hand, a higher estimate (0.94) is obtained for Slovenia in the study of Kustrin (2019), while Copaciu et al. (2015) find a relatively low estimate for Romania (0.38), the latter also featuring a much more volatile consumption series.

The implied Frisch labour supply elasticity, derived as $1 / \sigma_{L}$, is around 0.2 , a noticeably lower value than its prior one (0.33) and similar with the estimates obtained in the micro studies, as surveyed by Pencavel (1987). Relatively similar values were obtained by Christiano et al. (2011) and Copaciu et al. (2015) (i.e. a value around 0.13 for Sweden and Romania, respectively), Pedersen (2016) reports a value of 0.15 for Denmark, while Gertler et al. (2008) and Galí et al. (2011) estimate values of around 0.25 for US.

The mean estimated value of the investment adjustment cost parameter ( $S^{\prime \prime}$ ) is very low (i.e. 0.22 ), starting from a prior value of 4 . While lower when compared with the values found by Christiano et al. (2011) for Sweden (2.6) and Kustrin (2019) for Slovenia (8.6), the estimated value for the Macedonian economy is similar with the estimate of 0.25 obtained by Copaciu et al. (2015) for Romania. The posterior mean values for the capacity utilization parameters, $\sigma_{a, D C}$ and $\sigma_{a, F C}$ are 0.73 and 0.74 respectively, close to the prior values, implying low variation in capacity utilization. Analogous to the explanation in Copaciu et al. (2015), these results might be related to the model trying to match simultaneously an extremely volatile investment data and a relatively less volatile GDP data one.

The mean estimated value for the monitoring costs parameters, $\mu_{D C}$ and $\mu_{F C}$, are 0.26 and 0.39 , higher and respectively lower than the prior values. Thus, the model implied steady-state values for the spreads for new loans to non-financial corporations in domestic and foreign currency at the posterior mean are 1.5 and 4.1 percentage points respectively. On the other hand, the average empirical value of the spread for new loans in domestic currency is 2.9 percentage points, whereas the value of the spread for the ones in foreign currency is 5.6 percentage points over the analyzed period. Thus, both estimated steady-state values of the spreads are lower than their empirical counterpart, with the ranking (i.e. higher spreads for foreign currency loans) maintained. However, the results are in line with the volatility of the change in spreads (i.e. higher volatility for the change in spreads for domestic currency loans relative to the foreign currency ones - see table 6 for details). Compared to the empirical literature, our estimates of the monitoring costs are lower than the ones reported for example by Copaciu et al. (2015) for Romania. On the other hand, if one abstracts from the model relations and uses the (1 minus) recovery rates published in the Doing Business Report of the World Bank as a proxy for the overall monitoring costs in the Macedonian economy, this results in a corresponding value for $\mu$ of $0.57^{19}$, which is higher than our estimates. Compared to other countries, the recovery rate in Germany is much higher, and implicitly the proxy for monitoring costs much lower $(0.18$ cents on the dollar), whereas it is much lower in Romania, Serbia and Croatia, where the implicit proxy for the monitoring costs are around 0.7 cents on the dollar.

Table 5 summarizes the estimation results for the auto-regressive parameters and the standard deviations of shocks. The results for both categories reflect the estimation procedure that tries to

\footnotetext{
${ }^{19}$ World Bank Ease of Doing Business Database, Resolving insolvency: Recovery rate (cents on the dollar), for 2006-2020.
} 
match the volatility in the observed data. As for the estimated parameters and standard deviations for the external sector, these are presented in the Appendix A.1.

As previously mentioned, six observed ratios are matched exactly in the process of estimation, with the corresponding parameters being recalibrated after each draw and their posterior mean presented in Table 3. In this process, we find that the depreciation rate that matches the nominal investment to GDP ratio in the steady state takes a mean value of $4.2 \%$ on a quarterly basis, which is higher than the usual value of $2.5 \%$ used in the literature. This discrepancy is related to the relatively high ratio of nominal investment over GDP that we are trying to match and a relatively low capital to GDP ratio in the presence of high spreads ${ }^{20}$. Thus, there is a need for capital to depreciate relatively fast.

The posterior values for the entrepreneurial survival rates used to match the net worth to capital ratios for foreign and domestic currency borrowing firms are relatively low, being related to the high bankruptcy rates and spreads present in the model in order to match empirical counterparts. Matching the foreign to domestic currency loans ratio of $74 \%$ implies a share of entrepreneurs borrowing in domestic currency, $\omega_{k}$, of 0.39 (i.e. $39 \%$ ). Given that we are matching an implicit ratio of domestic to foreign currency credit of around 2.6, one would expect a share of domestic entrepreneurs higher than 0.5 . However, given the estimated spreads (higher for foreign currency), the per entrepreneur capital is higher for DC type relative to the FC type one and thus, in order to accommodate at the aggregate level the $74 \%$ share, the share of domestic entrepreneurs should be smaller than 0.5 .

Table 4 Estimated structural parameters

\begin{tabular}{|c|c|c|c|c|c|c|c|c|}
\hline \multirow[t]{2}{*}{ Parameter } & \multirow[t]{2}{*}{ Description } & \multicolumn{3}{|c|}{ Prior } & \multicolumn{4}{|c|}{ Posterior } \\
\hline & & Distr. & Mean & s.d & Mean & s.d. & $10 \%$ & $90 \%$ \\
\hline$\xi_{d}$ & Calvo, domestic & $\beta$ & 0.6 & 0.025 & 0.568 & 0.024 & 0.526 & 0.608 \\
\hline$\xi_{x}$ & Calvo, exports & $\beta$ & 0.5 & 0.075 & 0.257 & 0.029 & 0.202 & 0.312 \\
\hline$\xi_{m c}$ & Calvo, imported consumption & $\beta$ & 0.5 & 0.075 & 0.538 & 0.065 & 0.427 & 0.647 \\
\hline$\xi_{m i}$ & Calvo, imported investment & $\beta$ & 0.5 & 0.075 & 0.283 & 0.04 & 0.208 & 0.353 \\
\hline$\xi_{m x}$ & Calvo, imported exports & $\beta$ & 0.5 & 0.075 & 0.392 & 0.057 & 0.303 & 0.482 \\
\hline$\xi_{w}$ & Calvo, wages & $\beta$ & 0.8 & 0.075 & 0.268 & 0.033 & 0.207 & 0.326 \\
\hline$\kappa_{d}$ & Indexation, domestic & $\beta$ & 0.5 & 0.1 & 0.407 & 0.081 & 0.257 & 0.557 \\
\hline$\kappa_{x}$ & Indexation, exports & $\beta$ & 0.5 & 0.1 & 0.419 & 0.088 & 0.266 & 0.57 \\
\hline$\kappa_{m c}$ & Indexation, imported consumption & $\beta$ & 0.5 & 0.1 & 0.531 & 0.101 & 0.372 & 0.691 \\
\hline$\kappa_{m i}$ & Indexation, imported investment & $\beta$ & 0.5 & 0.1 & 0.42 & 0.066 & 0.264 & 0.58 \\
\hline$\kappa_{m x}$ & Indexation, imported exports & $\beta$ & 0.5 & 0.1 & 0.484 & 0.078 & 0.325 & 0.642 \\
\hline$\kappa_{w}$ & Indexation, wages & $\beta$ & 0.25 & 0.075 & 0.203 & 0.058 & 0.101 & 0.306 \\
\hline$\sigma_{L}$ & Inverse Frisch elasticity & $\Gamma$ & 3 & 1 & 5.1 & 1 & 3.47 & 6.59 \\
\hline$b$ & Habit in consumption & $\beta$ & 0.65 & 0.15 & 0.677 & 0.11 & 0.537 & 0.842 \\
\hline$S^{\prime \prime}$ & Investment adjustment costs & $N$ & 4 & 1.5 & 0.22 & 0.04 & 0.15 & 0.28 \\
\hline$\sigma_{a, D C}$ & Variable capital utilization DC & $\Gamma$ & 0.75 & 0.025 & 0.732 & 0.022 & 0.692 & 0.773 \\
\hline$\sigma_{a, F C}$ & Variable capital utilization FC & $\Gamma$ & 0.75 & 0.025 & 0.737 & 0.022 & 0.696 & 0.778 \\
\hline$\eta_{i}$ & Elasticity of subst., investment & $\Gamma$ & 1.5 & 0.075 & 1.743 & 0.082 & 1.614 & 1.872 \\
\hline$\eta_{f}$ & Elasticity of subst., foreign & $\Gamma$ & 1.5 & 0.075 & 1.464 & 0.056 & 1.358 & 1.566 \\
\hline$\eta_{c}$ & Elasticity of subst., consumption & $\Gamma$ & 1.5 & 0.075 & 1.359 & 0.076 & 1.217 & 1.502 \\
\hline$\eta_{x}$ & Elasticity of subst., exports & $\Gamma$ & 1.5 & 0.075 & 1.404 & 0.077 & 1.279 & 1.528 \\
\hline$\eta_{k}$ & $\begin{array}{l}\text { Elasticity of subst., capital } \\
\text { services }\end{array}$ & $\Gamma$ & 2.5 & 0.25 & 2.421 & 0.288 & 2.014 & 2.821 \\
\hline$\mu_{D C}$ & Monitoring cost DC & $\beta$ & 0.3 & 0.05 & 0.259 & 0.029 & 0.208 & 0.309 \\
\hline$\mu_{F C}$ & Monitoring cost FC & $\beta$ & 0.3 & 0.05 & 0.394 & 0.033 & 0.336 & 0.451 \\
\hline
\end{tabular}

Source: Authors' calculations.

\footnotetext{
${ }^{20}$ The nominal investment to GDP ratio in the steady state is $28.6 \%$, whereas the nominal and real capital to GDP ratio in annual terms is 1.5 and 2.9 , respectively.
} 
Table 5 Estimated auto-regressive parameters and standard deviations of shocks

\begin{tabular}{|c|c|c|c|c|c|c|c|c|}
\hline \multirow[t]{2}{*}{ Parameter } & \multirow[t]{2}{*}{ Description } & \multirow[b]{2}{*}{ Distr. } & \multicolumn{2}{|c|}{ Prior } & \multicolumn{4}{|c|}{ Posterior } \\
\hline & & & Mean & s.d/df & Mean & s.d. & $10 \%$ & $90 \%$ \\
\hline$\rho_{\mu_{\mathrm{z}}}$ & Persistence, unit-root tech. & $\beta$ & 0.85 & 0.05 & 0.708 & 0.044 & 0.614 & 0.805 \\
\hline$\rho_{\epsilon}$ & Persistence, stationary tech. & $\beta$ & 0.3 & 0.075 & 0.386 & 0.07 & 0.265 & 0.506 \\
\hline$\rho_{\Upsilon}$ & Persistence, MEI & $\beta$ & 0.3 & 0.075 & 0.202 & 0.049 & 0.113 & 0.29 \\
\hline$\rho_{\zeta^{c}}$ & Persistence, consumption prefs. & $\beta$ & 0.3 & 0.075 & 0.341 & 0.084 & 0.218 & 0.459 \\
\hline$\rho_{\zeta^{h}}$ & Persistence, labor prefs. & $\beta$ & 0.3 & 0.075 & 0.296 & 0.055 & 0.186 & 0.406 \\
\hline$\rho_{\widetilde{\phi}}$ & Persistence, country risk premium & $\beta$ & 0.75 & 0.075 & 0.837 & 0.042 & 0.768 & 0.905 \\
\hline$\rho_{\gamma} D C$ & Persistence, entrepren. wealth DC & $\beta$ & 0.75 & 0.075 & 0.74 & 0.063 & 0.653 & 0.829 \\
\hline$\rho_{\gamma^{F C}}$ & Persistence, entrepren. wealth FC & $\beta$ & 0.75 & 0.075 & 0.709 & 0.073 & 0.587 & 0.833 \\
\hline $10 \sigma_{\mu_{z}}$ & Unit-root technology & $\beta$ & 0.3 & 2 & 0.07 & 0.01 & 0.053 & 0.087 \\
\hline $10 \sigma_{\epsilon}$ & Stationary technology & $\ln v-\Gamma$ & 0.3 & 2 & 0.076 & 0.006 & 0.065 & 0.086 \\
\hline $10 \sigma_{\Upsilon}$ & $\mathrm{MEI}$ & $\operatorname{lnv}-\Gamma$ & 0.5 & 2 & 0.208 & 0.035 & 0.157 & 0.259 \\
\hline $10 \sigma_{\zeta^{c}}$ & Consumption prefs. & $\ln v-\Gamma$ & 0.4 & 2 & 0.651 & 0.165 & 0.289 & 1.004 \\
\hline $10 \sigma_{\zeta^{h}}$ & Labor prefs. & $\ln v-\Gamma$ & 3 & 2 & 1.172 & 0.219 & 0.754 & 1.571 \\
\hline $100 \sigma_{\widetilde{\phi}}$ & Country risk premium & $\ln v-\Gamma$ & 0.2 & 2 & 0.144 & 0.018 & 0.114 & 0.173 \\
\hline $10 \sigma_{\tau^{d}}$ & Markup, domestic & $\ln v-\Gamma$ & 0.6 & 2 & 0.364 & 0.056 & 0.258 & 0.468 \\
\hline $10 \sigma_{\tau^{x}}$ & Markup, exports & $\ln v-\Gamma$ & 1 & 2 & 0.404 & 0.05 & 0.302 & 0.503 \\
\hline $10 \sigma_{\tau^{m c}}$ & Markup, imports for consumption & $\ln v-\Gamma$ & 0.3 & 2 & 0.247 & 0.241 & 0.088 & 0.409 \\
\hline $10 \sigma_{\tau^{m i}}$ & Markup, imports for investment & $\ln v-\Gamma$ & 1.5 & 2 & 0.515 & 0.07 & 0.400 & 0.632 \\
\hline $10 \sigma_{\tau^{m x}}$ & Markup, imports for exports & $\ln v-\Gamma$ & 3 & 2 & 2.231 & 0.534 & 1.473 & 2.966 \\
\hline $10 \sigma_{\gamma^{D C}}$ & Entrepreneurial wealth DC & $\ln v-\Gamma$ & 0.3 & 2 & 0.174 & 0.025 & 0.137 & 0.212 \\
\hline $10 \sigma_{\gamma^{F C}}$ & Entrepreneurial wealth FC & $\ln v-\Gamma$ & 0.3 & 2 & 0.167 & 0.038 & 0.099 & 0.232 \\
\hline
\end{tabular}

Source: Authors' calculations.

\section{Impulse response functions}

This section discusses the dynamic characteristics of the Macedonian economy as captured by impulse response functions (IRFs) simulated using the estimated model (i.e. estimates of the parameters at their posterior mean). We analyze here the responses of the key macroeconomic and financial variables to a selection of exogenous shocks, namely stationary neutral technology shock, consumption preference shock, sovereign risk premium shock and entrepreneurial net worth shock. The rest of impulse response functions are presented in the Appendix A.2. The graphs presented below show the effect of one standard deviation shock on the dynamics of the selected endogenous variable over a period of twenty quarters. All variables are expressed as deviations from the steady state of the model: real variables are presented as percentage deviations ( $\%$ dev.); inflation measures, interest rates, spreads and the risk premium as annualized percentage deviations (APD); and the ratios of net foreign asset and net nominal exports to nominal GDP as level deviations.

Figure 3 depicts the impulse response functions of model variables to a positive stationary neutral technology shock $\left(\epsilon_{t}\right)$. This transitory supply shock yields the standard expansionary reaction of output as predicted in economic theory. The rise in total factor productivity has positive broad-based effects over the economy, inducing a persistent rise in private consumption and a less persistent increase in investment and net exports. As a result, GDP increases by around $0.25 \%$ on impact and, given also the extremely low persistence of this shock, returns to steady state after a two year period. Real wages initially marginally decline but then rise sharply due to the improved productivity effects, whereas total hours work decline due to the income effect dominating the substitution one. The increased productivity resulting from the shock generates a decrease in the real marginal cost of the domestic goods producers, generating disinflationary pressures in the economy, transmitted also on prices of final goods. Thus, the CPI inflation declines. Given the fixed nominal exchange rate, the fall in domestic/CPI inflation relative to foreign one results in a depreciation of the real exchange rate, with positive effects on domestic competitiveness and exports. On the other hand, imports drop on impact, due to the substitution effect of foreign with domestic goods.

Despite the temporary improvement in (nominal) net exports, negative valuation effects dominate in the first periods leading to an initial deterioration in the net foreign assets position and a consequent 
positive deviation from the steady for the sovereign risk premium (for the first three quarters). However, as a share of (annual terms) nominal GDP, the net foreign assets position improves. In order the fixed exchange rate to be maintained, the interest rate marginally increases on impact, and then declines in line with the ensuing improvement of the net foreign asset position and the risk premium.

Since the cost of debt is fixed in nominal terms, the decline in prices activates the Fisher's debtdeflation channel, leading to an increased real value of debt. Given the extremely small increase in the domestic nominal interest rate and in the cost of foreign currency debt expressed in domestic currency (driven by the evolution of the risk premium), the above mentioned channel leads to a small increase in spreads that mutes the evolution of net worth in the first period. Following the demand for investment goods and the decline in spreads the net worth increases in the subsequent periods, as the financial accelerator kicks in.

Figure 3: IRFs to the stationary neutral technology shock
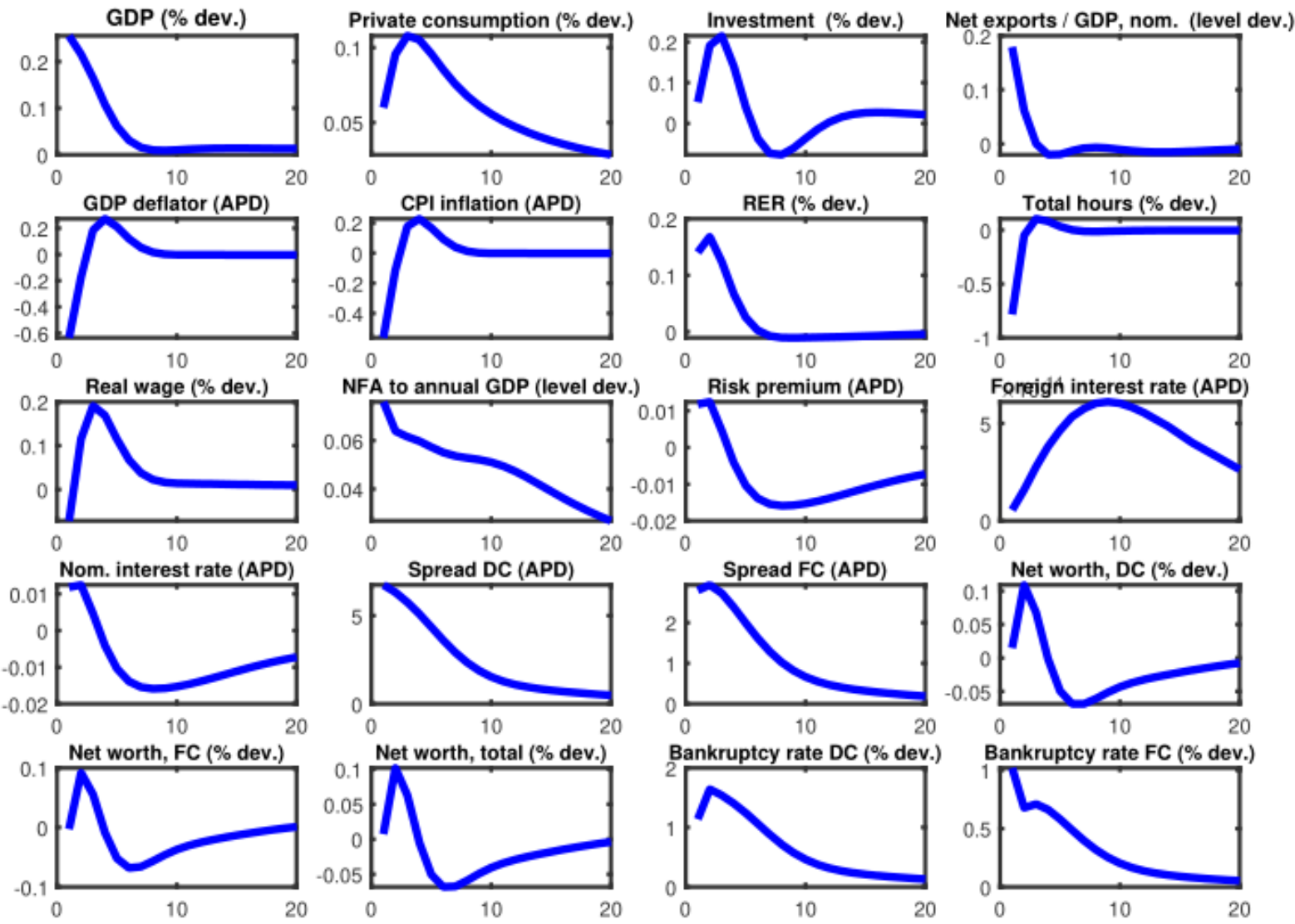

Source: Authors' calculations.

Figure 4 plots the impulse responses to a country risk premium shock $\left(\tilde{\phi}_{t}\right)$, extremely relevant for countries with fixed exchange rate regime. Since this shock entails a rise in the exogenous component of the sovereign risk premium, domestic interest rate increases immediately and by the same magnitude, mimicking over the entire horizon the behavior of the risk premium.

The higher risk premium for $\mathrm{FC}$ entrepreneurs together with the hike in the domestic interest rate for DC entrepreneurs lead to higher bankruptcy rates, higher spreads and a decline in net worth. In this case, the debt deflation mechanism enhances the financial accelerator one, which is the case for demand like shocks. As for the latter mechanism, it is perpetuated by the ensuing lower demand for capital from capital producers, resulting in a significantly lower demand for investment, which drops more than $2 \%$ below steady state on impact. Total hours worked and real wages in the economy are also negatively affected due to the lower demand levels. These induce a decline in marginal costs of production, hence domestic prices and $\mathrm{CPI}$ inflation go down. In an environment of higher interest 
rates and lower inflation, the real interest rate goes up, which induces private consumption to decline, amid higher saving preferences of consumers.

Since the nominal exchange rate is fixed, when domestic inflation goes down, the real exchange rate slightly depreciates, with a positive impact on the external competitiveness and on exports. This has a positive impact on net exports, which also improve because the diminishing domestic demand at the same time curbs imports. As a consequence of improved (nominal) net exports, the net foreign asset position of the country improves.

The fall in investment and consumption outweighs the improvement of net exports, with real GDP dropping by around $0.3 \%$ on impact. This finding is characteristic for many emerging economies with partial dollarization, where negative balance sheet and wealth effects neutralize the positive effect of (real terms) depreciation on the economy. However, with a nominal fixed exchange rate, the nominal domestic interest rate does not react to the change in the domestic variables (e.g. inflation) and reflects only the (small) changes in the sovereign risk premium or the ones in the foreign interest rate. Thus, for both DC and FC entrepreneurs the cost of funds does not vary much, and even more they co-move leading in general to no significant differences in terms of FC and DC net worth. We make the conjunction that in this case, the debt deflation channel is more important relative to the financial accelerator one (compared to the flexible exchange rate case).

Figure 4: IRFs to the country risk premium shock
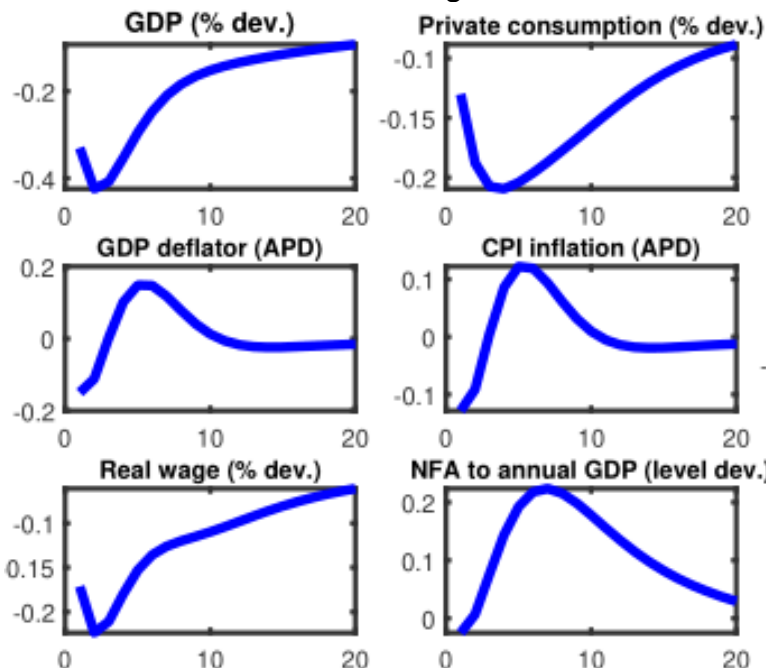

Nom. interest rate (APD)
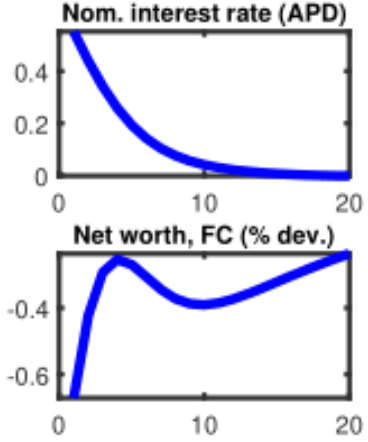

Private consumption ( $\%$ dev.)

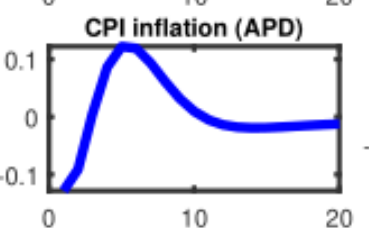

20
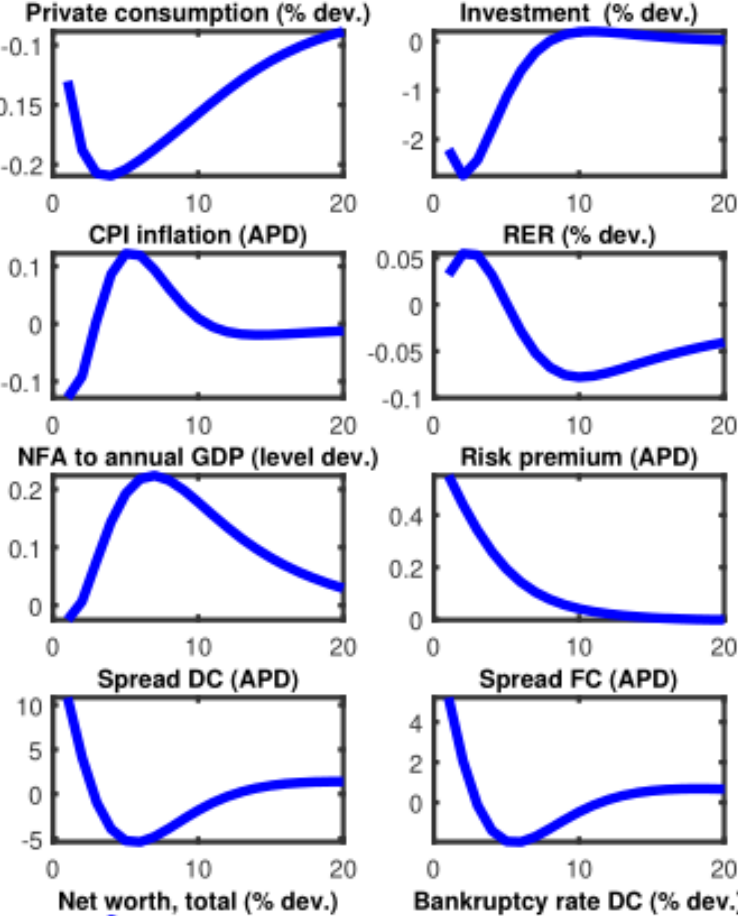

Bankruptcy rate DC (\% dev.)

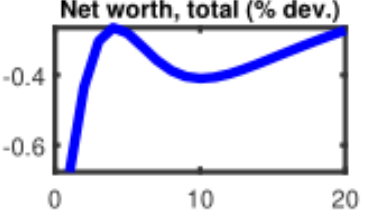

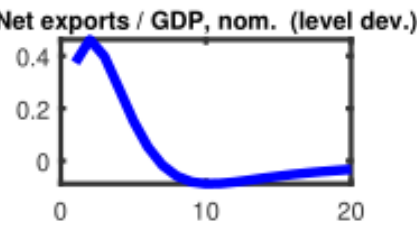

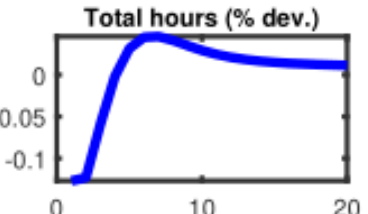

Foneigh interest rate (APD)
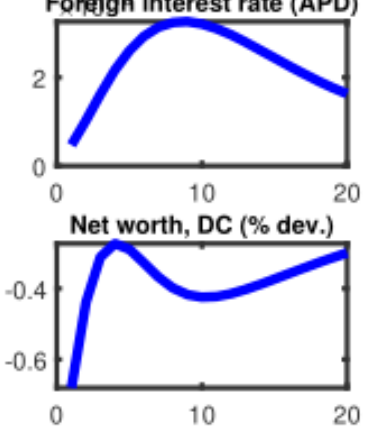

Bankruptcy rate FC (\% dev.)

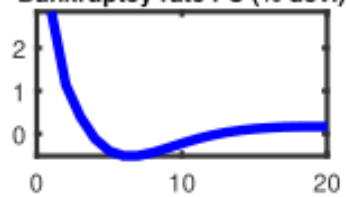

Source: Authors' calculations.

Figure 5 illustrates the effects of a positive shock to consumption preferences $\left(\zeta_{t}^{c}\right)$. This is a typical demand-side shock with positive responses of both output and prices. Consumption surges by $2 \%$ on impact and remains persistently above steady state in the next 10 quarters. As households spend more in the consumer market and favor dissaving, investment drops, despite the positive effects this expansionary economic shock has on interest rate spreads and net worth of entrepreneurs. However, although investment declines, imports still grow due to the high share of imported components that consumption goods contain. At the same time, as the shock is propagated in the economy, exports 
drop as well because of their increased relative prices, following increased input prices. However, the increase in consumption more than compensates for the unfavorable movements in the other components, so the combined effect of this shock is a rise in GDP by around $0.7 \%$ on impact. The higher domestic demand that firms need to meet as well as the lower importance that consumers put on leisure lead to a rise in total hours worked, accompanied by rise in real wages. Consequently, real marginal costs of domestic goods firms increases, which drives up CPI inflation. Since foreign prices are unchanged, this in turn results in a slight appreciation of the real exchange rate. The combination of lower export demand (higher relative prices) and the higher imports (higher demand for consumption goods), also in nominal terms entail a gradual deterioration of the net foreign assets position of the country (although as a share of annual GDP it improves marginally in the first period), with a resulting increase in the risk premium. In turn, the higher risk premium induces a slight upward movement of the interest rate, given the fixed exchange rate regime.

Figure 5: IRFs to the consumption preference shock
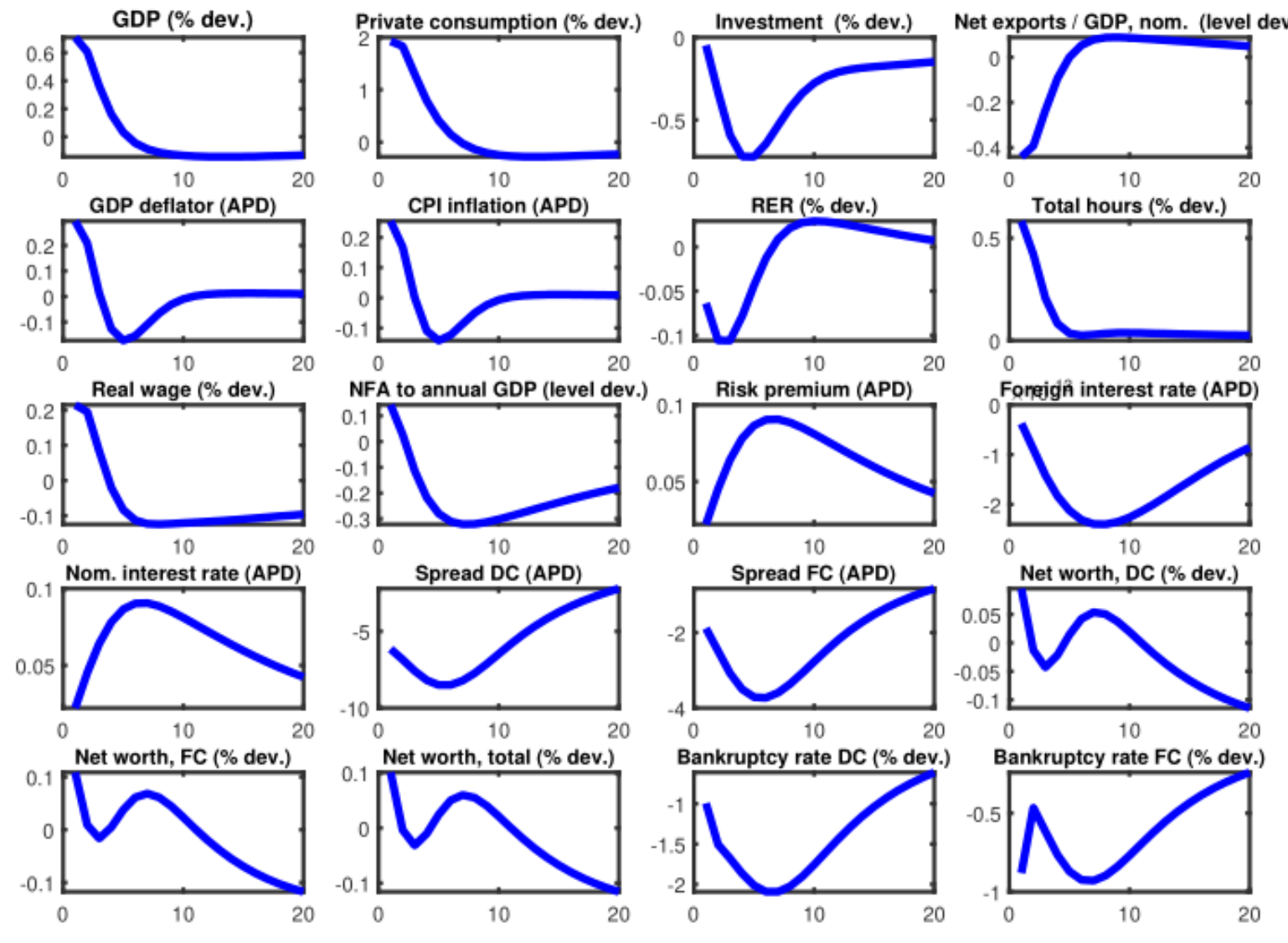

Finally, we discuss the impulse responses to a positive shock to the net worth of entrepreneurs borrowing in domestic currency $\left(\gamma_{t}^{D C}\right)$, as depicted in Figure 6. In response to this shock, net worth of entrepreneurs borrowing in domestic currency improves on impact and peaks at about $5 \%$ above steady state during the second year of the shock and then, given also the stock nature of the affected variable, gradually dies out. On the other hand, the net worth of entrepreneurs borrowing in foreign currency responds positively only during the first year, and then moves into the negative territory as the substitution effect between foreign and domestic currency funds prevails. Still, the combined effect is a long-lasting hump-shaped increase in aggregate net worth. The positive changes in the balance sheets of entrepreneurs drive bankruptcy rates down, resulting in lower spreads, more in the case of entrepreneurs borrowing in domestic currency. This in turn leads to an increased demand for capital which translates into higher investment that jumps by around $4 \%$ on impact relative to the steady state. On the other hand, consumption declines given also the developments for the real interest rate, as well as net exports, as imports rise faster than exports despite a weaker real exchange rate (induced by falling CPI), due to the higher demand for investment goods from abroad. Overall, real 
GDP increases by $0.4 \%$ on impact, and peaks at about $0.75 \%$ one year after the shock occurs. The rise in output causes higher demand for labor, with both total hours worked and real wages rising. However, as a consequence of the diminishing net exports, the net foreign asset position of the country deteriorates, leading to a rise in the risk premium and therefore in the domestic interest rate.

Figure 6: IRFs to the DC entrepreneurial net worth shock
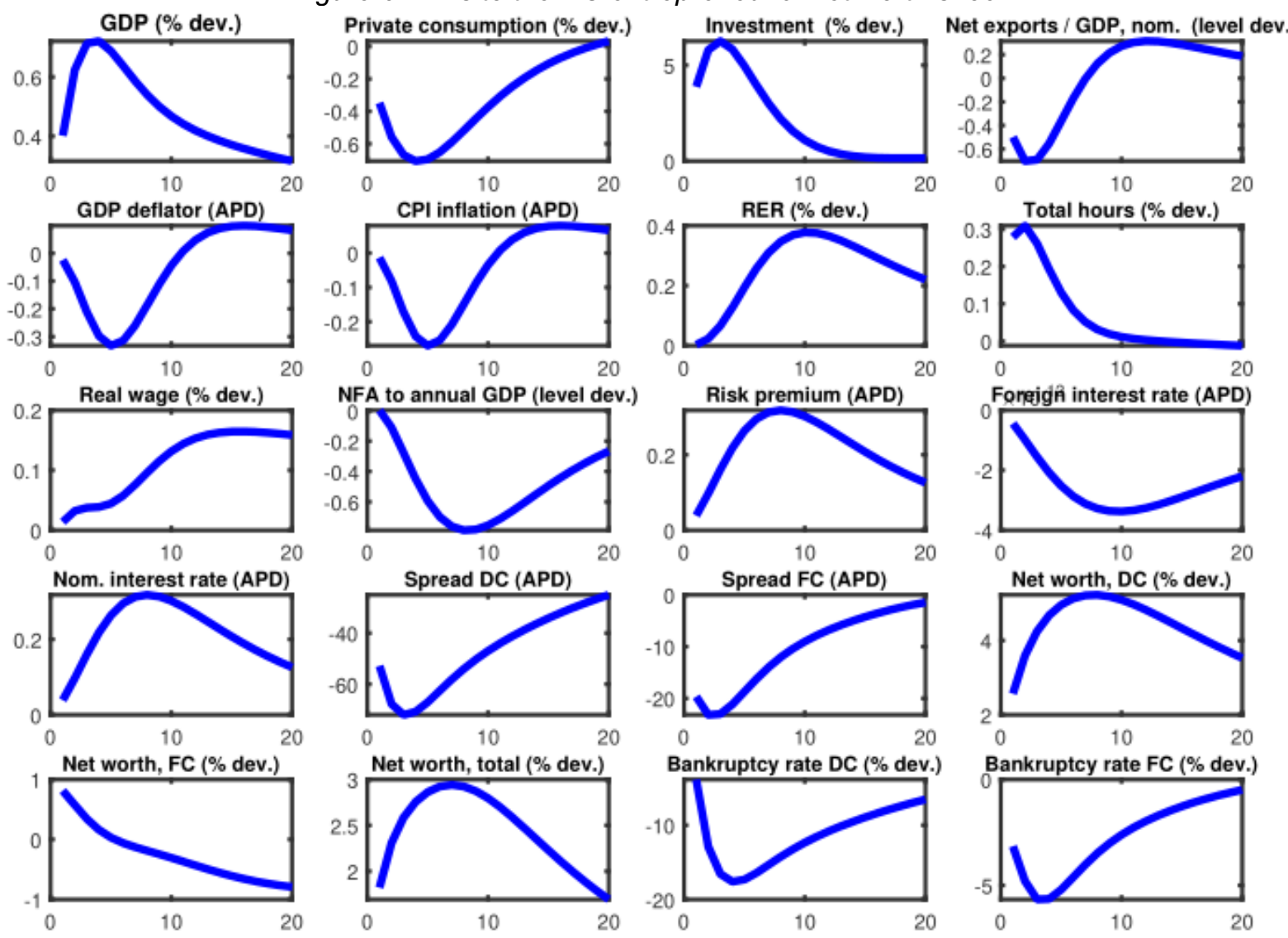

Bankruptcy rate DC (\% dev.)

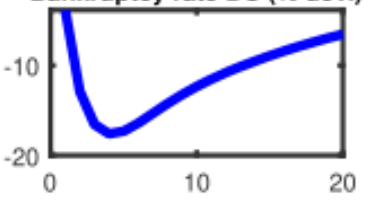

Bankruptcy rate FC (\% dev.)

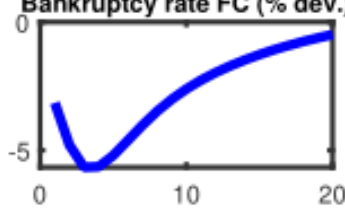

Source: Authors' calculations.

\section{Model and data moments and variance decomposition}

To analyze the model's fit of the data we present in Table 6 the fit of the model standard deviations for the observed series relative to their data counterparts. This is done for the model estimated both with and without endogenous priors. The use of the endogenous priors approach as suggested by Christiano et al. (2011) fosters better moment matching as the variance of the observed variables is included through a sequential-learning approach to the Bayesian estimation of the model.

By looking at the volatility observed in the data and that implied from the model estimated with endogenous priors, it can be seen that the model performs relatively well in terms of its fit, given the constraints imposed by the number of variables, length of the sample and high data variability. In terms of volumes, the model matches closely the volatility of GDP, consumption and exports and slightly underestimates the variability investment and imports. In terms of prices, it closely matches $\mathrm{CPI}$ inflation and the GDP deflator, slightly underestimates the volatile exports and imports deflators and underestimates with a higher degree the extremely volatile investments deflator. The domestic interest rate and the labor market variables are slightly overestimated. As for the change in spreads' variability, extremely volatile in the observed series, the one for foreign currency loans is matched closely, while the one for domestic currency loans is overestimated. The volatility in the foreign sector variables is matched very closely. 
Compared to the model with endogenous priors, the model estimated without endogenous priors performs worse in terms of matching the variability in the data. For most of the variables (with the exception of exports, investment and export deflators) it overestimates the variability of the observed variables. This is most noticeable in the case of the financial frictions related variables (spreads DC and FC) where the variability is severely overestimated. Therefore, overall, we assess the model's fit to the data with the use of the endogenous prior approach to be relatively solid.

Variance decomposition of the posterior means of the observed variables over the 8 quarter horizon is shown in Table 7. The discussion that follows decomposes the variance in terms of the contribution coming from different groups of shocks (supply, demand and foreign shocks) and the contribution coming from the observed series' measurement errors (ME). In addition, the most relevant shock within each group of shocks is commented in the text.

Table 6 Data and model moments

\begin{tabular}{lccc}
\hline Series & Data & Model (EP) & Model (no EP) \\
\hline Gross domestic product $(G D P)$ & 2.73 & 2.43 & 4.31 \\
Consumption $(C)$ & 2.85 & 2.49 & 3.59 \\
Investment $(I)$ & 18.75 & 14.52 & 20.55 \\
Imports $(M)$ & 9.23 & 6.45 & 9.48 \\
Exports $(X)$ & 7.10 & 6.69 & 6.54 \\
Domestic interest rate $(R)$ & 1.75 & 2.05 & 3.03 \\
GDP deflator $\left(\pi_{G D P}\right)$ & 9.39 & 10.13 & 11.63 \\
CPI $\left(\pi_{C}\right)$ & 3.23 & 3.10 & 3.97 \\
Investment deflator $\left(\pi_{I}\right)$ & 36.99 & 20.50 & 29.26 \\
Import deflator $\left(\pi_{M}\right)$ & 23.87 & 18.23 & 32.15 \\
Export deflator $\left(\pi_{X}\right)$ & 20.49 & 17.80 & 15.01 \\
Wages $(w)$ & 1.59 & 1.99 & 2.97 \\
Hours worked $(H)$ & 1.46 & 2.25 & 7.22 \\
Spread FC $(\operatorname{spread}$ & 14.95 & 12.83 & 38.27 \\
Spread DC spread & 17.78 & 25.09 & 50.99 \\
Foreign output gap $\left(y_{\text {gap }}^{*}\right)$ & 2.14 & 2.28 & 2.58 \\
Foreign inflation $\left(\pi^{*}\right)$ & 2.39 & 2.69 & 2.72 \\
Foreign interest rate $\left(R^{*}\right)$ & 1.59 & 1.68 & 1.60 \\
\hline & Source: Authors' calculations. &
\end{tabular}

To begin with, aside from ME, most of the variance in the observed series for GDP growth and its components is explained predominantly by supply shocks, with the exception of consumption (where demand shocks account for more than three quarters of this series' variability). More specifically, the consumption preference shock explains around $73.8 \%$ of the variation in consumption, similar to Copaciu et al. (2015). In terms of GDP growth, the most important supply shocks are the permanent neutral technology and the markup shocks of exporters. Turning to investment, around $30 \%$ of the variation explained comes from the marginal efficiency of investment and markup shocks for importers of investment goods. Moreover, out of the $18.5 \%$ of the variance explained by the demand shocks, most of it comes from shocks to the net worth of domestic $(10.8 \%)$ and foreign entrepreneurs $(4.5 \%)$. Furthermore, the most relevant supply shocks for imports growth are markup shocks, more specifically, those of importers of goods used in the production of investment and export goods. Markup shocks are even more relevant for the series of exports, with shocks to exports and imports of goods used in the production of exports accounting for over $80 \%$ of the observed variation.

Next, the observed variation in prices is mostly explained by supply shocks and foreign shocks - by order of relevance. Over $80 \%$ of the variation in the GDP deflator is explained by supply shocks - or more concretely, markup shocks. When it comes to consumption prices, a large part of the variability in the CPI index comes from markup shocks (around 36\%) and foreign shocks (around 33\%). Supply shocks also account for more than half of the variation in the import and export deflators.

Regarding the labor market variables, technology shocks account for around one third of the variation in wages and one quarter of the variation in hours worked. Thus, wages are predominantly explained by permanent technology shocks, while hours worked, by transitory technology shocks. Another important contribution to the variation in wages comes from labor disutility shocks (around $25 \%$ ), while exports related markups shocks account for $27.5 \%$ of the variation in hours worked. 
In the context of financial sector variables, demand shocks are more significant drivers of the observed variation in the data. Hence, shocks to the net worth of FC/DC entrepreneurs account for more than $30 \%$ of the variation in the respective spreads and for more than $20 \%$ in the domestic interest rate. Part of the variability in the spreads also originates from supply side shocks (i.e. marginal efficiency of investment shocks and markup shocks to importers of goods used in the production of investment). As for the domestic interest rate, the sovereign risk premium has a relevant role, accounting for around $25.4 \%$ of the variation. Given the monetary policy regime in place, foreign shocks play a substantial role, explaining close to half of domestic interest rate variability.

As explained above, for a number of reasons, measurement errors were introduced and consequently they have a role in explaining part of the data variability. Table 7 shows that measurement errors account for a high degree of variability of investment and of imports (volume and price series). This result is rather expected, given the large and frequent data revisions made for Macedonian data that are particularly common for investment volumes and for investment and import deflators. Measurement errors are also relevant for the variation in the foreign currency spread, given its relatively high volatility.

Table 7 Variance decomposition over 8 quarters horizon of observed variables at their posterior mean

\begin{tabular}{|c|c|c|c|c|c|c|c|c|c|c|c|c|c|c|c|}
\hline & $G D P$ & $C$ & $I$ & $X$ & $M$ & $\pi_{G D P}$ & $\pi_{C}$ & $\pi_{I}$ & $\pi_{X}$ & $\pi_{M}$ & $H$ & $W$ & $R$ & $S_{D C}$ & $S_{F C}$ \\
\hline$\epsilon_{\mu, z}$ & 12.9 & 8.2 & 4.9 & 1.6 & 8.4 & 0.7 & 5.4 & 0.0 & 0.1 & 0.0 & 1.6 & 35.8 & 0.8 & 3.2 & 2.0 \\
\hline$\epsilon_{\epsilon}$ & 1.3 & 0.1 & 0.0 & 0.1 & 0.5 & 0.6 & 4.8 & 0.0 & 0.1 & 0.0 & 23.3 & 4.1 & 0.0 & 0.5 & 0.3 \\
\hline$\epsilon_{\Upsilon}$ & 8.8 & 0.0 & 16.8 & 0.0 & 9.9 & 0.1 & 0.8 & 0.0 & 0.0 & 0.0 & 10.1 & 3.0 & 1.0 & 9.8 & 8.5 \\
\hline$\epsilon_{\zeta^{c}}$ & 10.9 & 73.8 & 0.1 & 0.0 & 2.7 & 0.2 & 1.6 & 0.0 & 0.0 & 0.0 & 8.5 & 4.5 & 1.5 & 0.4 & 0.2 \\
\hline$\epsilon_{\phi}$ & 2.2 & 0.3 & 3.2 & 0.0 & 2.1 & 0.1 & 0.8 & 0.0 & 0.0 & 0.0 & 0.5 & 2.1 & 25.4 & 2.0 & 1.7 \\
\hline$\epsilon_{\zeta^{h}}$ & 0.2 & 0.0 & 0.0 & 0.0 & 0.1 & 0.1 & 1.0 & 0.0 & 0.0 & 0.0 & 6.2 & 24.9 & 0.0 & 0.1 & 0.1 \\
\hline$\epsilon_{g}$ & 0.1 & 0.0 & 0.0 & 0.0 & 0.0 & 0.0 & 0.0 & 0.0 & 0.0 & 0.0 & 0.3 & 0.1 & 0.0 & 0.0 & 0.0 \\
\hline$\epsilon_{\tau^{d}}$ & 1.0 & 0.1 & 0.2 & 0.1 & 0.1 & 2.3 & 21.1 & 0.1 & 0.2 & 0.0 & 3.3 & 2.4 & 0.3 & 0.1 & 0.1 \\
\hline$\epsilon_{\tau^{x}}$ & 19.3 & 0.0 & 0.0 & 30.4 & 7.2 & 26.2 & 0.6 & 0.0 & 32.0 & 0.0 & 14.0 & 3.2 & 0.1 & 0.2 & 0.1 \\
\hline$\epsilon_{\tau^{m c}}$ & 0.0 & 0.0 & 0.0 & 0.0 & 0.0 & 0.5 & 11.3 & 0.0 & 0.0 & 0.2 & 0.2 & 0.2 & 0.0 & 0.0 & 0.0 \\
\hline$\epsilon_{\tau^{m i}}$ & 4.9 & 0.0 & 12.7 & 0.0 & 11.7 & 9.1 & 2.8 & 17.3 & 0.0 & 3.4 & 7.2 & 0.9 & 2.0 & 19.0 & 14.4 \\
\hline$\epsilon_{\tau^{m x}}$ & 10.1 & 0.3 & 0.3 & 50.4 & 23.8 & 47.8 & 0.4 & 0.0 & 53.2 & 52.1 & 13.4 & 3.0 & 1.5 & 0.4 & 0.3 \\
\hline$\epsilon_{\gamma^{D C}}$ & 3.9 & 3.1 & 10.8 & 0.1 & 4.5 & 0.5 & 3.2 & 0.0 & 0.1 & 0.0 & 1.8 & 1.3 & 14.8 & 31.4 & 16.3 \\
\hline$\epsilon_{\gamma^{F C}}$ & 2.7 & 0.3 & 4.5 & 0.0 & 2.1 & 0.3 & 2.1 & 0.0 & 0.0 & 0.0 & 1.0 & 0.7 & 6.3 & 12.1 & 15.6 \\
\hline$\epsilon_{y^{*}}$ & 7.4 & 0.1 & 2.2 & 5.6 & 4.8 & 1.5 & 17.2 & 0.4 & 0.5 & 0.6 & 3.7 & 4.8 & 23.4 & 3.9 & 2.9 \\
\hline$\epsilon_{\pi^{*}}$ & 0.9 & 0.2 & 0.7 & 0.4 & 0.7 & 1.3 & 15.2 & 0.6 & 0.5 & 0.8 & 0.6 & 1.3 & 19.5 & 3.2 & 2.3 \\
\hline$\epsilon_{R^{*}}$ & 1.0 & 0.1 & 1.4 & 0.0 & 0.9 & 0.1 & 0.7 & 0.0 & 0.0 & 0.0 & 0.2 & 1.0 & 3.4 & 1.0 & 0.8 \\
\hline For. & 9.3 & 0.4 & 4.3 & 6.0 & 6.4 & 2.8 & 33.0 & 1.0 & 1.1 & 1.4 & 4.4 & 7.1 & 46.3 & 8.1 & 5.9 \\
\hline Sup. & 58.4 & 8.7 & 35.1 & 82.6 & 61.6 & 87.5 & 48.1 & 17.6 & 85.5 & 55.7 & 79.3 & 77.6 & 5.7 & 33.2 & 25.9 \\
\hline Dem. & 19.7 & 77.5 & 18.5 & 0.1 & 11.4 & 1.1 & 7.7 & 0.1 & 0.1 & 0.0 & 12.2 & 8.8 & 48.0 & 46.0 & 33.8 \\
\hline$M E$ & 12.6 & 13.4 & 42.2 & 11.3 & 20.6 & 8.6 & 11.2 & 81.4 & 13.3 & 42.9 & 4.1 & 6.6 & 0.0 & 12.8 & 34.4 \\
\hline
\end{tabular}

For. are foreign shocks, Sup. are supply shocks, Dem. are demand shocks and ME are measurement errors. Source: Authors' calculations.

\section{Smoothed shock processes and historical decomposition}

In figure 7 we illustrate the smoothed exogenous processes as retrieved by the two-sided Kalman filter, with the red line depicting the corresponding steady state value of the shocks. First of all, most of the shocks associated with the domestic economy lack persistence given the relatively low values of the estimated AR (1) coefficients and the white noise specification in case of the markup shocks. This is a rather expected result given the highly volatile data set the shocks need to match. The shocks 
associated with investment, both for volumes and prices, like the marginal efficiency of investment and the imports for investment markup shock, are such an example. The exception is represented by the risk premium and to a lesser extent by the permanent technology and net worth shocks for which the estimated AR (1) coefficients have relatively higher values, as shown in table 5. Some shocks, especially related to the real sector capture relatively well the evolution across the business cycle. Negative innovations are associated with the onset of the end 2008 global financial crisis or the mid2010- mid-2012 period for the permanent technology shock. For the latter period the evolution of the consumption preference and net worth shocks is also relevant. As for the first half of 2020, the end of our sample, the impact of the pandemics is usually reflected by extremely negative innovations for the shocks related to the real sector, most of these shocks being driven below their steady state values. The risk premium shock was hit by favorable innovations before the financial crisis hit. It went rapidly well above the steady state and remained there until the first part of 2011. Starting in 2017 it went below the steady state being hit by favorable innovations, with the pandemic crisis leading only to a marginal increase at the end of the sample. 
Figure 7: Smoothed shock processes
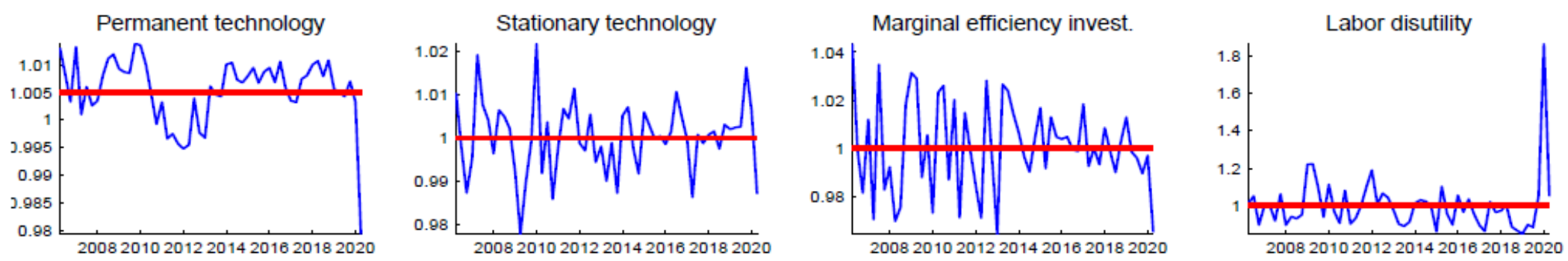

Consumption preference
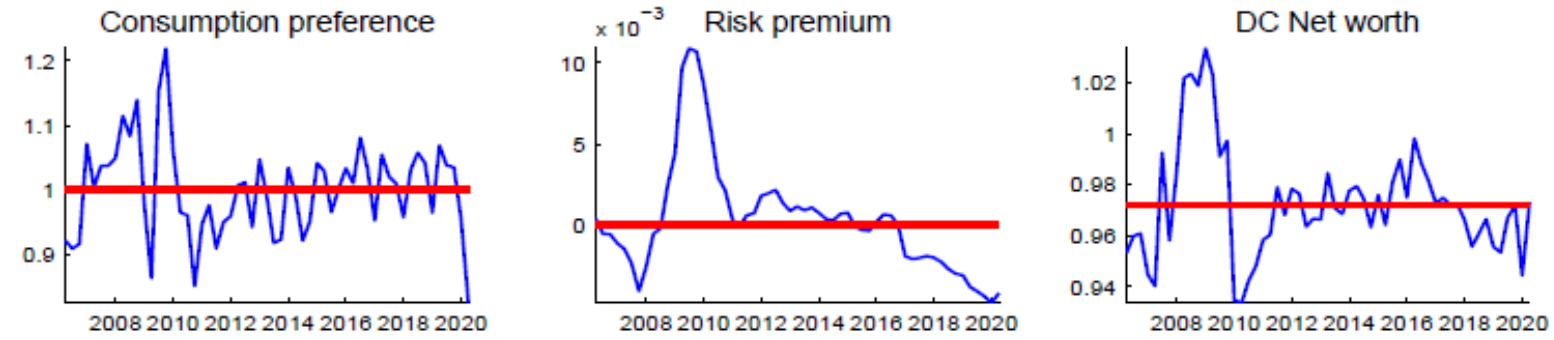

FC Net worth
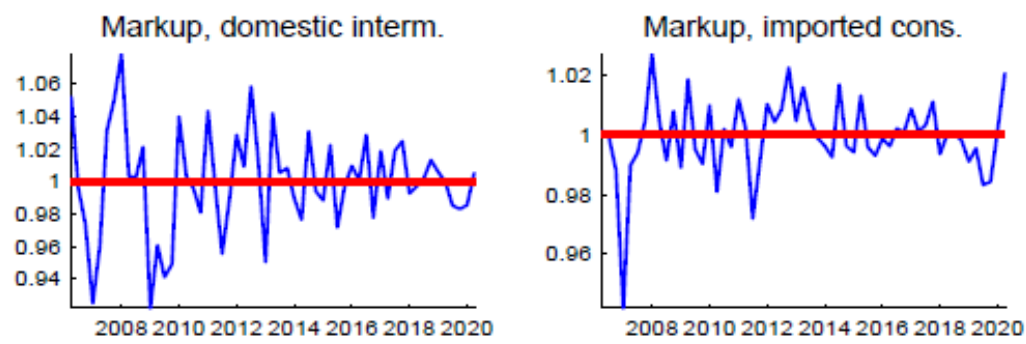

Markup, imported invest
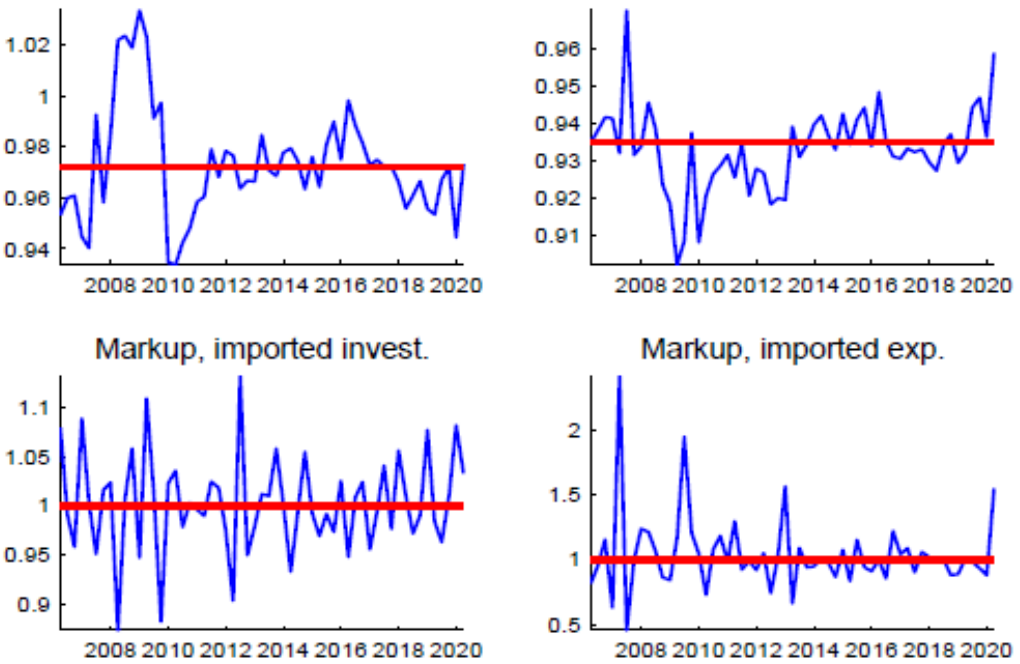

Markup, imported exp.

Markup, exports
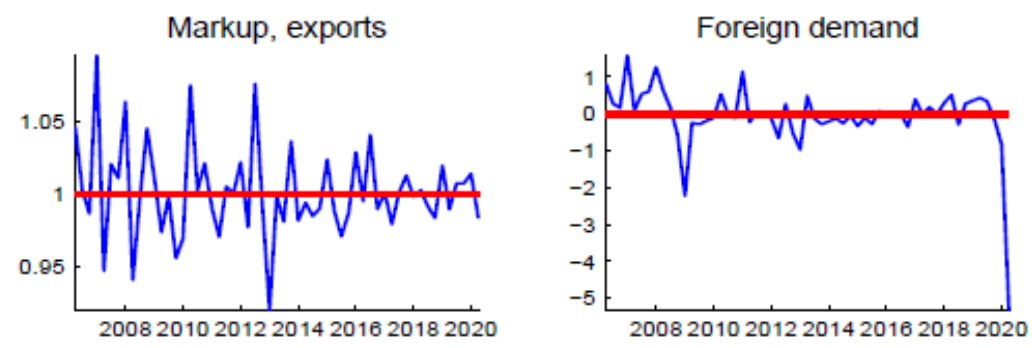

Foreign inflation

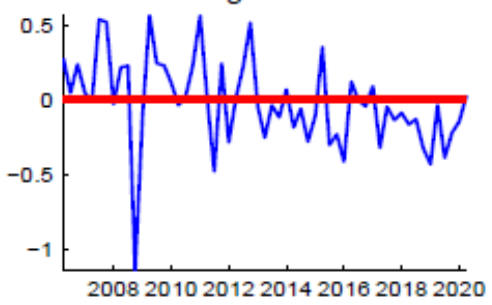

Source: Authors' calculations.
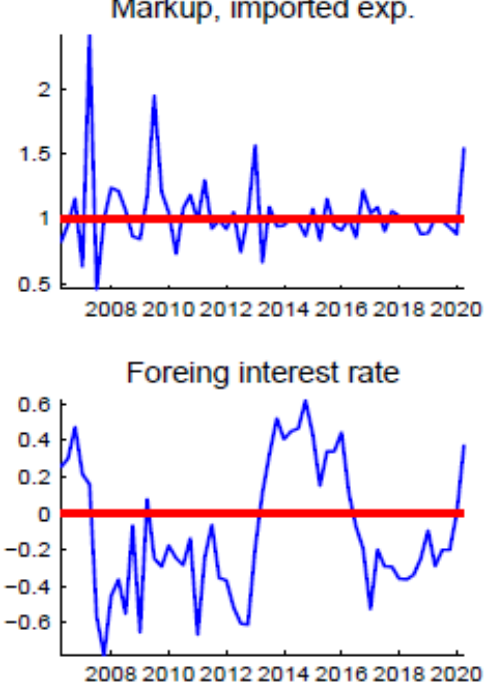
When estimating the model, a particular attention was given to the fit of some unobserved variables from the model, as retrieved by the two sided Kalman filter (smoother), against some counterparts retrieved from Macedonian Policy Analysis Model (MAKPAM) as evaluated in the October 2020 forecasting round. More precisely, as illustrated in figure 8, we looked at the relative fit of gaps for GDP and its components, potential output growth rate, risk premium and the gap between import and GDP deflators, as the latter measure is considered to be the relevant real exchange rate measure in MAKPAM. As it can be visually inspected the two models offer a relatively similar evaluation over the common sample for the gaps of GDP and its components. However, over some periods differences in the magnitude of the smoothed variables recovered with the two models appear. This is the case for the output gap for the 2010-2014, where the lower magnitude for the DSGE evaluation comes from the lower consumption gap. As for the potential output growth, with the growth rate of permanent technology trend representing the corresponding DSGE measure, it is evaluated at slightly lower values for most of the analyzed periods. The risk premium retrieved with the DSGE model is much smoother relative to the one retrieved from the MAKPAM.

Next, we describe the historical shock decomposition of some actual and model smoothed unobserved endogenous variables during the analyzed sample. Starting from the vector movingaverage representation of the model, any (observed or unobserved) variable can be decomposed in contributions of present and past shocks, with weights assigned to previous innovations decaying in accordance to their moment of occurrence. We restrain our attention to the 7 most important shocks as measured by the absolute average contribution to a variable's dynamics over the investigated sample, storing the remained innovations in a common "Other" group. The exception is represented by the risk premium shock, which given its relative importance in an economy with a fixed exchange rate regime, is presented, regardless of its importance, for each variable. Moreover, we do not focus on explaining the shock decomposition, at least for the unobserved variables, in the first quarters of the sample, given the impact of the initialization of the filter that fades out afterward. Overall, while the historical decomposition delivers conclusions similar to the variance decomposition, it also offers additional insights regarding the importance of particular shocks during specific periods. The q-o-q growth rates are expressed in deviation from the mean, while the cyclical components are deviations from the steady-state.

Figure 8: Smoothed unobserved variables and data counterparts
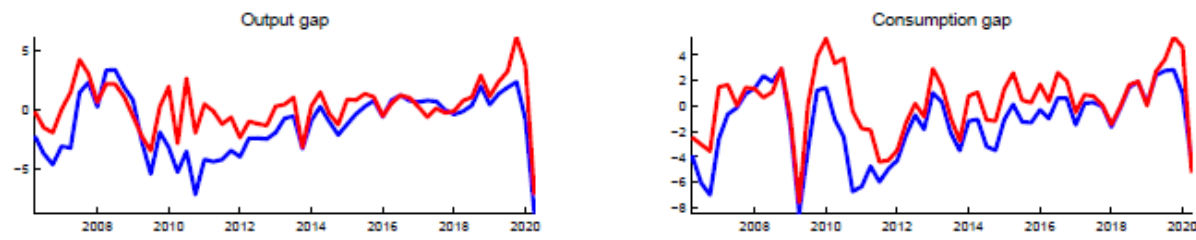

Investment gap
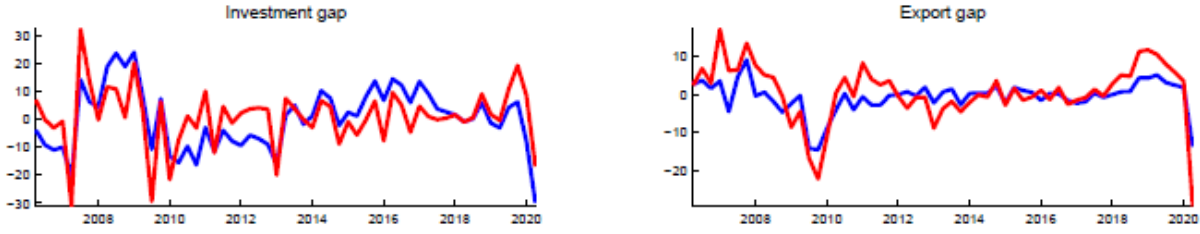

Import gap
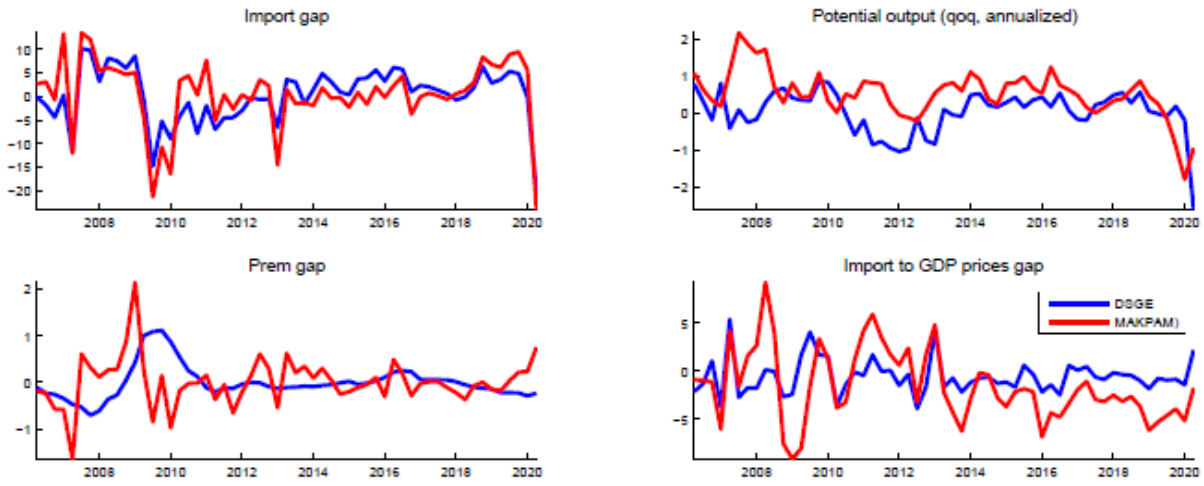

Source: Authors' calculations. 
In Figure 9 we present the (steady state deviation) dynamics of GDP and private consumption expressed, both in terms of quarterly growth rates and levels.

For real GDP growth, given its extremely volatile nature and the fact that we allow for a measurement error, the latter ranks first in terms of absolute contributions over the sample, although its contribution is not dominant for most of the time periods. This is also supported by looking at the variance decomposition of GDP growth, with the measurement error explaining only around $12.5 \%$ of it. Going further, the growth rate of GDP is explained by a mix of shocks belonging to its components: markup shocks for exports and imports used in the production of exports, consumption preference shock, marginal efficiency of investment shock. Last but not least, there is some contribution from the permanent technology shock. By investigating the first half of 2020, it can be seen that the drop in GDP associated with the pandemic is associated with negative innovations to the consumption preference shock, and in 2020Q2 also for the permanent technology shock (i.e. a negative shock to the trend) and to a lesser extent for the marginal efficiency of investment and the markup for the imports used in the production of exports shocks.

Figure 9: Historical decomposition (1) Output gap
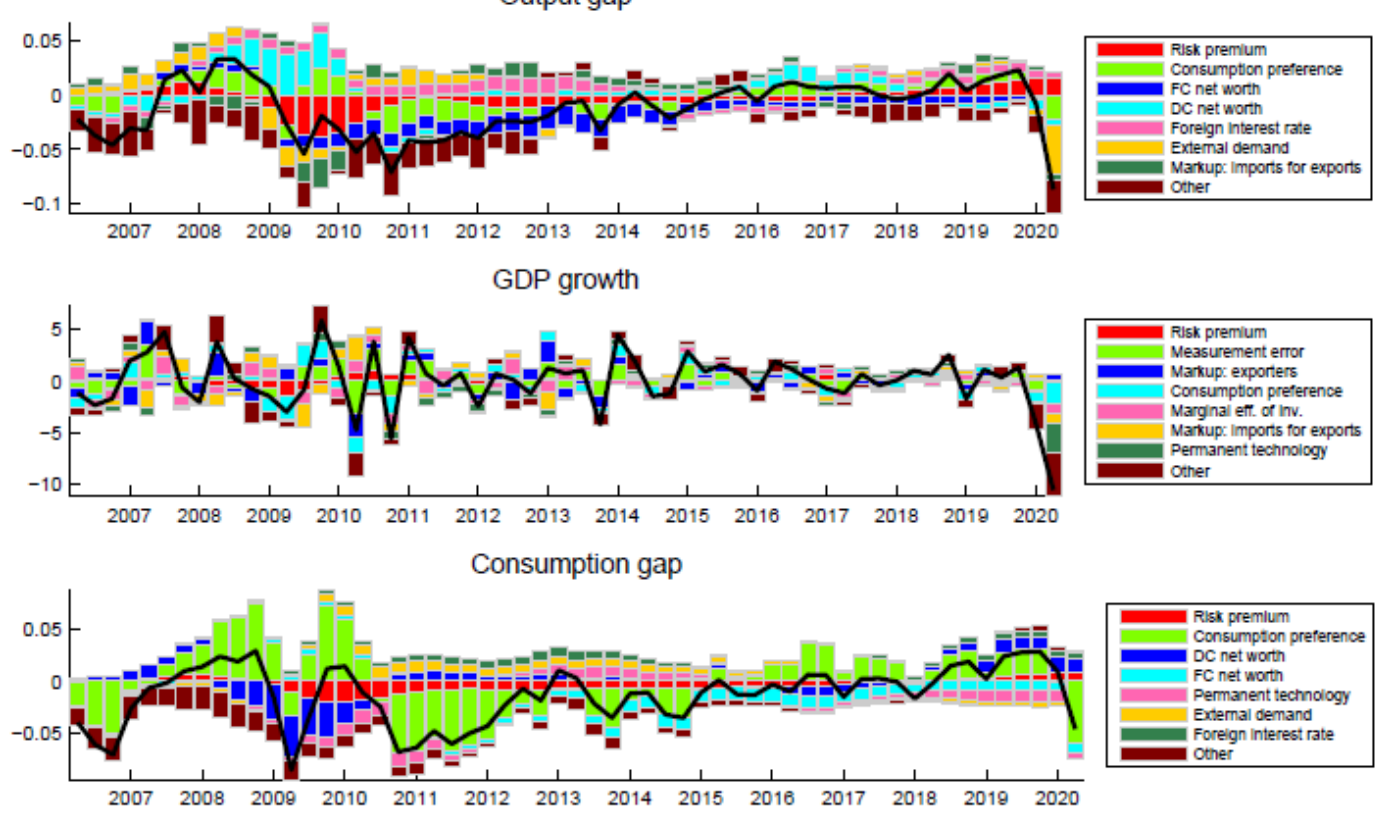

Consumption growth

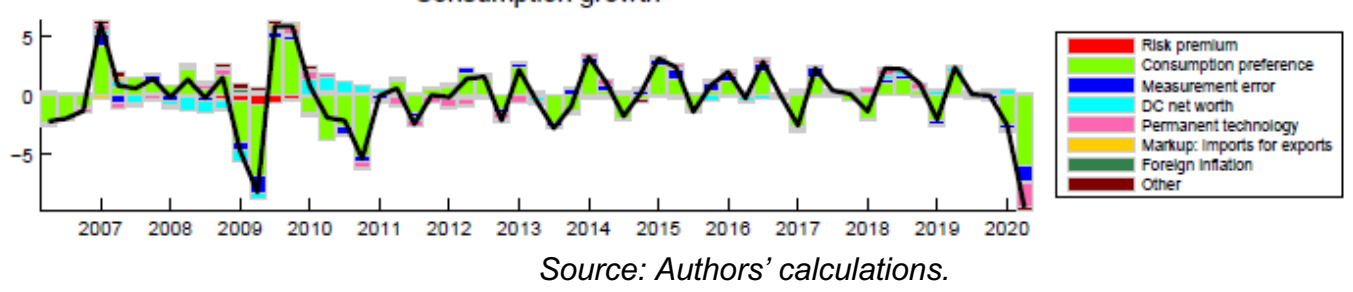

Smoothed deviation of GDP from the corresponding steady state was positive for the mid-2007-end of 2008 period reaching a maximum of about $3.5 \%$, then entered negative territory following the financial crisis onset and remained there for a relatively long period of time, albeit at relatively low values. When the pandemic hit in 2020, the output gap adjusted significantly from values above $2 \%$ at end 2019 to below $-8 \%$ in 2020Q2. In terms of shocks, mostly demand related shocks explain the evolution of the output gap: the consumption preference shock, net worth shocks and external shocks (demand and interest rate ones). As for the latter, as expected, their relevance in an economy with a fixed exchange rate, relative to an economy with a flexible one, is relatively larger. As for the risk premium shock, it had positive contributions until the financial crisis hit and it turned negative afterward for a relatively long period of time, but being compensated more or less by the contribution of the external interest rate shock. The dive of the output gap in negative territory once the pandemic hit is mostly explained 
by the negative contribution of the consumption preference and external demand shocks, while the risk and external interest rate shocks attenuated the fall.

The growth rate of private consumption and its smoothed deviation from the corresponding steady state were driven mostly by the evolution of the consumption preference shock as also confirmed by the variance decomposition analysis. Large negative innovations on the before mentioned shock are also responsible for the evolution of the growth rate of private consumption at the end of our sample, during the beginning of the pandemic period. The contribution of the entrepreneurs net worth shocks reflects for most of the periods in the sample the substitution effect between investments and private consumption.

Moving to investment, as illustrated in figure 10, the higher relative importance of the measurement error in explaining the growth rate of this variable should be noted. This was expected, given its extremely high volatility in the analyzed sample (i.e. almost 7 times more volatile than the GDP growth). As for the structural shocks, both demand (especially net worth shock for entrepreneurs borrowing in domestic currency) and supply ones (marginal efficiency of investment and markup for imported investment goods) were relevant in explaining the dynamics of both the growth rate and the cyclical component. External demand and interest rate shocks were also relatively important, with the former being significant in the pandemic related adjustments.

When it comes to exports, the markup shocks related to both exports and imports used in the production of exports, as well as the foreign demand shock are the ones explaining most of the variation in the growth rate and the cyclical component. The importance of the imports for exports markup shock that affects the corresponding producers' real marginal costs is related to the rather high share of imported inputs in final exported goods (i.e. 50.9\%). The mentioned shocks are also the ones explaining the adjustments at the beginning of the pandemic period.

Figure 10: Historical decomposition (2)
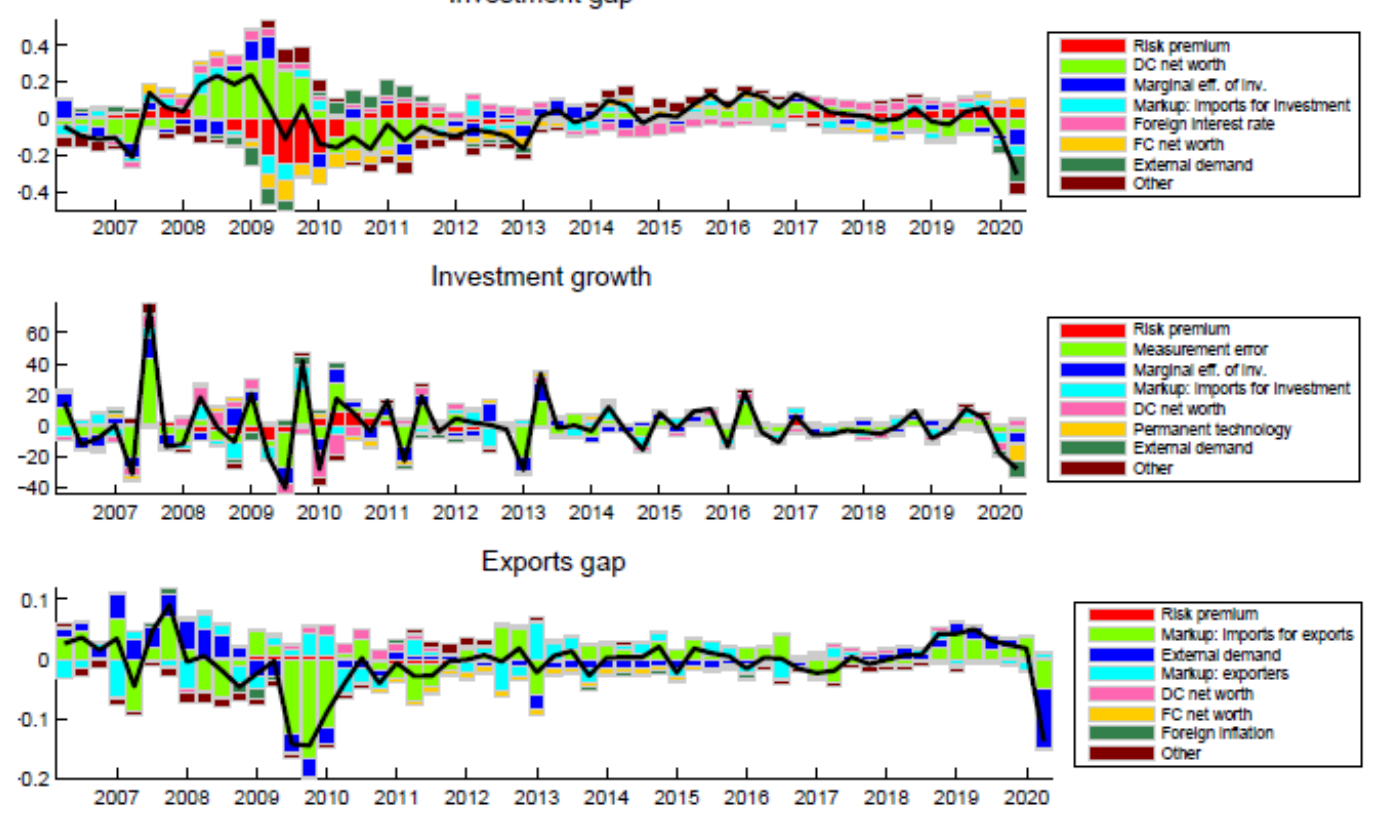

Exports growth

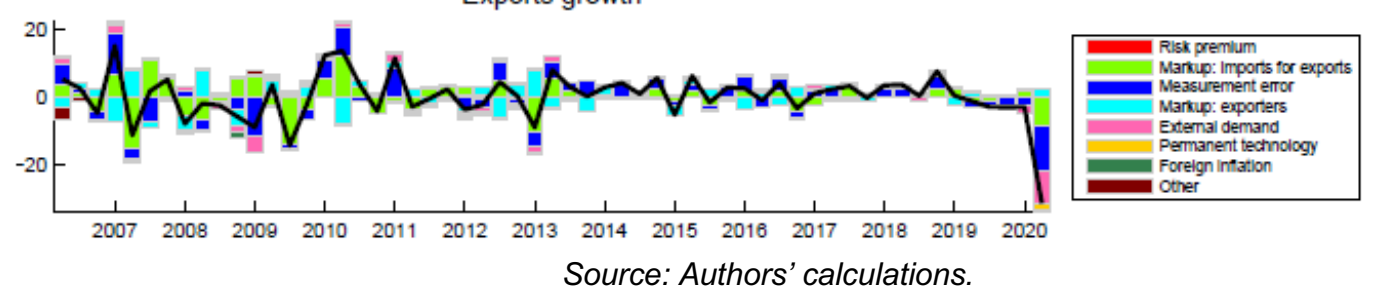


As for real imports, as shown in figure 11, the shocks driving their dynamics are related to their share in the production of final domestic goods. Thus, the importance of investment and exports related shocks, both demand and supply, is relatively higher compared with the consumption related ones. Also the external demand is relatively important in explaining the cyclical component of exports, even more in the case of the downward adjustment at the beginning of the pandemic. Almost the same group of shocks, with a relatively lower contribution of the export sector, is explaining a good part of the net exports to GDP ratio. The positive value from the end of the sample reflects mostly the contribution of the investment and consumption related negative shocks with a negative impact on the demand for imports. The latter mentioned shocks, together with a higher contribution from all the external shocks (demand, inflation and interest rate) explain the deviation from the steady state of the net foreign asset position of the economy that registered mostly positive values until the second part of 2015 , remaining negative afterwards.

Figure 11: Historical decomposition (3)

Imports gap
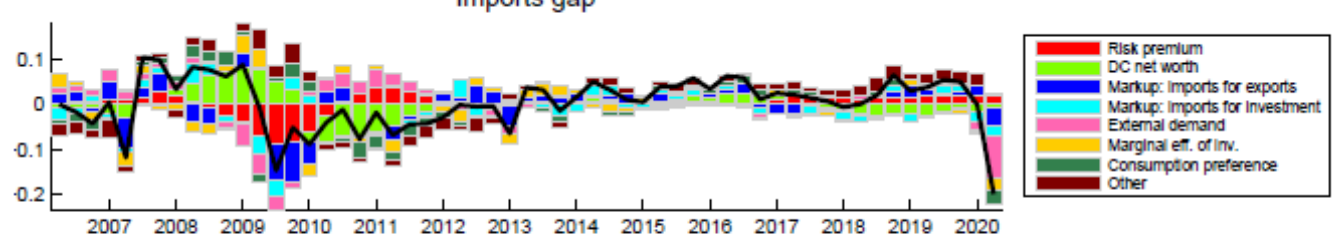

Imports growth
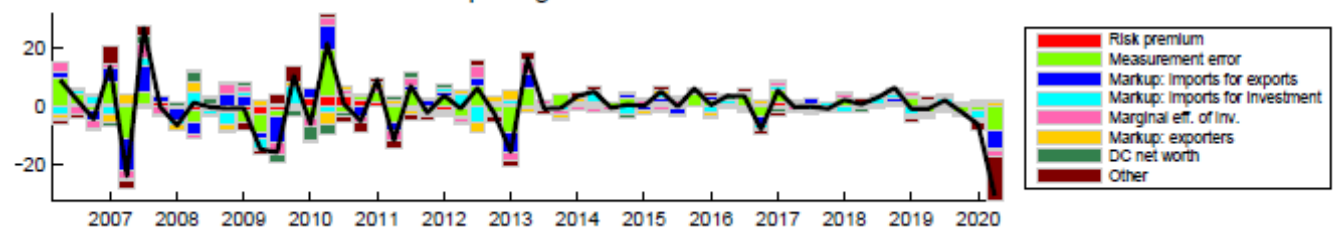

Net exports to GDP
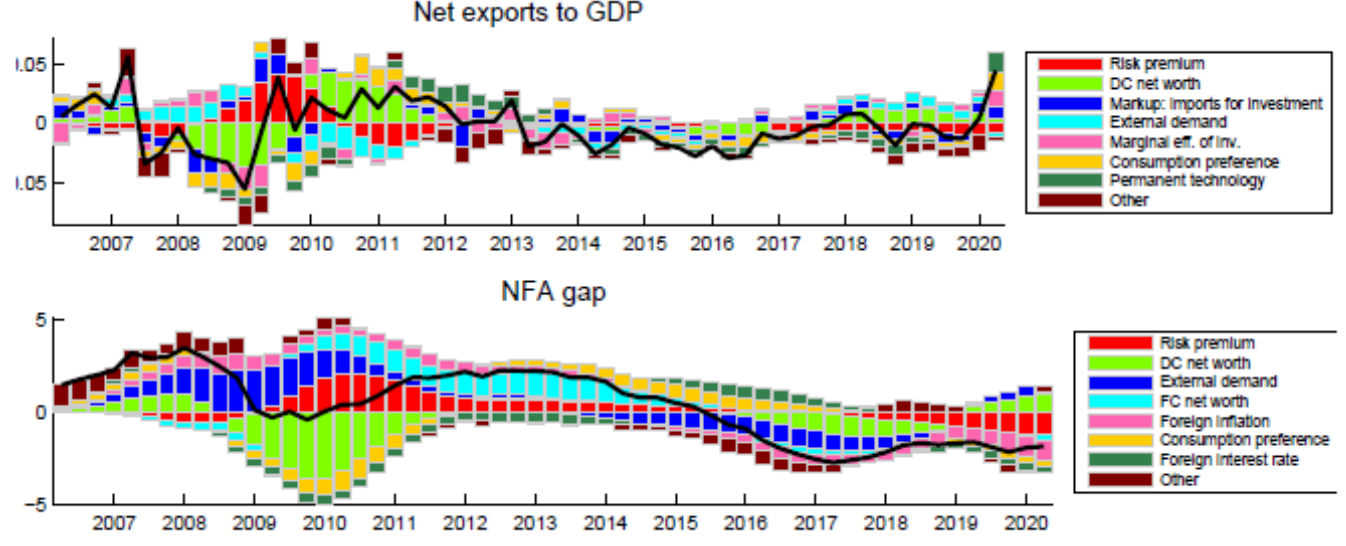

Source: Authors' calculations.

Labor market variables historical decompositions are presented in figure 12. As for the real wage gap, it is evaluated as close to zero, but slightly below for most of the analyzed period. The domestic intermediate good producers' markup shock appears as the most important one, while labor disutility and consumption preferences shocks appear in the households' utility function and show up as determinants as well. There is also a role for the permanent technology shock related to the trend productivity in the economy. The latter, together with its stationary counterpart and the labor disutility shock are the main drivers for the growth rate of nominal wages. The adjustment at the end of the sample for the latter variable is driven by the labor disutility, permanent technology and external demand shocks. With the exception of the consumption preference shock, the observed hours worked and their cyclical component are explained mostly by supply-side shocks: temporary technology, markup and, for the cyclical component, labor disutility. The latter is responsible for the adjustment of the gap in hours into negative territory, following the start of the pandemic. 
Figure 12: Historical decomposition (4)

Real wage gap
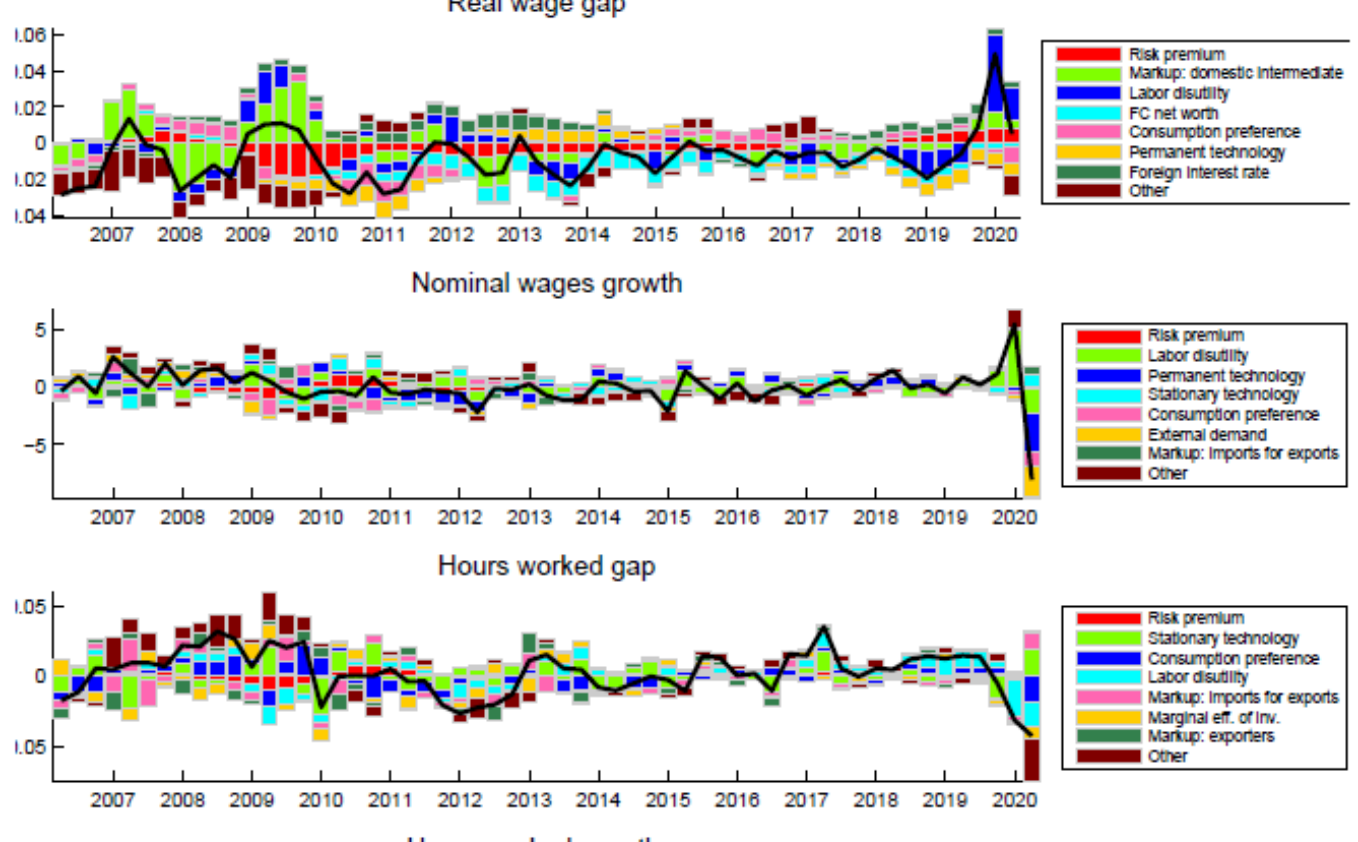

Hours worked growth
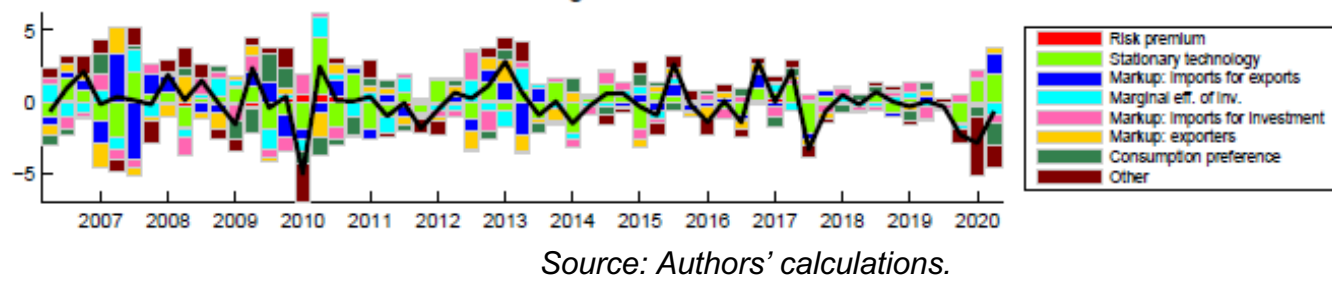

Source: Authors' calculations.

Historical decompositions for interest rate spreads (growth rates and gaps) exchange rate are presented in figure 13. For both domestic and foreign currencies spreads the wealth shocks are relevant. As the entrepreneurs are responsible for investment allocations, the marginal efficiency of investment and markup for imports used in the production of investment goods shocks produce also significant effects. Moreover, given the monetary policy regime in place, the external shocks, mostly inflation and demand related ones, are also important in explaining the evolution of spreads. Last but not least, for the observed spreads growth rates, the measurement error is more important relative to other observed variables, given their relatively much higher volatility. Starting 2010 , after the financial crisis, the gaps for spreads were usually positive albeit having a low magnitude. 
Figure 13: Historical decomposition (5) Domestic currency spread gap
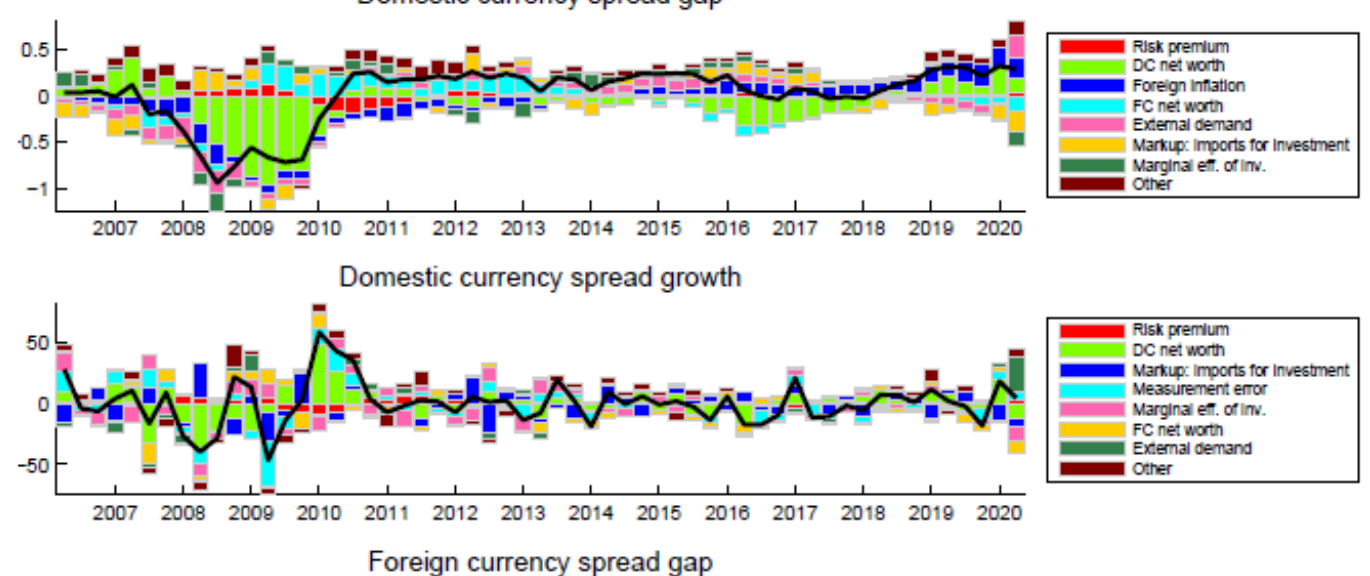

Foreign currency spread gap
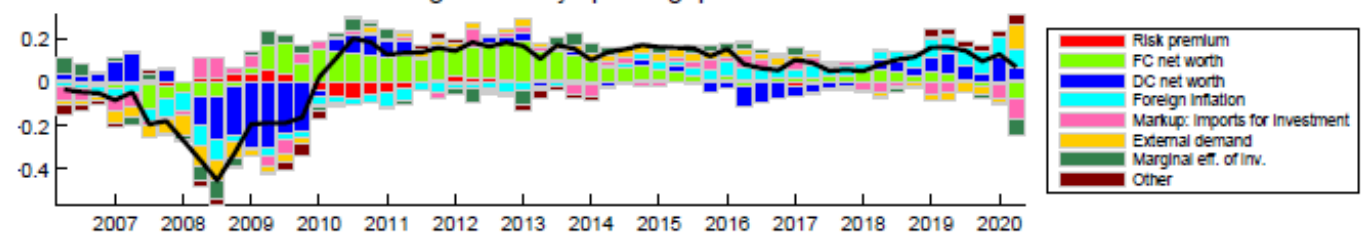

Foreign currency spread growth

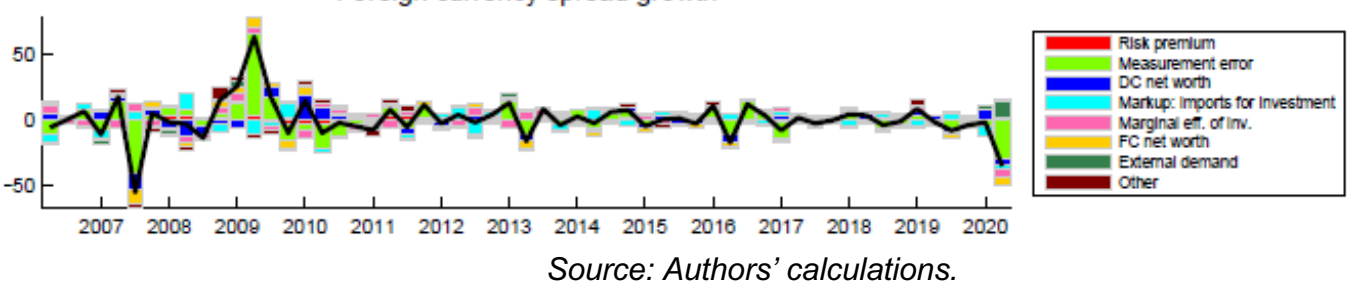

Finally, figure 14 plots the shock decomposition for the GDP deflator, imports deflator and CPI inflation. For all three variables supply-side shocks dominate their evolution, mostly markups related ones. For the GDP deflator the imports and exports markup shock dominate the impact of the markup shock for the domestic intermediate goods. This is a rather expected result, given the monetary regime in place and the relatively high openness degree of the economy. Related to the latter, influence is coming also from the external demand shock. As for the deflator of imports, the markup shocks for imports used in the production of exports and investment goods are the relevant ones, followed by all three external shocks: inflation, demand and interest rate related. A significant influence of the external demand foreign inflation shocks was exerted also on the CPI inflation rate. However, in this case, there is also relevance of the domestic supply shocks: the markup shock for the domestic intermediate goods and the temporary technology shock. Last but not least, the markup shock for imports used in the production of consumption goods had influence over some periods of time. 

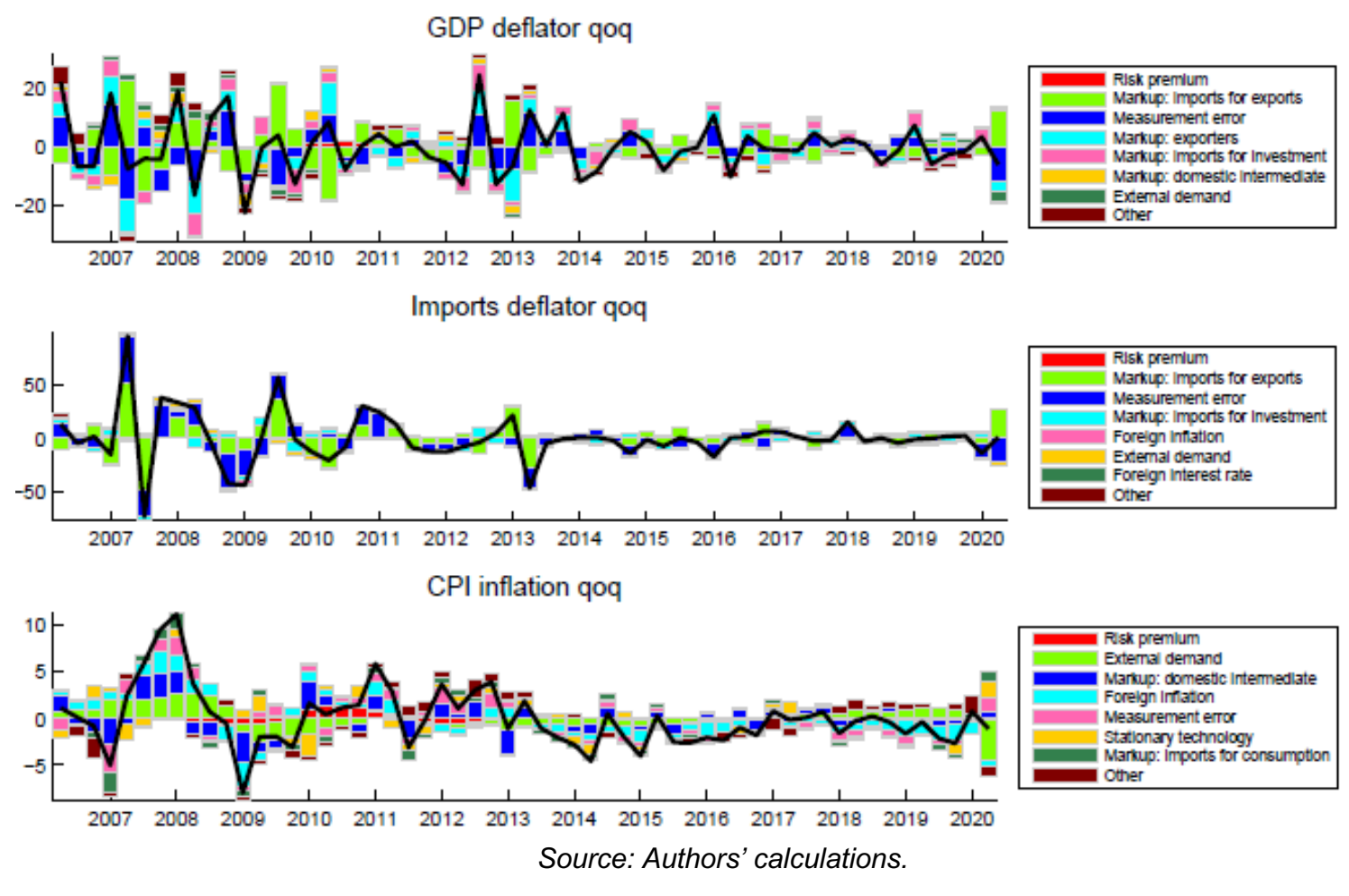

\section{Conclusions and recommendations}

This paper presented the newly developed New-Keynesian small open economy DSGE model for the Macedonian economy. The model is a simplified version of the one described in Copaciu et al. (2015), which was additionally modified to accommodate for the fixed exchange rate regime of the country. The model structure incorporates financial frictions in the spirit of Bernanke et al. (1999) to better understand the role of financial shocks in explaining the macroeconomic fluctuations in the Macedonian economy, an issue that became particularly relevant after the outburst of the global financial crisis. As an additional feature, the model accounts for the existence of partial credit euroization in the economy, as measured by the relatively high share of foreign currency denominated loans, and thus differentiates between two types of entrepreneurs - those borrowing in domestic currency (i.e. Macedonian Denars) and those borrowing in foreign currency (i.e. Euro).

The main structural parameters of the model are estimated using standard Bayesian techniques over the period 2006Q2 to 2020Q2, thus taking into account the immediate impact of the Covid-19 crisis on the economy. The time span of the data was essentially determined by availability and methodological differences regarding certain data series. In the process of estimation, 18 observable variables were used and the endogenous priors' procedure suggested in Christiano et al. (2011) was implemented, for the purpose of better matching the variability in the macroeconomic series. During the estimation of the model we also used as references a set of unobserved variables (i.e. gaps for GDP and GDP components, real exchange rate, potential GDP growth rate and risk premium) that come out from the main quarterly projection model used by the National bank (MAKPAM).

The parameter estimates reflect, given also the endogenous priors procedure applied, the relatively high variability of the observed series. The results indicate that the degree of price stickiness appears to be lower than the one for developed countries, but it is comparable with the one for other emerging countries. However, the estimated stickiness in wages is found to be significantly lower than in domestic prices. We also find that both price and wage inflation are partially indexed to past inflation, but the backward-looking component is more pronounced in the price setting mechanism. In addition, our estimates show that there is a relatively high degree of habit persistence in consumption of 
households, that the labor supply sensitivity to real wages is similar with the estimates obtained in the micro studies and that the investment adjustment costs are small. Regarding the estimated parameters related to the financial sector, we find that the model- implied monitoring costs in the economy are lower when compared with the ones which are proxied by the recovery rates published in the Doing Business Report of the World Bank.

The analysis of impulse response functions indicates responses in line with the economic theory. However, given the monetary policy regime in place, the debt deflation channel is more important relative to the financial accelerator one when compared to the flexible exchange rate case. Moreover, as the cost of funds for both types of entrepreneurs are similar and co-move given the lack of balance sheet effects, there are, in general, no significant differences in terms of net worth evolution across the two types of entrepreneurs. This is the case for example when a shock is applied to the exogenous component of the risk premium, while in an alternative monetary policy regime (e.g. inflation targeting), given the balance sheet effects resulting from implied nominal depreciation of the currency, the effect on the entrepreneurs borrowing in foreign currency will be larger. The evolution of the net foreign assets position, with impact on the risk premium and consequently on the domestic interest rate, reflects both valuation effects and the evolution of the (nominal) net exports under the impact of different shocks.

The estimated model, using the endogenous priors approach, performs relatively well in terms of matching the variability in the data, taking into account all the constraints that were imposed by the number of observed variables, length of the sample, data volatility and the MAKPAM counterparts serving as an exogenous reference. As for the latter, it was found that the DSGE model and MAKPAM offer relative similar evaluations over the common sample for the gaps of GDP and its components. Moreover, the performance is significantly better relative to that resulting from estimating the model without using the endogenous priors procedure.

The variance decomposition results show that the variation in the observed series for GDP and most of its components is explained mainly by supply shocks, with the exception of consumption (where demand shocks account for more than three quarters of this series' variability). With regard to GDP growth, the most important supply shocks are the permanent neutral technology shock (i.e. trend component) and the markup shock of exporters, whereas for investment the marginal efficiency of investment shock. In addition, we find that markup shocks are relatively more relevant for exports and imports. When it comes to prices, markup shocks and foreign shocks seem to account for most of the fluctuations in CPI inflation, the latter being expected given the fixed exchange rate regime. As for the domestic interest rate, the sovereign risk premium has a relevant role, accounting for around a quarter of its variation. Given the monetary policy regime in place, foreign shocks play a substantial role, explaining close to half of domestic interest rate variability. The shocks related to the financial sector appear to be especially important for investment on the real side of the economy, and for the domestic interest rate and interest rate spreads on the financial side, thus highlighting the importance of the financial frictions segment of the model.

Last but not least, a complementary tool employed to evaluate the model refers to the historical shock decomposition analysis that highlights the importance of each structural shock for the observed dynamics of the key macroeconomic variables. The growth rate of GDP is explained by a mix of shocks belonging to its components: markup shocks for exports and imports used in the production of exports, consumption preference shock, and marginal efficiency of investment shock. The drop in GDP associated with the pandemic is associated with negative innovations to the consumption preference shock, and in 2020Q2 also for the permanent technology shock (i.e. a negative shock to the trend) and to a lesser extent for the marginal efficiency of investment and the markup for the imports used in the production of exports shocks. The results suggest that demand side shocks are the main driving force of the output gap dynamics during the analyzed period. Specifically, besides the consumption preference shock and external related ones, shocks originating in the financial sector also proved to be very important factor in explaining business cycle fluctuations in the Macedonian economy. As for the risk premium shock, it had positive contributions until the financial crisis hit and it turned negative afterward for a relatively long period of time, but being compensated more or less by the contribution of the external interest rate shock. The dive of the output gap in negative territory once the pandemic hit is mostly explained by the negative contribution of the consumption preference and external 
demand shocks, while the risk and external interest rate shocks attenuated the fall. The analysis shows that demand side (preference) shocks are the key driver of private consumption dynamics, whereas both demand (especially financial sector related ones) and supply shocks contributed importantly to the developments of investment. The path of export and import demand is determined mostly by exports and investment related shocks, with the external demand shock also being relatively important, as expected given the high degree of openness of the Macedonian economy. Financial sector related shocks appear to be also relevant for the net foreign asset position of the country as well as for the interest rate spreads, together with the foreign related ones, given the monetary policy regime in place. The evolution of $\mathrm{CPI}$ inflation over the studied period is mostly explained by external shocks (i.e. foreign demand and foreign inflation) and domestic supply shocks, the former being the main reason behind the observed deceleration of prices at the onset of the pandemic crisis.

Given the monetary policy regime in place, with monetary policy interest rate not answering to domestic variables other than the sovereign risk premium, the direct impact of monetary policy on the domestic variables is limited. This is the case also for the euroization degree that is relatively unchanged, as both firms that borrow in domestic and foreign currency are affected in a rather similar manner.

The developed DSGE model can be used for regular analysis and forecasting, trying to identify the nature of shocks that affect the domestic variables. The model also represents a complementary evaluation tool to the MAKPAM, so it can be used to assess the cyclical stance of the economy as a support for eventual measures. At a next stage, the model can be enriched to assess the impact of macro-prudential measures on the economy.

The net foreign assets position of the economy is especially relevant. Although not necessarily related to monetary policy, measures to improve the current account position are desirable, especially those that aim at improving the net exports capacity of the country. This is even more the case as shocks originating in the exports and imports sector are extremely relevant for the macroeconomic variables, GDP included.

The bankruptcy rates in the economy/sectors should be closely monitored, as their effect on the economy, banking sector included is important. Banks should properly analyze the companies before issuing loans to them and ensure that provisions are in place when negative signals arise.

Given that lower euroization is desirable, additional macro prudential measures aimed at discouraging it can be implemented. Usually, measures targeting the demand side proved to be more efficient in the case of other developing economies. Moreover, encouraging foreign currency loans only towards hedged borrowers is advisable. In the case of Romania, a substantial decrease in the credit euroization was obtained when government subsidized programs (e.g. to buy the first house) allowed only loans in domestic currency. Last but not least, differentiated minimum reserve requirements based on the currency denomination of the loans can be maintained, while taking into account the potential increase of costs on consumers' side.

\section{References}

Adolfson, M., Laseen S., Linde J., and Villani M. (2007), "Bayesian estimation of an open economy DSGE model with incomplete pass-through", Journal of International Economics, Vol. 72 No. 2, pp.481-511.

Aghion, P., Bacchetta P., and Banerjee A. (2000), "A simple model of monetary policy and currency crises", European economic review, Vol. 44 No. 4-6, pp.728-738.

Aghion, Philippe, P. B. and Banerjee A. (2001), "Currency crises and monetary policy in an economy with credit constraints", European economic review, Vol. 45 No. 7, pp.1121-1150.

Ajevskis, V. and Vitola K. (2011), "Housing and Banking in a Small Open Economy DSGE Model", Working Papers 3/2011, Latvijas Banka. 
Andres, J. and Arce O. (2012), "Banking competition, housing prices and macroeconomic stability", The Economic Journal, pp.1346-1372.

Argov, E., Barnea E., Binyamini A., Borenstein E., Elkayam D., and Rozenshtrom I. (2012), "MOISE: A DSGE Model for the Israeli Economy", Discussion Paper 2012.06, Bank of Israel.

Basso, H. S., Calvo-Gonzalez O., and Jurgilas M. (2007), "Financial dollarization, the role of banks and interest rates", ECB Working Paper, European Central Bank.

Beckmann, E. and Stix H. (2015), "Foreign currency borrowing and knowledge about exchange rate risk", Journal of Economic Behavior \& Organization, Vol. 112, pp.1-16.

Berganza, J. C., Chang R., and Herrero A. G. (2004), "Balance sheet effects and the country risk premium: an empirical investigation," Review of World Economics, Vol. 140 No. 4, pp.592-612.

Bernanke, B. S., Gertler M., and Gilchrist S. (1999), "The financial accelerator in a quantitative business cycle framework", Taylor J. B. and Woodford M. (Ed.s), Handbook of Macroeconomics, Elsevier, New York, Vol. 1, Chap. 21, pp.1341-1393.

Bogoev, J. (2016), "What drives bank lending in domestic and foreign currency loans in a small open transition economy with fixed exchange rate? The case of Macedonia", Brada J. C. and Wachtel P. (Ed.s), Global Banking Crises and Emerging Markets, Palgrave Macmillan, London, pp.175-200.

Brown, M. and de Haas R. (2012), "Foreign banks and foreign currency lending in emerging Europe", Economic Policy, Vol.27 No.69, pp.57-98.

Brown, M. and Stix H. (2015), "The euroization of bank deposits in Eastern Europe", Economic Policy, Vol. 30 No. 81, pp.95-139.

Bussiere, M., Callegari G., Ghironi F., Sestieri G., and Yamano N. (2011), "Estimating Trade Elasticities: Demand Composition and the Trade Collapse of 2008-09", NBER Working Papers 17712, National Bureau of Economic Research.

Castillo, P., Montoro C., and Tuesta V. (2006), "An estimated stochastic general equilibrium model with partial dollarization: a Bayesian approach", Documentos de Trabajo 381, Banco Central de Chile.

Christensen, I. and Dib A. (2008), "The financial accelerator in an estimated New Keynesian model", Review of economic dynamics, Vol. 11 No. 1, pp.155-178.

Christiano, L. J., Gust C., and Roldos J. (2004), "Monetary policy in a financial crisis", Journal of Economic theory, Vol. 119 No. 1, pp.64-103.

Christiano, L. J., Trabandt M., and Walentin K. (2011), "Introducing financial frictions and unemployment into a small open economy model", Journal of Economic Dynamics and Control, Vol. 35, pp.1999-2041.

Copaciu, M., Nalban V., and Bulete C. (2015), "R.E.M. 2.0, An estimated DSGE model for Romania", Dynare Working Papers No. 48, CEPREMAP.

Curdia, V. and Woodford M. (2009), "Conventional and unconventional monetary policy", FRB of New York Staff Report No. 404, Federal Reserve Bank of New York.

Cespedes, L. F., Chang R. and Velasco A. (2004), "Balance sheets and exchange rate policy", American Economic Review, Vol. 94 No. 4, pp.1183-1193.

de Walque, G., Jeanfils P., Lejeune T., Rychalovska Y., and Wouters R. (2017), "An estimated twocountry EA-US model with limited exchange rate pass-through", Working Paper Research 317, National Bank of Belgium.

Djukic, M., Hledik T., Polansky J., Trajcev L. and Vlcek J. (2017), "A DSGE Model with Financial Dollarization - the Case of Serbia", CNB Working paper series, Czech National Bank.

Elekdag, S. and Tchakarov I. (2004), "Balance Sheet Effects, Exchange Rate Policy and Welfare", IMF Working Paper 04/63, International Monetary Fund.

Elekdag, S. A. and Alp H. (2011), "The Role of Monetary Policy in Turkey during the Global Financial Crisis", IMF Working Papers 11/150, International Monetary Fund. 
Erceg, C. J., Henderson D. W., and Levin A. T. (2000), "Optimal monetary policy with staggered wage and price contracts", Journal of monetary Economics, Vol. 46 No. 2, pp.281-313.

Faia, E. (2010), "Financial frictions and the choice of exchange rate regimes", Economic Inquiry, Vol. 48, No. 4, pp.965-982.

Gali, J., Smets F., and Wouters R. (2011), "Unemployment in an Estimated New Keynesian Model", NBER Working Paper 17084, National Bureau of Economic Research.

Gerali, A., Neri S., Sessa, L. and Signoretti F. M. (2010), "Credit and Banking in a DSGE Model of the Euro Area", Journal of money, Credit and Banking, No. 42, pp.107-141.

Gertler, M. and Karadi P. (2009), "A model of unconventional monetary policy", New York University Working Paper, New York University.

Gertler, M. and Kiyotaki N. (2010), "Financial intermediation and credit policy in business cycle analysis", Handbook of monetary economics, Vol. 3, pp.547-599.

Gertler, M., Sala L., and Trigari A. (2008), "An Estimated Monetary DSGE Model with Unemployment and Staggered Nominal Wage Bargaining", Journal of Money, Credit and Banking, Vol. 40 No. 8, pp.1713-1764.

Gertler, M., Gilchrist S. and Natalucci F. M. (2007), "External constraints on monetary policy and the financial accelerator", Journal of Money, Credit and Banking, Vol. 39 No. 2-3, pp.295-330.

Goodfriend, M. and McCallum B. T. (2007), "Banking and interest rates in monetary policy analysis: A quantitative exploration", Journal of Monetary Economics, Vol. 54 No. 5, pp.1480-1507.

Grabek, G., Klos B., and Koloch G. (2011), "SOEPL 2009 - An Estimated Dynamic Stochastic General Equilibrium Model for Policy Analysis And Forecasting," Working Paper 83, National Bank of Poland.

Haiss, P. R. and Rainer W. (2012), "Credit Euroization in Eastern Europe: The 'Foreign Funds' Channel at Work", Comparative Economic Studies, Vol. 54 No. 3, pp.471-505.

Hlousek, M. (2016), "An Estimated DSGE Model with a Housing Sector for the Czech Economy", Statistika, Vol. 93 No. 4, pp.37-55.

lacoviello, M. (2005), "House prices, borrowing constraints, and monetary policy in the business cycle", American economic review, Vol. 95 No. 3, pp.739-764.

lacoviello, M. (2015), "Financial business cycles", Review of Economic Dynamics, Vol.18 No.1, pp.140-163.

Iradian, G. (2007), "Rapid Growth in Transition Economies: Growth-Accounting Approach", IMF Working Papers 2007/164, International Monetary Fund.

Jakab, Z. and Vilagi B. (2008), "An estimated DSGE model of the Hungarian economy", MNB Working Papers 2008/9, Magyar Nemzeti Bank.

Jovanovic, B. and Kabashi R. (2011), "Potencijalen proizvod I proizvoden jaz za Makedonija spored nekolku metodi na presmetka", NBRM Working paper series, National Bank of the Republic of Macedonia.

Jovanovski, K. (2015), "Determinants of credit euroization in CESEE countries", in BozinovskaLazarevska Z. (Ed.) Annual of the Faculty of Economics - Skopje, Faculty of Economics - Skopje, pp.159-176.

Justiniano, A., Primiceri G. E. and Tambalotti A. (2011), "Investment shocks and the relative price of investment", Review of Economic Dynamics, Vol. 14 No. 1, pp.102-121.

Kiyotaki, N. and Moore J. (1997), "Credit cycles", Journal of political economy, Vol. 105 No. 2, pp.211248.

Kolasa, M. and Lombardo G. (2011), "Financial frictions and optimal monetary policy in an open economy", NBP Working Paper No.91, National Bank of Poland.

Krugman, P. (1999), "Balance sheets, the transfer problem, and financial crises", International finance and financial crises, pp.31-55. 
Kustrin, A. (2019), "A DSGE Model for the Slovenian Economy: Model Estimates and application", Economic and Business Review, Vol. 21 No. 2, pp.143-212.

Luca, A. and Petrova I. (2008), "What drives credit dollarization in transition economies?", Journal of banking \& finance, Vol. 32 No. 5, pp.858-869.

Minella, A., de Castro M. R., Souza-Sobrinho N. F., Santos R. C. and de Gouvea S. N. (2011), "SAMBA: Stochastic Analytical Model with a Bayesian Approach", Brazilian Review of Econometrics, Vol. 35 No. 2.

Nikolov, K., Suarez J., Supera D., Mendicino C. (2017), "Optimal Dynamic Capital Requirements", in 2017 Meeting Papers 1216, Society for Economic Dynamics.

Papai, A. (2017), "A DSGE Model of Slovakia with Frictional Labor Market and Monetary Regime Switch", Review of Economic Perspectives, Vol.17 No.3, pp.287-313.

Pedersen, J. (2016), "An Estimated DSGE model for Denmark with Housing, Banking, and Financial Frictions”, Danmarks Nationalbank's Working Papers No. 108, Danmarks Nationalbank.

Pencavel, J. (1987), "Labor supply of men: A survey", Ashenfelter O. and Layard R. (Ed.s), Handbook of Labor Economics, Elsevier, New York, Vol. 1, Chap. 1, pp.3-102.

Petkovska, B. (2008), "Estimation of the investment function for the Republic of Macedonia", Working Papers 2008-04, National Bank of the Republic of Macedonia.

Ramadani, G. and Naumovski N. (2015), "Wage and Price Setting in Macedonia: Evidence from Survey Data", NBRM Research Paper, National Bank of the Republic of Macedonia.

Scheiber, T. and Worz J. (2018), "How are reduced interest rate differentials affecting euroization in Southeastern Europe? Evidence from the OeNB Euro Survey", Focus on European Economic Integration, Vol. 1, pp.48-60.

Schmitt-Grohe, S. and Uribe M. (2003), "Closing small open economy models", Journal of international Economics, Vol. 61 No. 1, pp.163-185.

Schneider, M. and Tornell A. (2004), "Balance sheet effects, bailout guarantees and financial crises", The Review of Economic Studies, Vol. 71 No. 3, pp.883-913.

Smets, F. and Wouters R. (2007), "Shocks and frictions in US business cycles: A Bayesian DSGE approach", American economic review, Vol. 97 No. 3, pp.586-606.

Urosevic, B. and Grga N. (2014), "Application of dynamic stochastic general equilibrium models to the case of the Serbian economy”, Economic Annals, Vol. 59 No. 201, pp.35-68.

\section{Appendix A}

\section{A.1 Estimated external sector parameters}

The estimated parameters and standard deviations of the shocks are presented in table 8 below. One can observe that the posterior values of the estimated parameters and standard deviations are close to the prior ones. This is the result of first estimating the exogenous external sector model outside the main model. In this step, similar with the main model, we use the endogenous priors procedure as proposed by Christiano et al. (2011). Then, when estimating the entire model, we set up priors for the external sectors close to the values obtained when estimated separately.

Table 8 External sector: estimated parameters and standard deviations

\begin{tabular}{lccccccc}
\hline \multirow{2}{*}{ Parameter Description } & \multicolumn{3}{c}{ Prior } & \multicolumn{3}{c}{ Posterior } \\
\cline { 2 - 6 } & Distr. & Mean & s.d/df & Mean & s.d. & $\mathbf{1 0 \%}$ & $\mathbf{9 0 \%}$ \\
\hline Foreign effective aggregate demand curve & & & & & & & \\
\hline is $\mathrm{bl}_{\mathrm{l}} \quad$ Backward looking parameter & $\beta$ & 0.45 & 0.01 & 0.444 & 0.008 & 0.429 & 0.458
\end{tabular}




\begin{tabular}{lllllllll}
$\mathrm{is}_{\mathrm{r}} \quad$ Real interest rate & $\Gamma$ & 0.04 & 0.005 & 0.038 & 0.004 & 0.031 & 0.046 \\
\hline Foreign Phillips curve & & & & & & & \\
\hline $\mathrm{pc}$ bl & Backward looking parameter & $\beta$ & 0.35 & 0.010 & 0.351 & 0.007 & 0.334 & 0.367 \\
$\mathrm{pc}_{\mathrm{mc}} \quad$ Marginal cost & $\Gamma$ & 0.026 & 0.005 & 0.025 & 0.004 & 0.019 & 0.032 \\
\hline Foreign Taylor rule & & & & & & & & \\
\hline $\operatorname{tr}_{\mathrm{bl}} \quad$ Backward looking parameter & $\beta$ & 0.9 & 0.02 & 0.892 & 0.008 & 0.879 & 0.906 \\
$\operatorname{tr}_{\mathrm{y}} \quad$ Output gap & $\Gamma$ & 0.04 & 0.01 & 0.039 & 0.008 & 0.024 & 0.055 \\
$\operatorname{tr}_{\pi} \quad$ Inflation & $\Gamma$ & 1.65 & 0.02 & 1.651 & 0.016 & 1.617 & 1.684 \\
\hline Standard deviations & & & & & & & & \\
\hline$\sigma_{\mathrm{y}^{*}} \quad$ Output, foreign & Inv- $\Gamma$ & 1 & 2 & 0.837 & 0.065 & 0.741 & 0.934 \\
$\sigma_{\pi^{*}} \quad$ Inflation, foreign & Inv- $\Gamma$ & 0.3 & 2 & 0.338 & 0.025 & 0.293 & 0.383 \\
$\sigma_{\mathrm{R}^{*}} \quad$ Monetary policy, foreign & Inv- $\Gamma$ & 0.5 & 2 & 0.641 & 0.129 & 0.432 & 0.845 \\
\hline
\end{tabular}

Source: Authors' calculations

\section{A.2 Impulse response functions}

Figure 15: IRFs to the unit root neutral technology shock
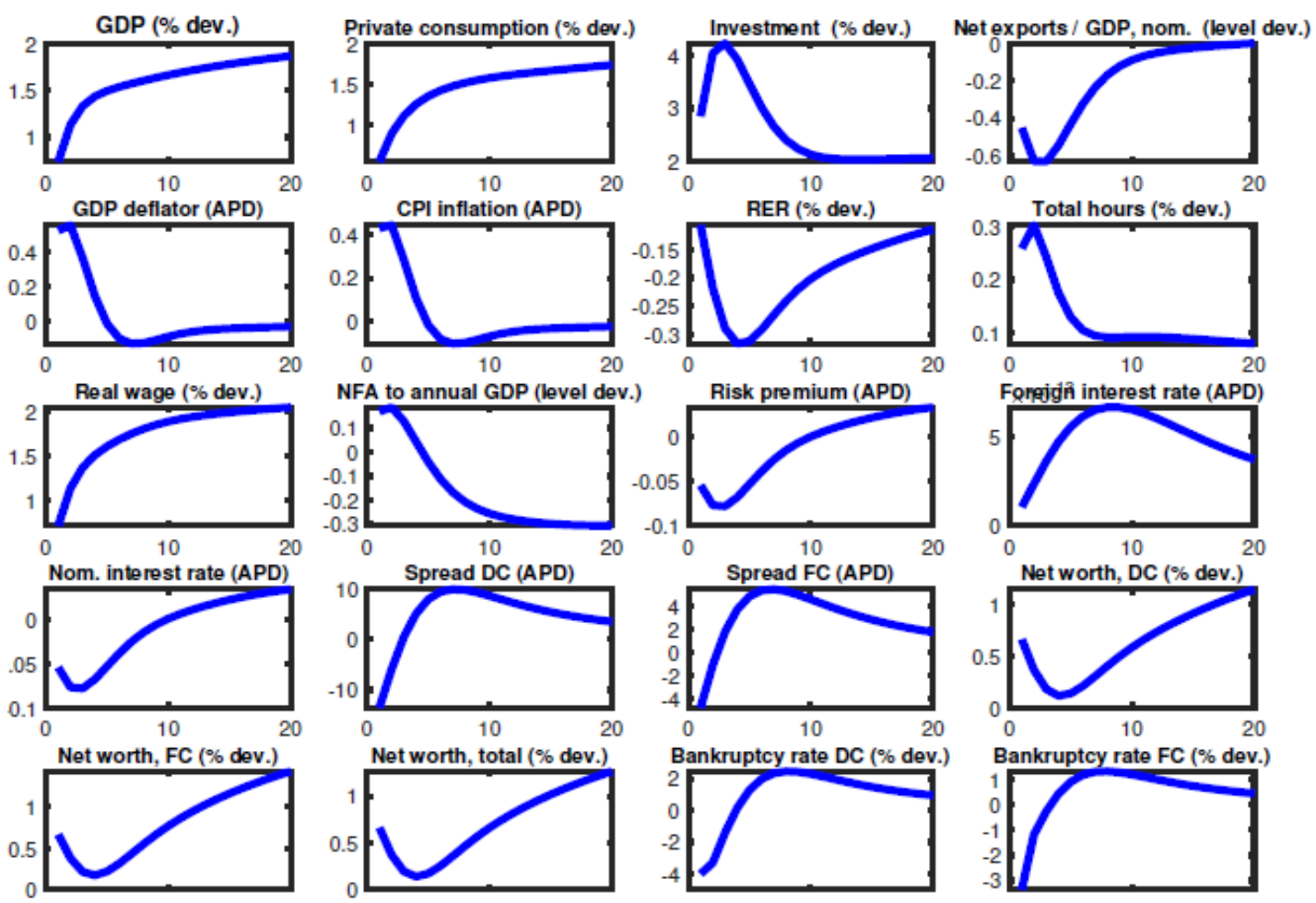

Source: Authors' calculations.

Figure 16: IRFs to the marginal efficiency of investment shock 

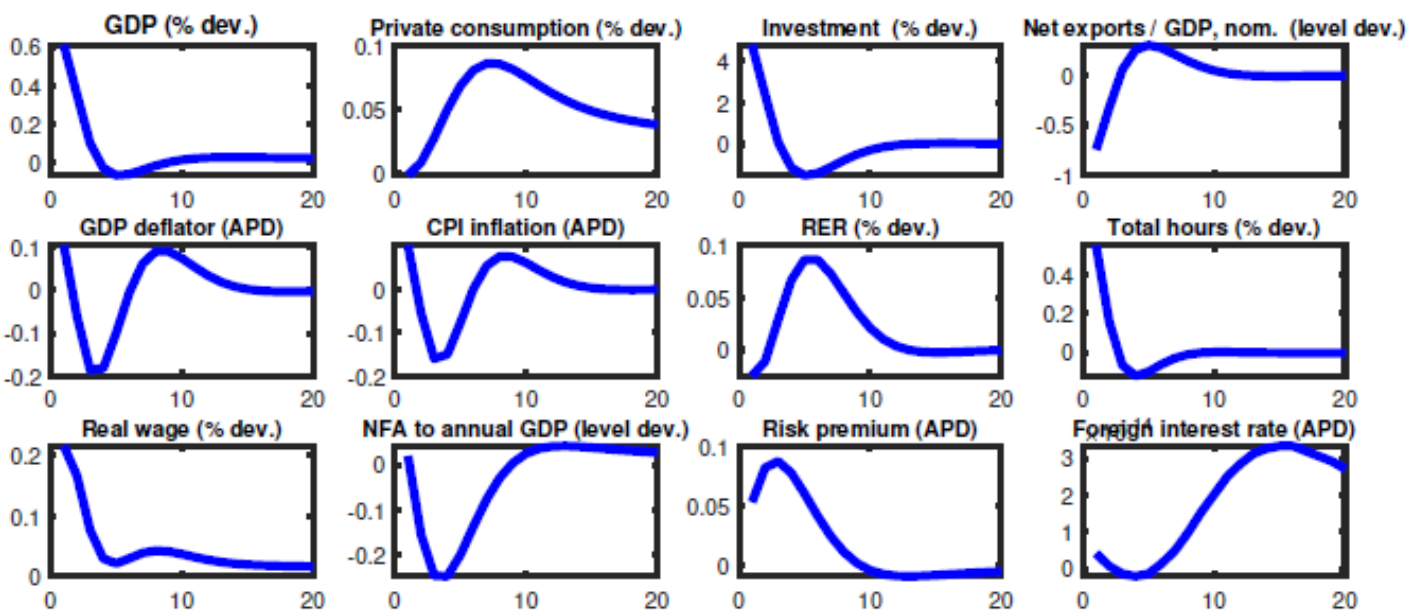

Foreight interest rate (APD)
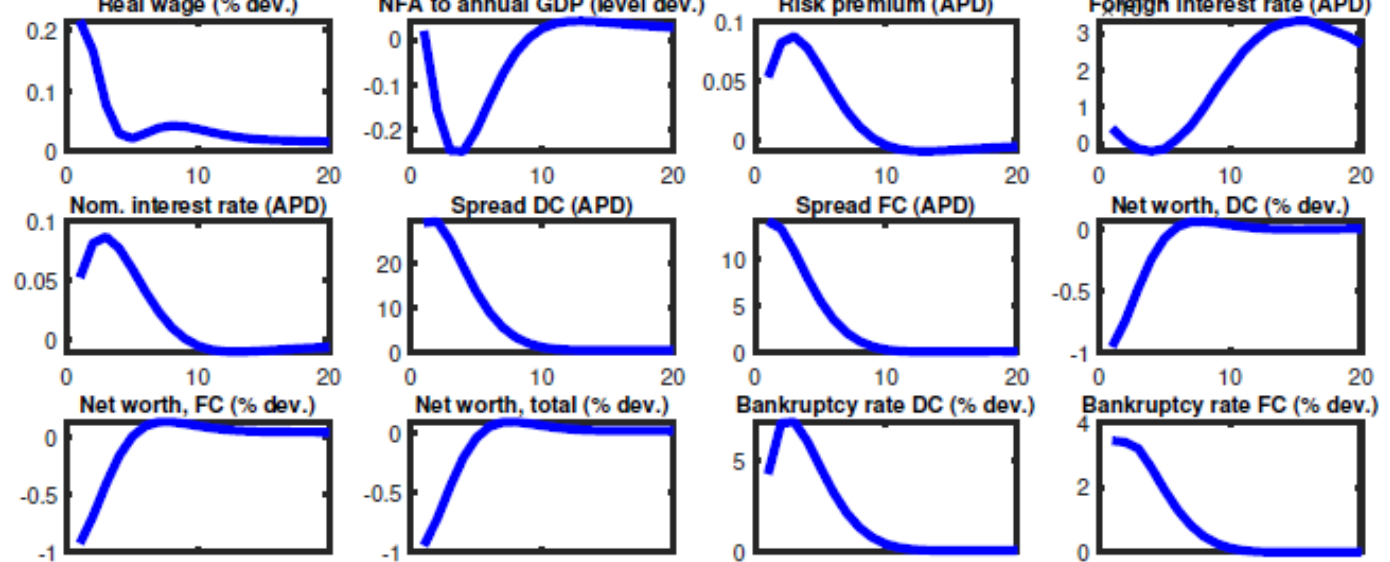

Source: Authors' calculations.

Figure 17: IRFs to the labor disutility shock
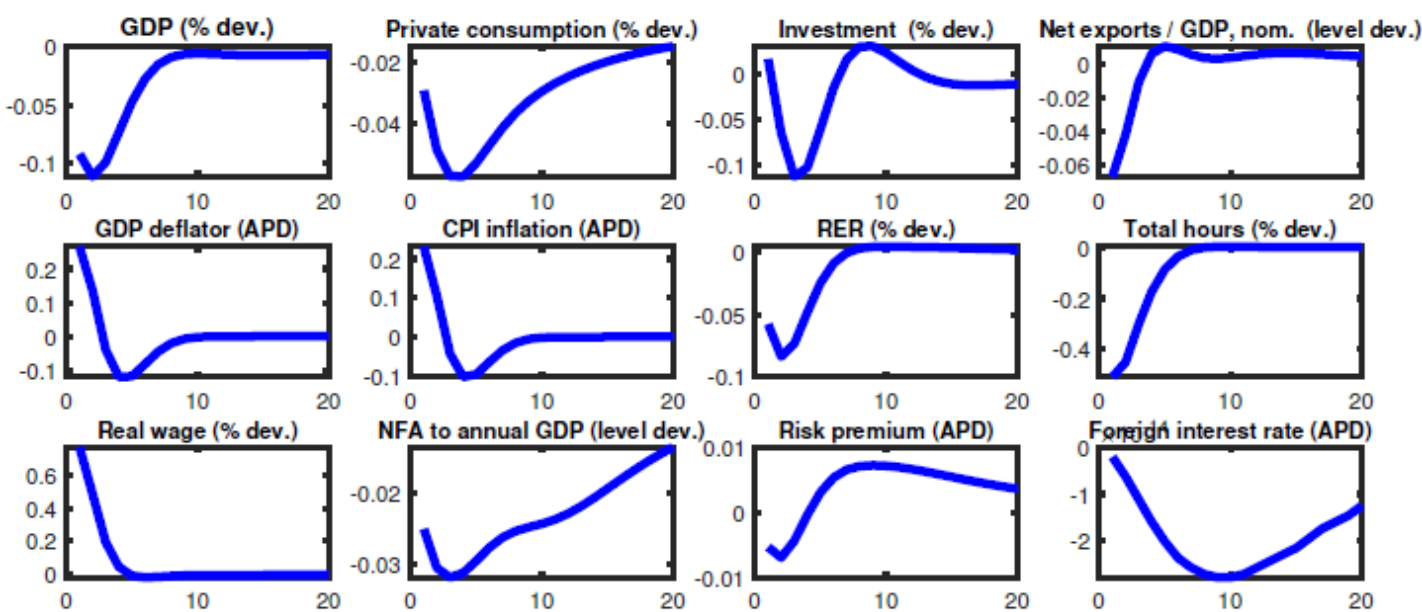

NFA to annual GDP (level dev
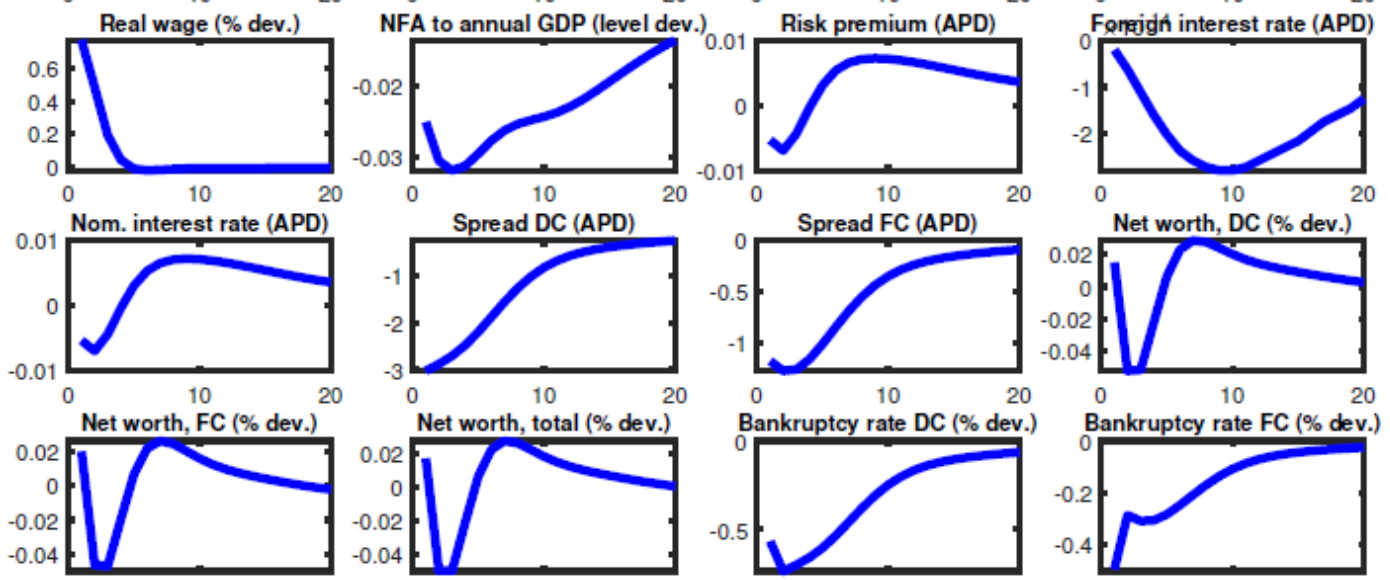

Source: Authors' calculations.

Figure 18: IRFs to the FC entrepreneurial net worth shock 

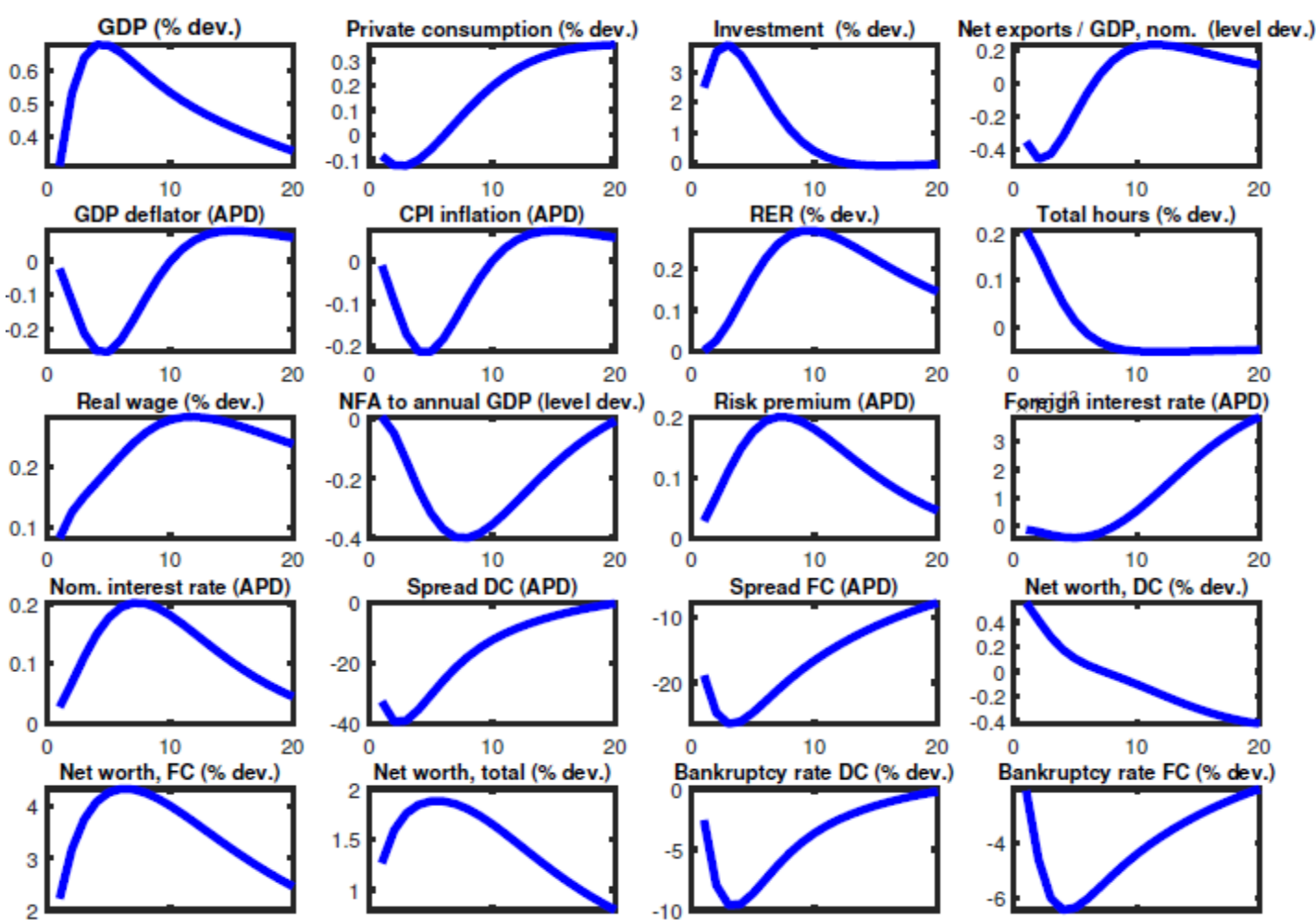

Source: Authors' calculations.

Figure 19: IRFs to the domestic products markup shock
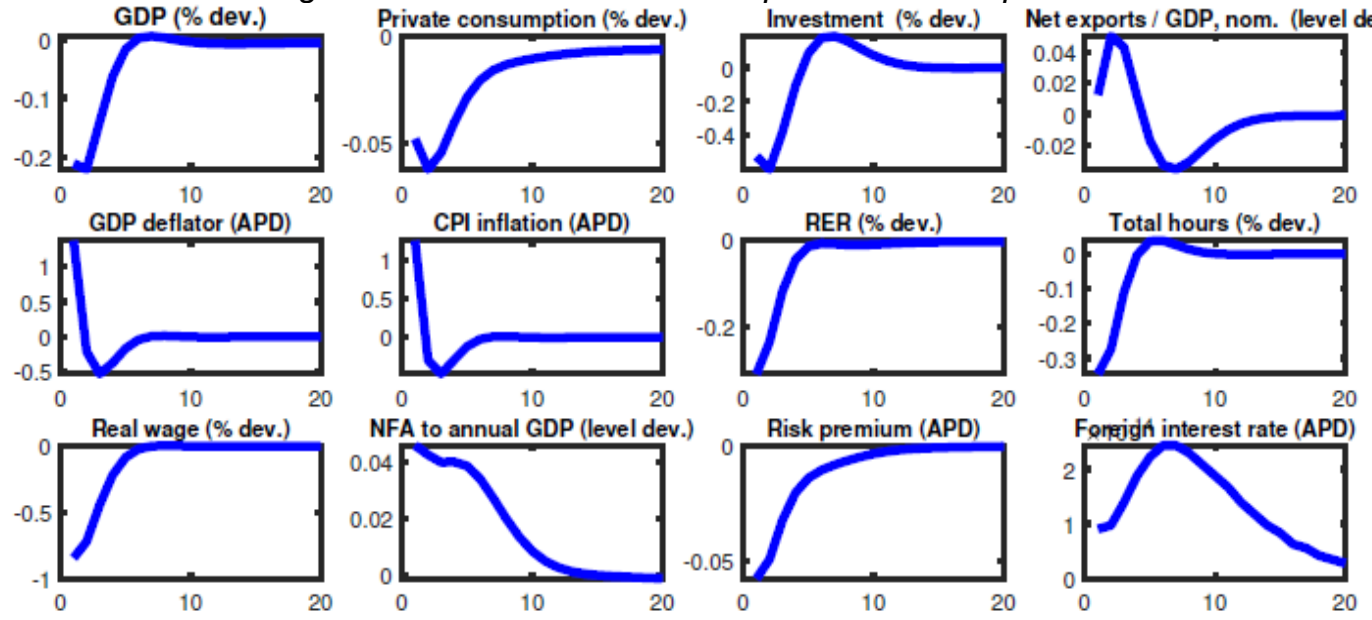

NFA to annual GDP (level dev.)

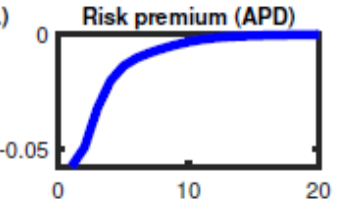

Fonejigh interest rate (APD)
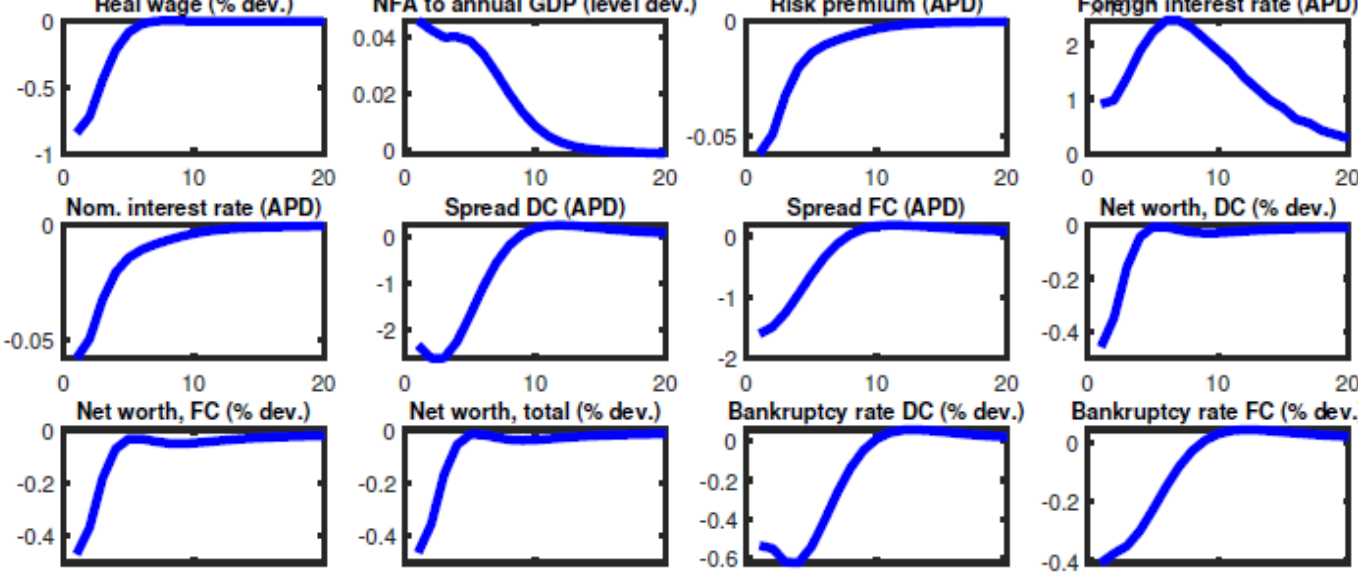

Source: Authors' calculations.

Figure 20: IRFs to the exports markup shock

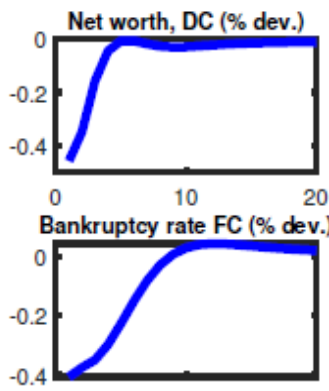


GDP (\% dev.)

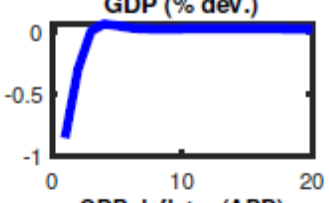

GDP deflator (APD)

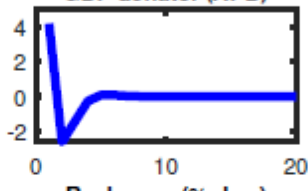

Real wage $(\%$ dev. $)$

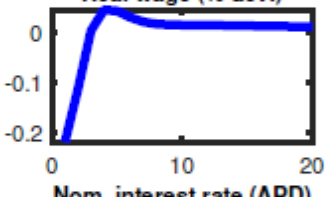

Nom. interest rate (APD)
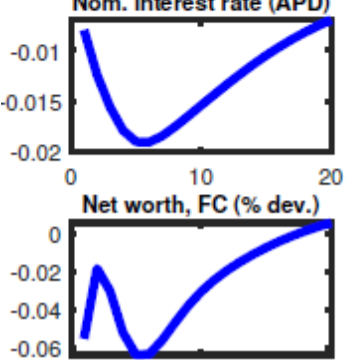
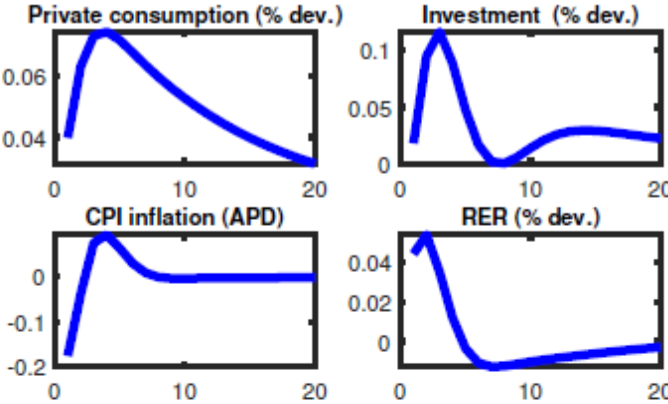

NFA to annual GDP (level dev.)
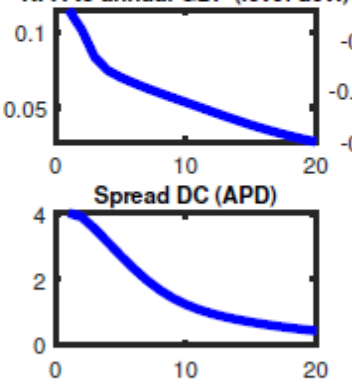

Net worth, total (\% dev.)

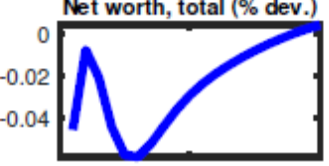

RER (\% dev.)
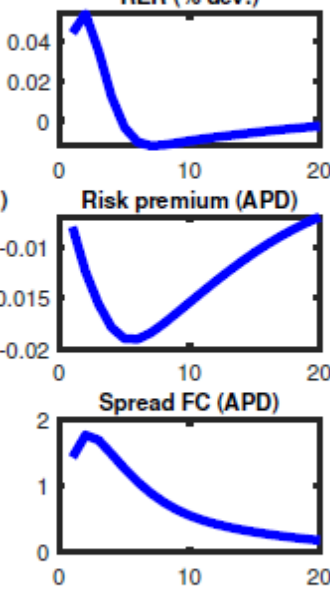

Bankruptcy rate DC (\% dev.)

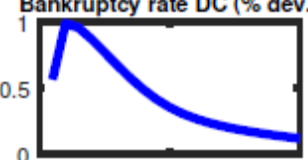

Source: Authors' calculations.
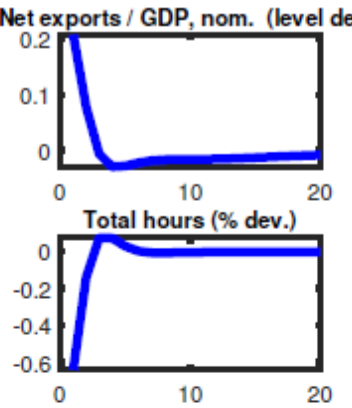

Foreight interest rate (APD)
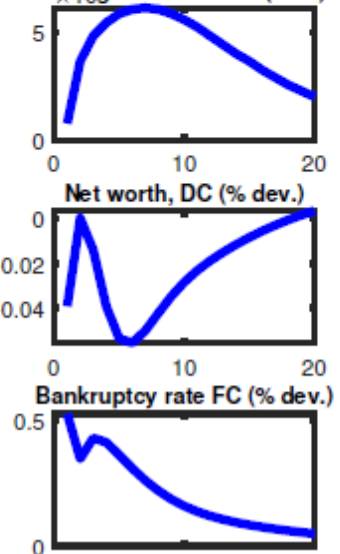

Figure 21: IRFs to the imported consumption markup shock
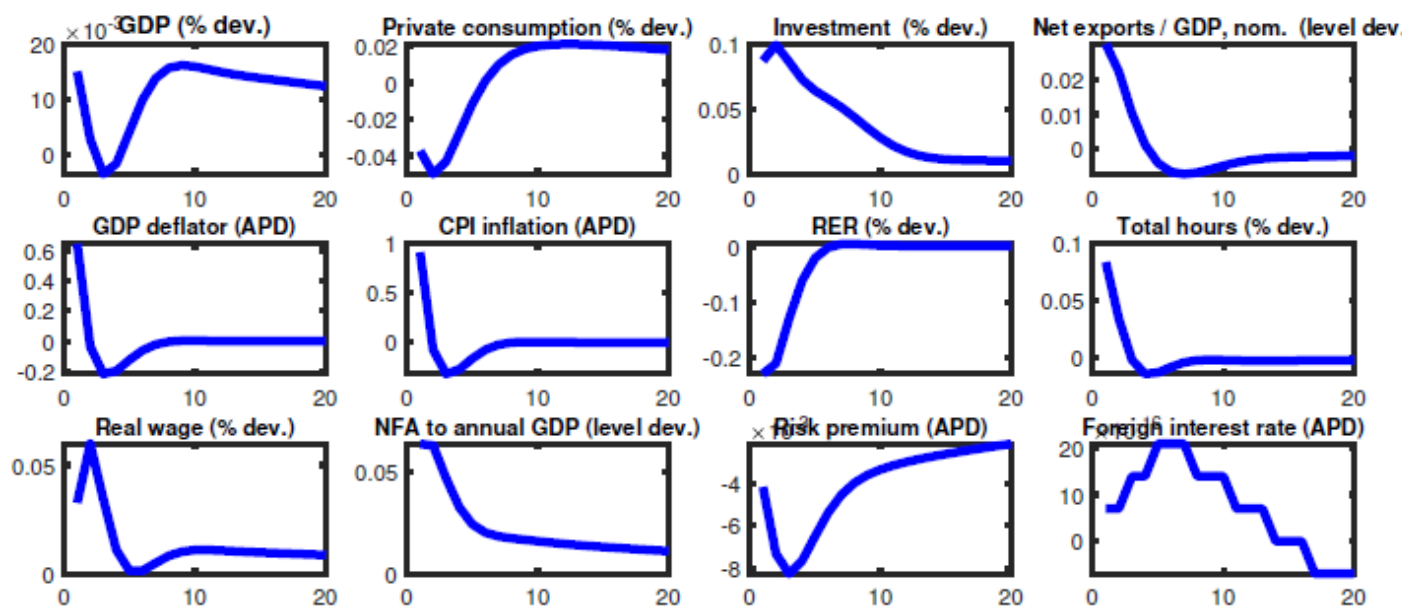

NFA to annual GDP (level dev.)
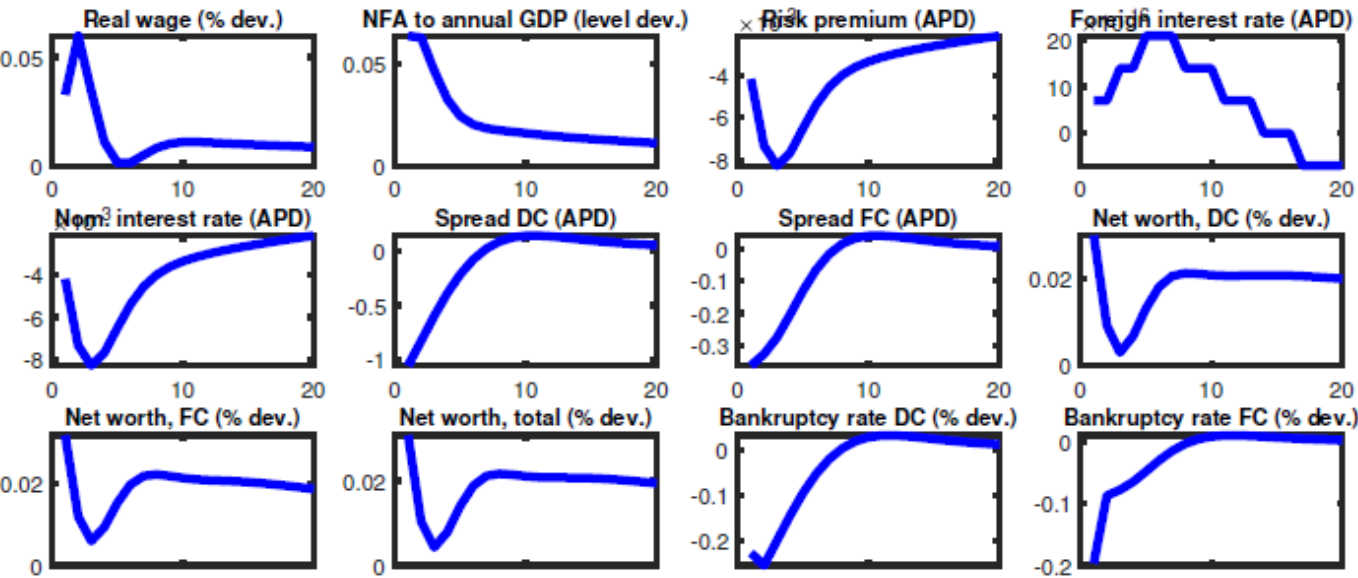

Source: Authors' calculations.

Figure 22: IRFs to the imported investment markup shock 

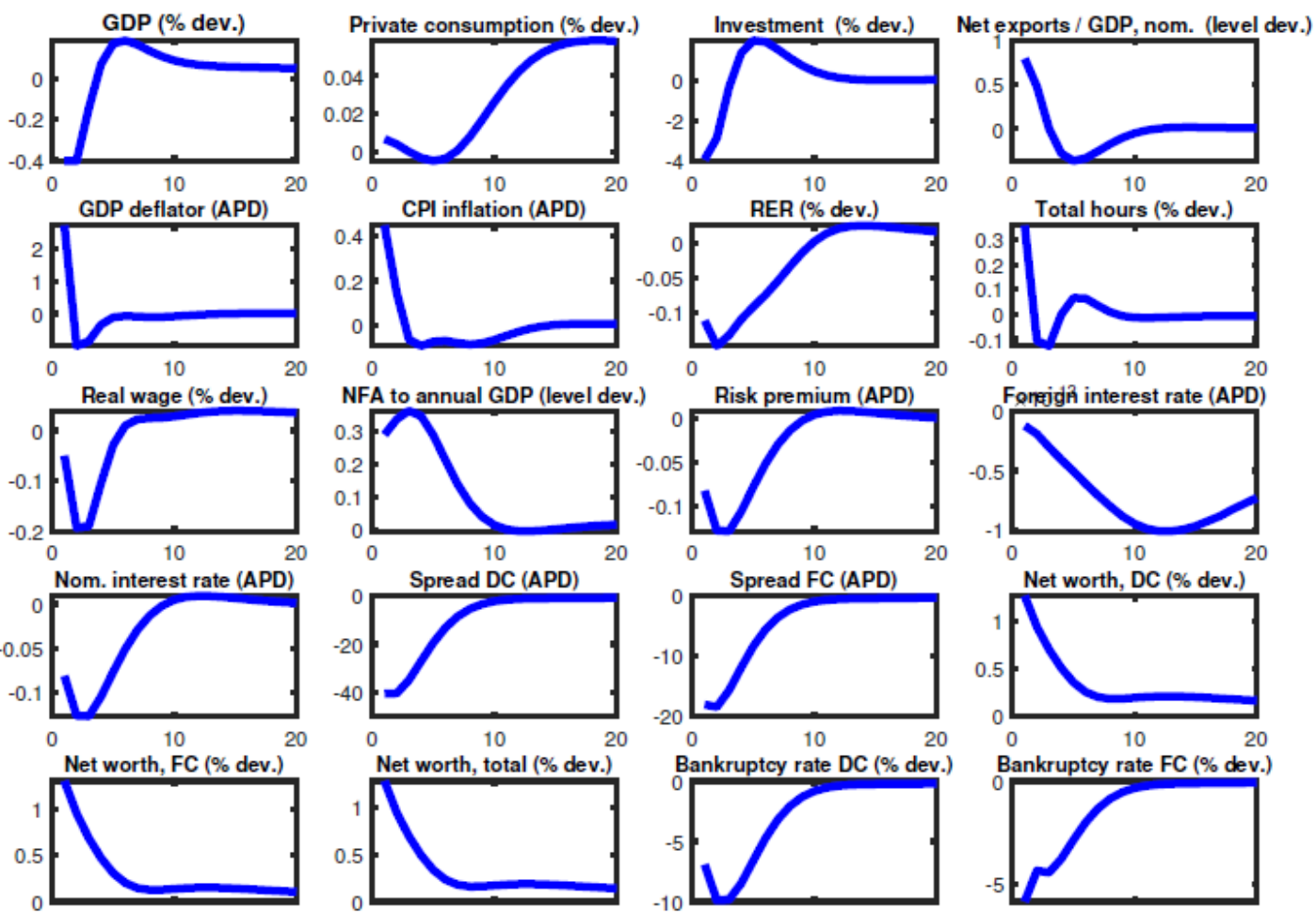

Source: Authors' calculations.

Figure 23: IRFs to the imported exports markup shock
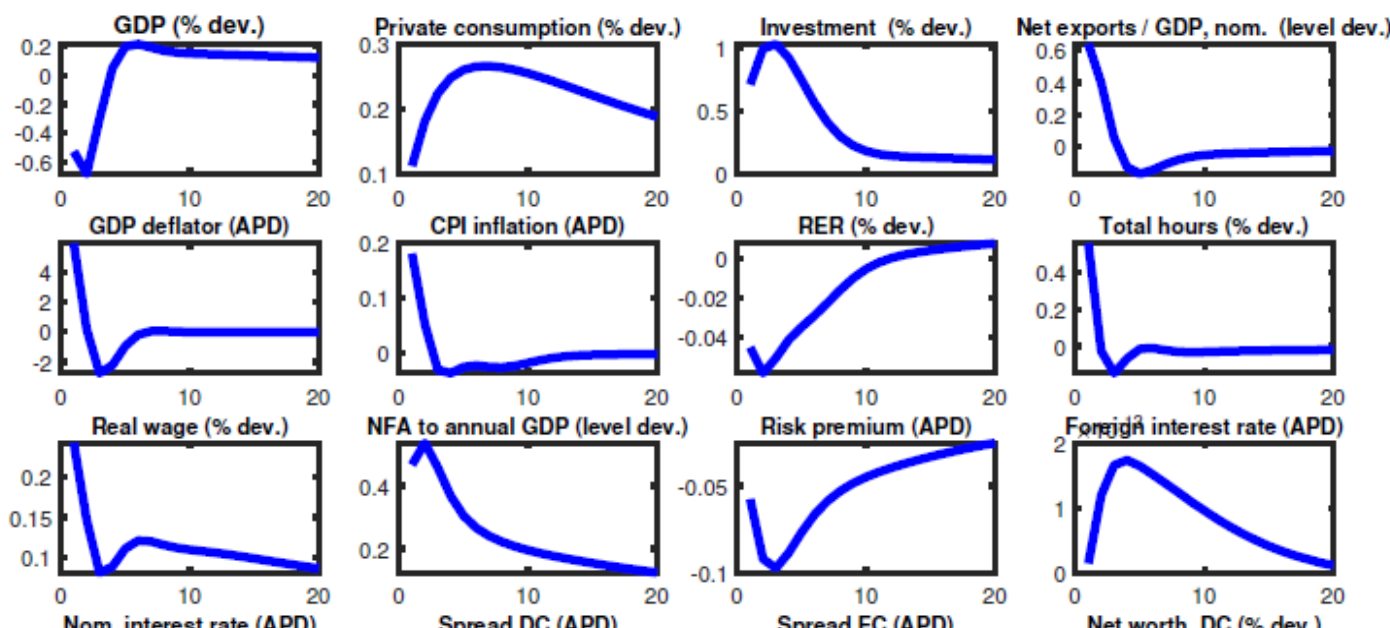

Fonejgh interest rate (APD)
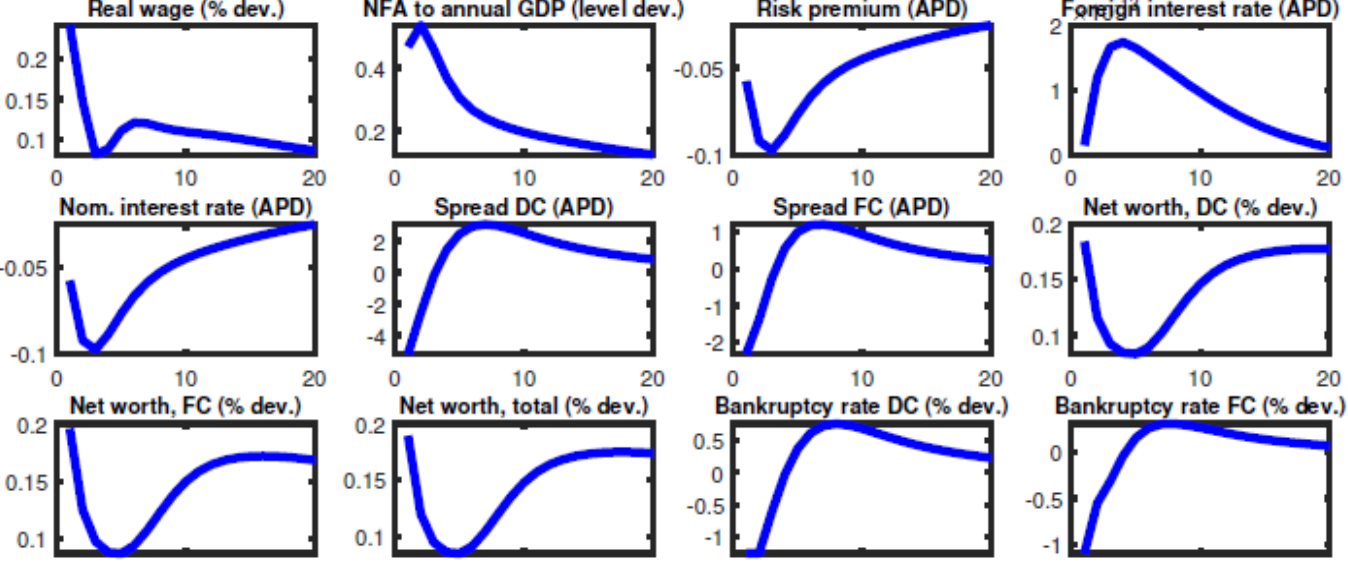

Bankruptcy rate DC (\% dev.)

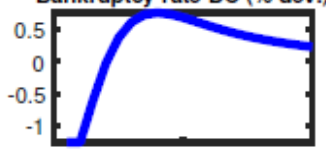

Bankruptcy rate FC (\% dev.)

Source: Authors' calculations.

Figure 24: IRFs to the foreign inflation shock 

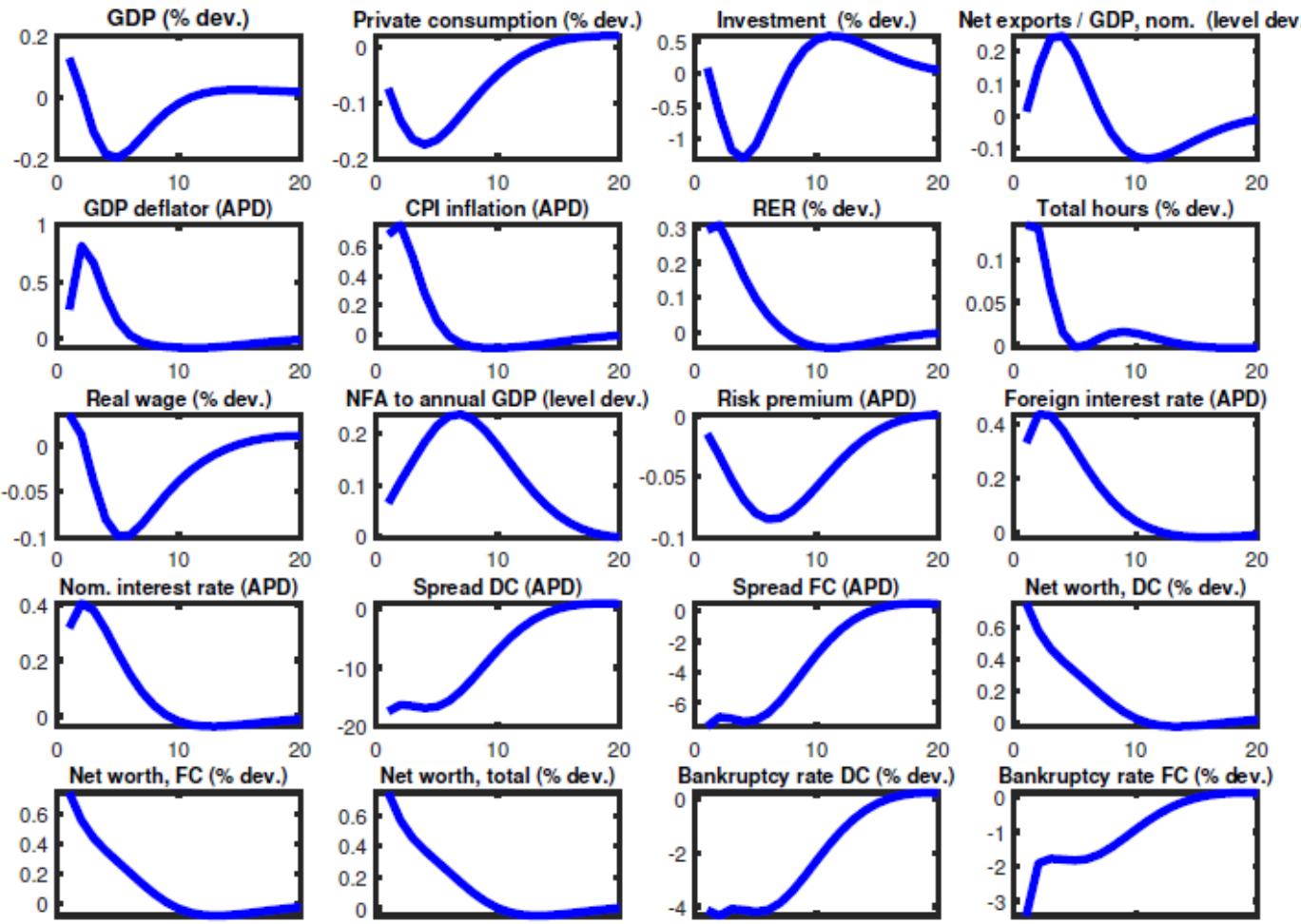

Bankruptcy rate DC (\% dev.)

Foreign interest rate (APD)
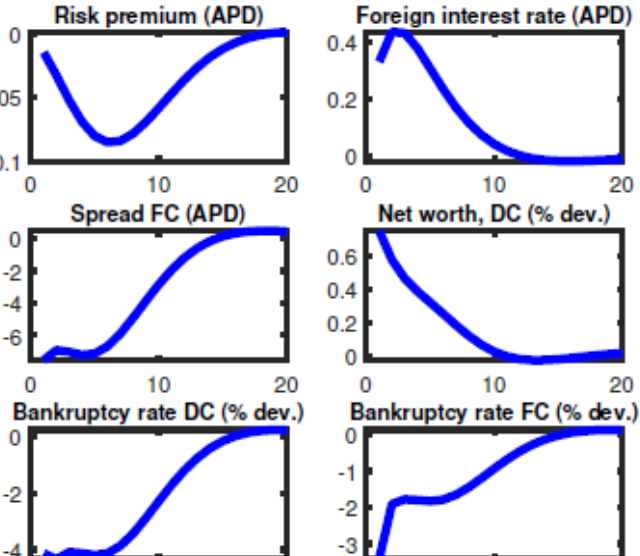

Bankruptcy rate FC (\% dev.)

Source: Authors' calculations.

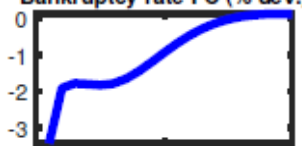

Figure 25: IRFs to the foreign interest rate shock
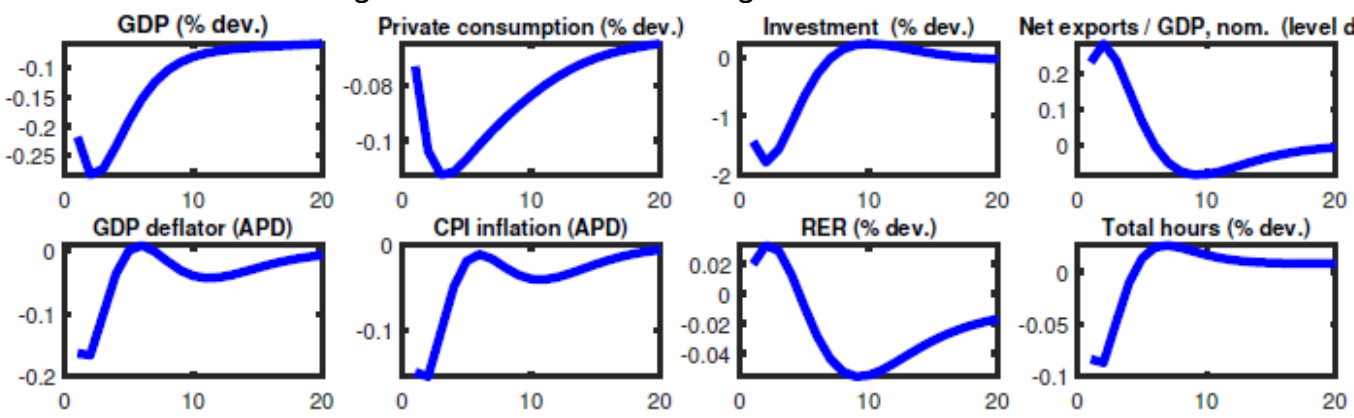

NFA to annual GDP (level dev.)
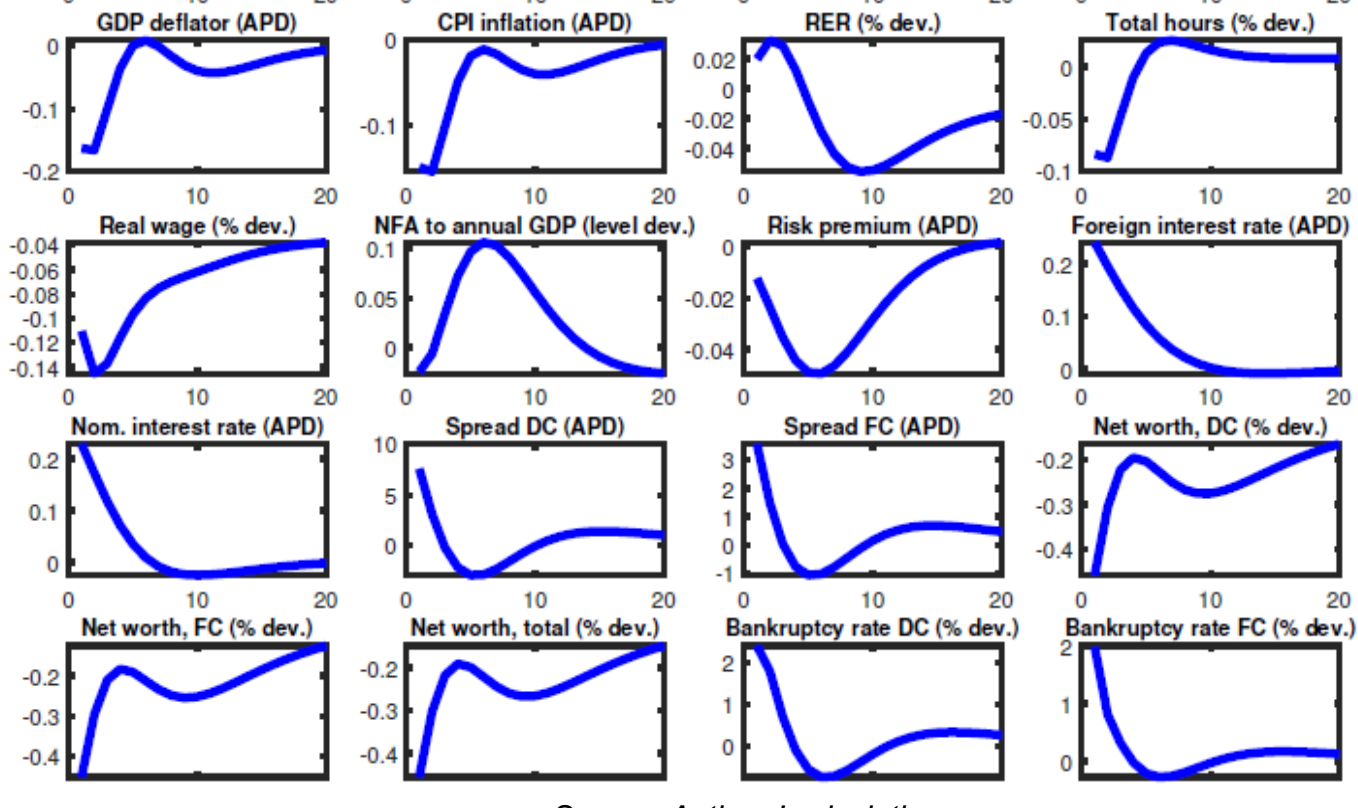

Source: Authors' calculations.

Figure 26: IRFs to the foreign demand shock 

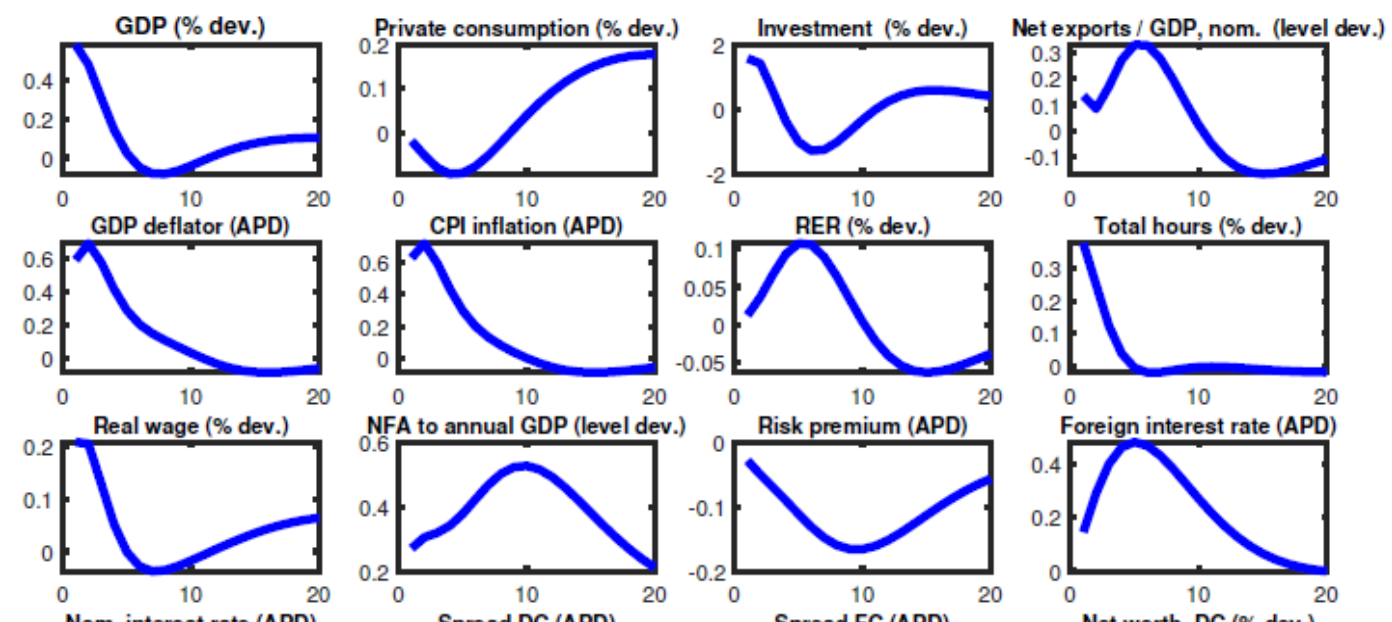

Foreign interest rate (APD)
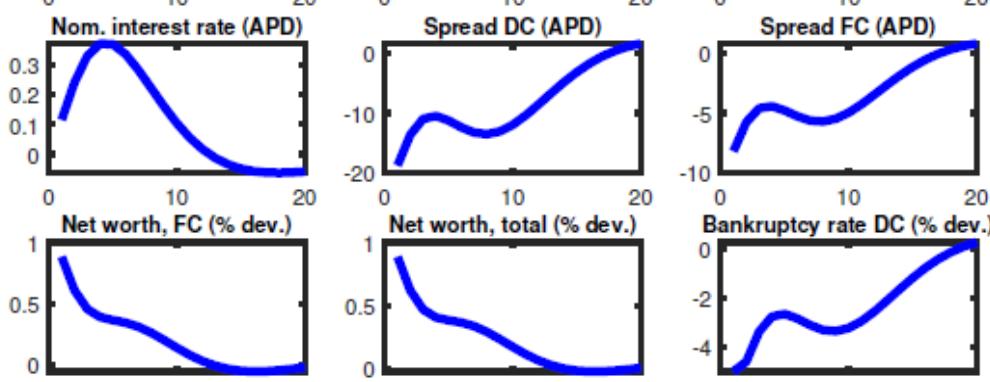

Bankruptcy rate DC (\% dev.)
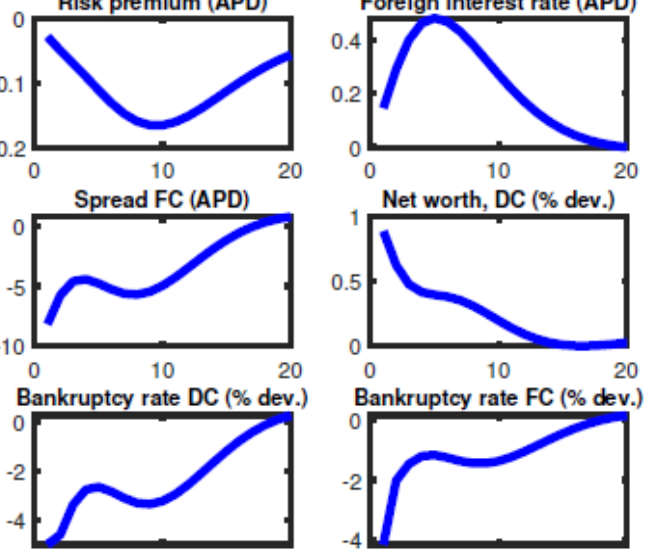

Bankruptcy rate FC (\% dev.)

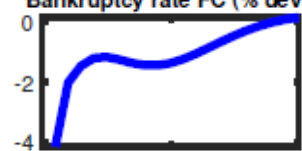

Source: Authors' calculations. 


\section{A.3 Prior and posterior distributions}
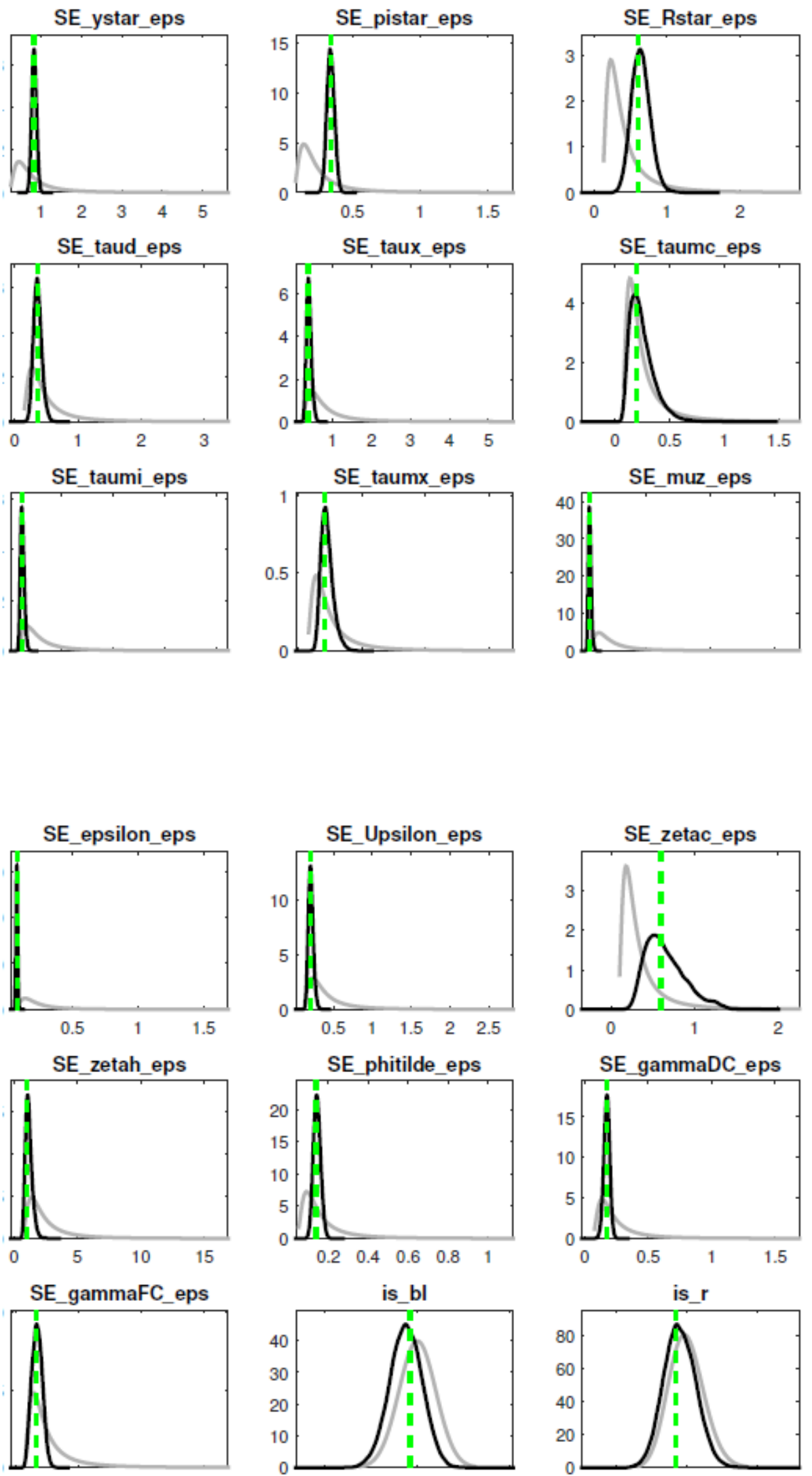

Source: Authors' calculations. 

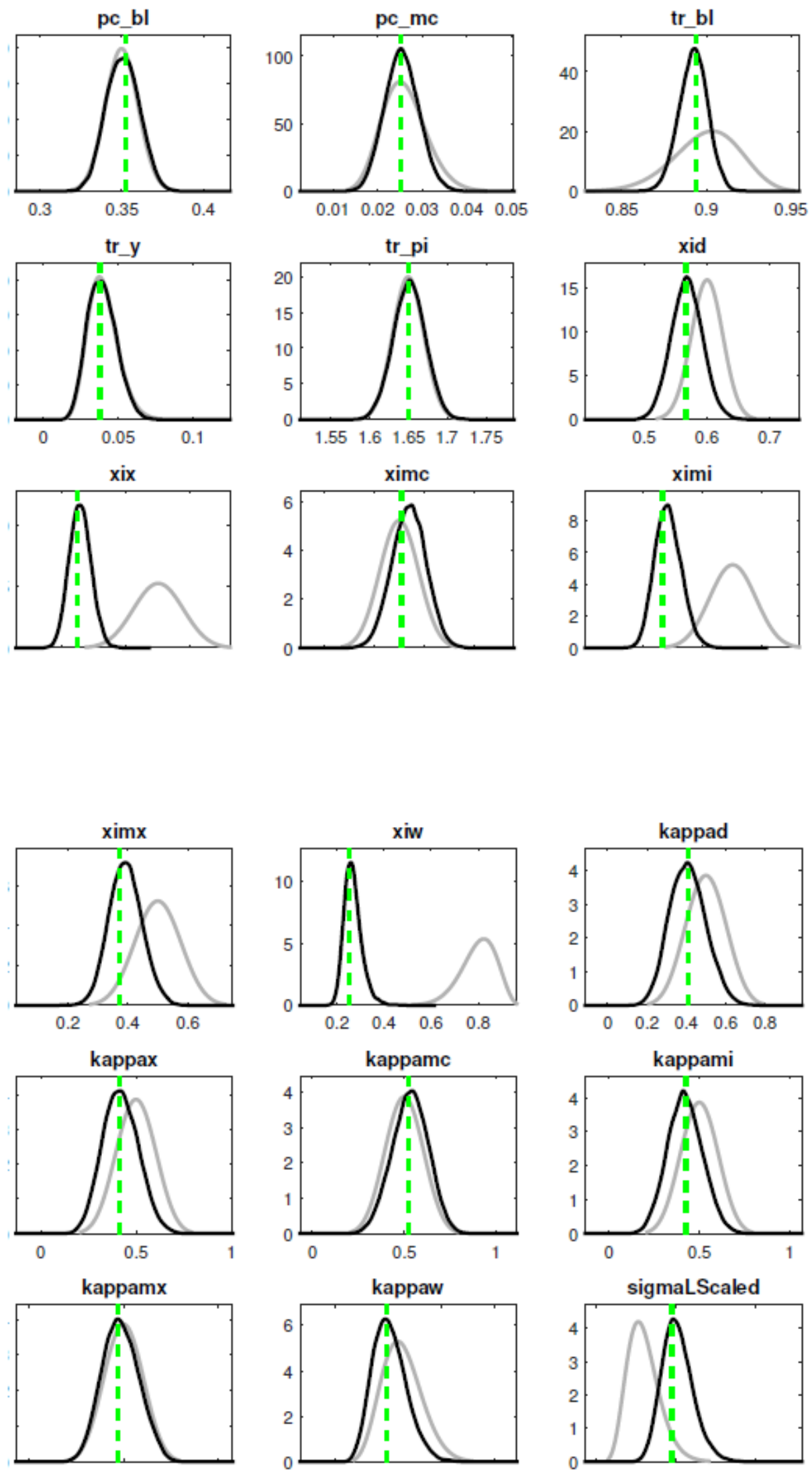

Source: Authors' calculations. 

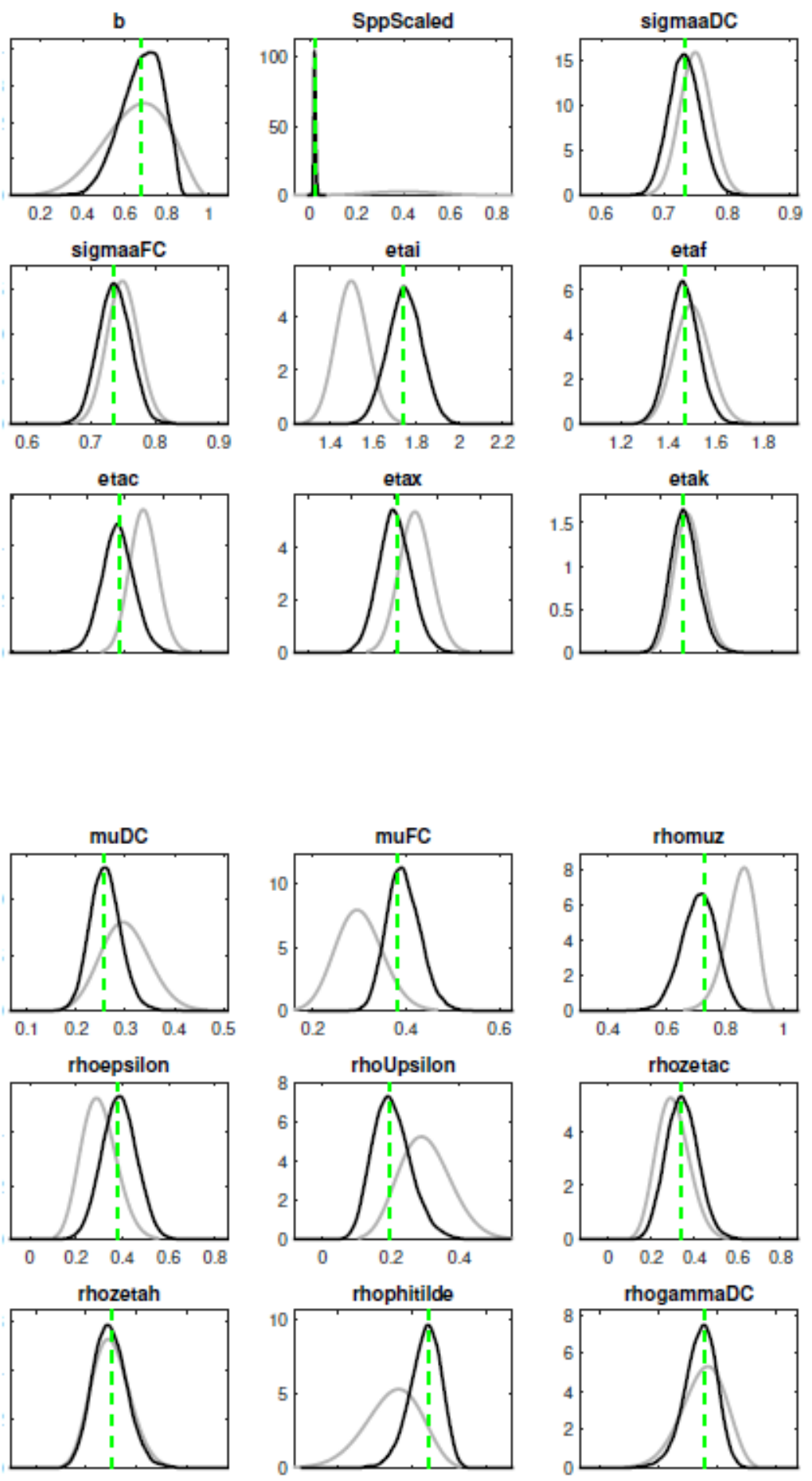

\section{rhogammaFC}

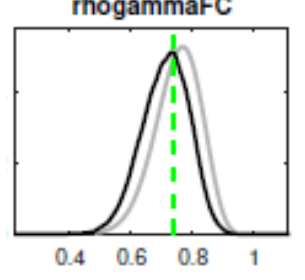

Source: Authors' calculations. 